Aus der Abteilung Nephrologie und Rheumatologie (Prof. Dr. med. G. Müller)

im Zentrum Innere Medizin

der Medizinischen Fakultät der Universität Göttingen

\title{
Einfluss der LDL-Apherese auf die Plaqueentstehung und -stabilität anhand der Konzentrationsbestimmung von Biomarkern
}

\author{
INAUGURAL - DISSERTATION \\ der Medizinischen Fakultät \\ vorgelegt von \\ Julia Strauchman \\ aus \\ Unna
}

zur Erlangung des Doktorgrades

der Georg-August-Universität zu Göttingen

Göttingen 2011 
De k a n:

I. Berichterstatter:

II. Berichterstatter/in:

III. Berichterstatter/in:

Tag der mündlichen Prüfung:
Prof. Dr. med. C. Frömmel

Priv. Doz. Dr. med. M. Koziolek 


\section{INHALTSVERZEICHNIS}

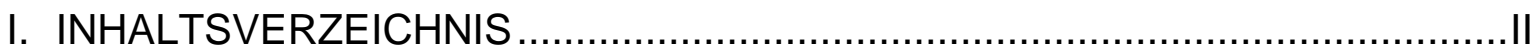

II. ABKÜRZUNGEN, ABBILDUNGEN UND TABELLEN .............................. IV

II.1 Liste der verwendeten Abkürzungen ................................................. IV

II.2 Abbildungsverzeichnis .............................................................. VI

II.3 Tabellenverzeichnis ...................................................................... VII

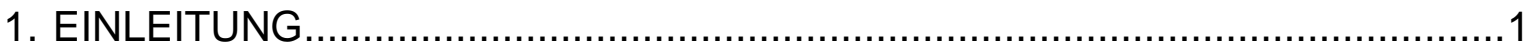

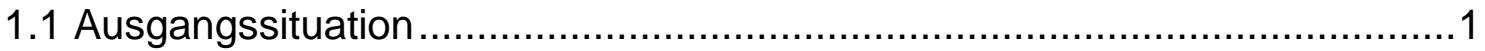

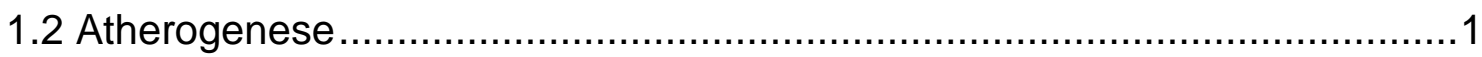

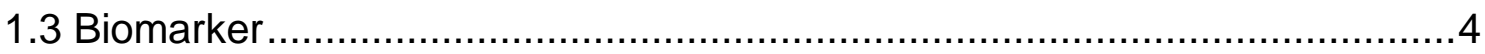

1.3.1 Proinflammatorische Zytokine .................................................

1.3.2 Plaque-Bildung/-Destabilisation .............................................6

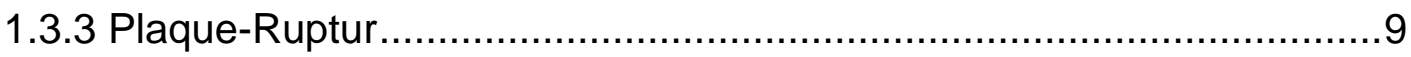

1.3.4 Akute-Phase-Reaktion ........................................................ 10

1.3.5 Myokardiale Dysfunktion ........................................................10

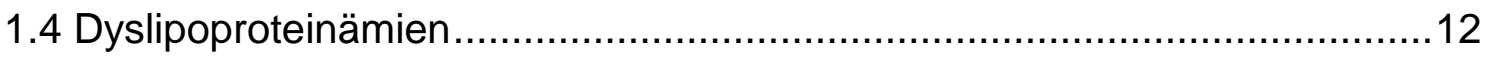

1.4.1 Primäre Dyslipoproteinämien .................................................. 12

1.4.2 Sekundäre Dyslipoproteinämien ............................................... 13

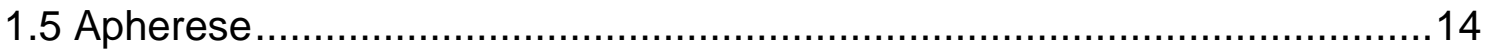

1.5.1 H.E.L.P. = Heparininduzierte extrakorporale LDL-Präzipitation .........17

1.5.2 DFPP = Double Filtration Plasmapheresis (Doppelmembran-

/Thermofiltration) .................................................................. 19

1.5.3 DALI = Direkte Adsorption von Lipoproteinen aus Vollblut ..............20

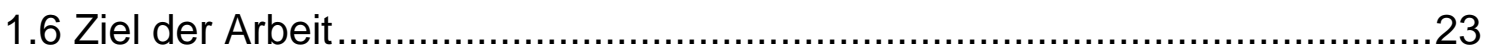

2. PATIENTEN UND METHODEN ............................................................. 24

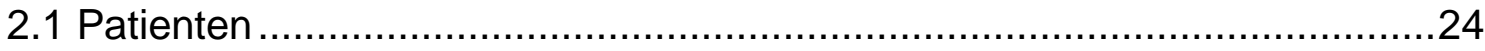

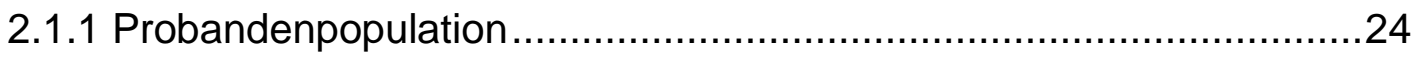

2.1.2 Einschlusskriterien ............................................................ 25

2.1.3 Ausschlusskriterien ...............................................................26

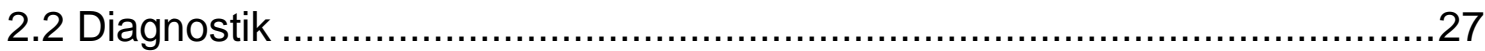

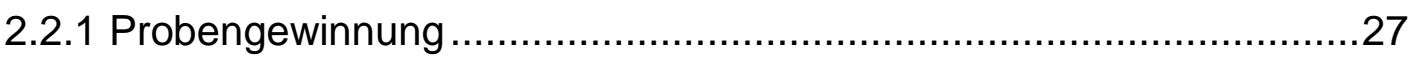

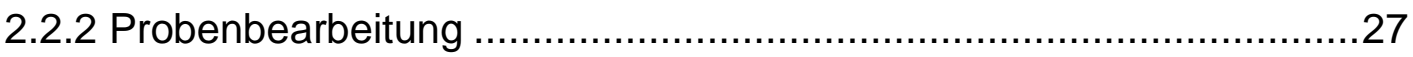

2.2.3 Probenlagerung ...................................................................28

2.3 Versuche zur Bestimmung der Biomarker..........................................28

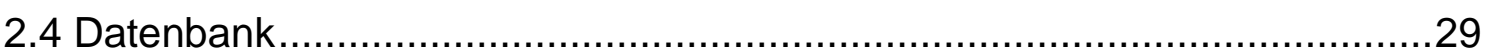

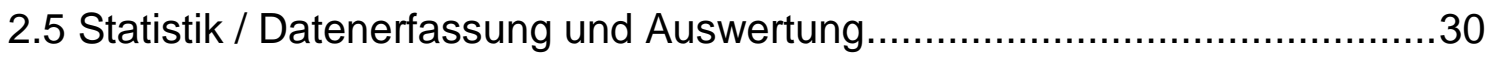

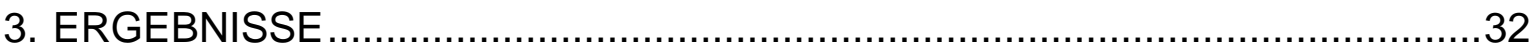

3.1 Epidemiologie und demographische Daten der gemessenen Probanden...32

3.1.1 Patientengruppe A (Hauptkollektiv) 
3.1.2 Patientengruppe B (gesundes Kontrollkollektiv) ...........................34

3.1.3 Patientengruppe C (krankes Kontrollkollektiv) ................................35

3.2 Analyse der gemessenen Werte (Hauptkollektiv) ....................................36

3.3 Auswertung der Ergebnisse bezogen auf den Zeitpunkt der

Atherosklerose.

3.3.1 Biomarker für proinflammatorische Prozesse (IL-6, IL-1ß, TNF-a, sIL-2R)

3.3.2 Biomarker für Plaque-Bildung/Destabilisierung (ADMA, sVCAM, MMP-9) .44

3.3.3 Biomarker für Plaqueruptur (PAPP-A) .49

3.3.4 Biomarker für die Akute-Phase-Reaktion (hsCRP) .51

3.3.5 Biomarker für Myokardiale Dysfunktion (NT-proBNP, NT-proANP) ...53

3.4 Patientenkollektive (Kontrollkollektive) .............................................. 56

3.4.1 Biomarker ADMA im Vergleich .57

3.4.2 Biomarker MMP-9 im Vergleich .59

3.4.3 Biomarker sVCAM im Vergleich..........................................60

3.4.4 Biomarker PAPP-A im Vergleich..........................................61

3.4.5 Biomarker hsCRP im Vergleich ...............................................62

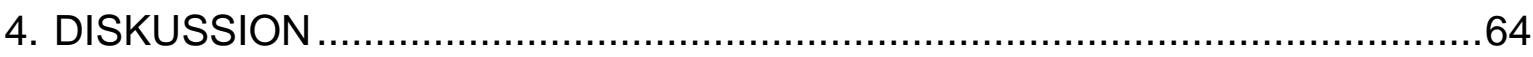

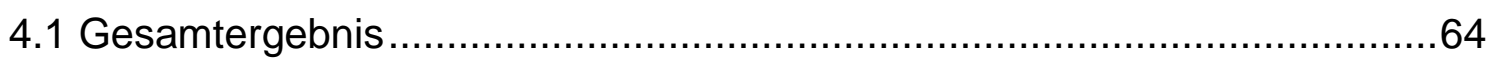

4.2 Einschränkungen der Arbeit ........................................................65

4.3 Ergebnisse in Bezug auf den Zeitpunkt der Atherosklerose .....................65

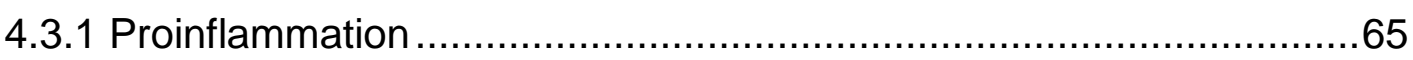

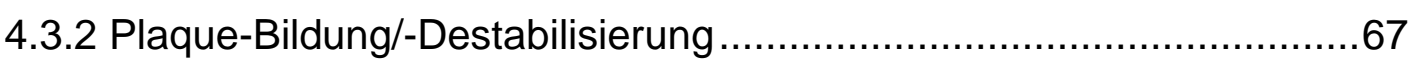

4.3.3 Plaqueruptur ................................................................. 70

4.3.4 Akute-Phase-Reaktion ........................................................ 71

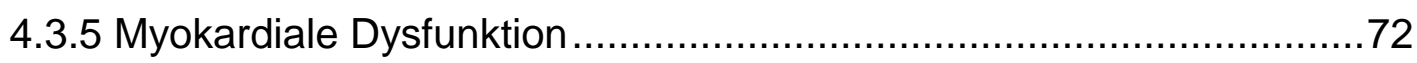

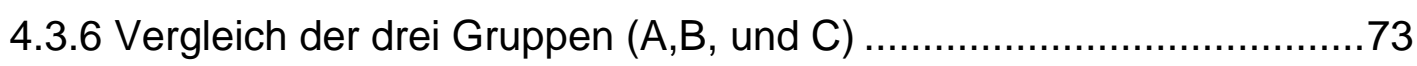

4.3.7 Schlussfolgerung und Ausblicke ............................................... 74

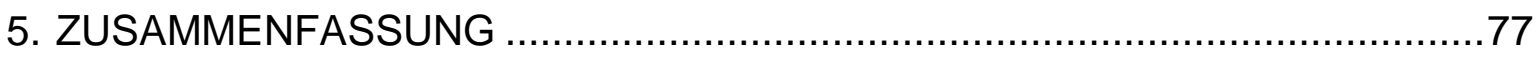

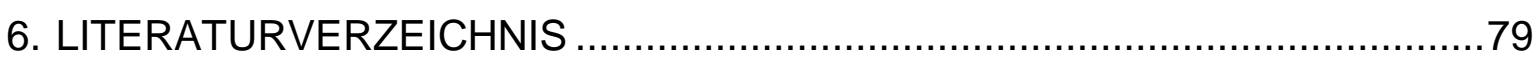




\section{Abkürzungen, Abbildungen und Tabellen}

\section{II.1 Liste der verwendeten Abkürzungen}

Abb.

Abbildung

Abs.

Absolut

Abw

Abweichung

ACE

Angiotensin converting enzym

ACVB

Aorto-Koronarer-Venen-Bypass

ADMA

Asymmetrisches Dimethylarginin

AP

Anfangspunkt

ASS

Acetylsalicylsäure

$\mathrm{BB}$

Blutbild

$\mathrm{BMI}$

Body mass index

BNP

$B$-Type natriuretic peptide

BSG

Blutsenkungsgeschwindigkeit

(hs)CRP

(high sensitiv) C-reactive-protein

cTnl

Cardiac troponin I

cTnT

Cardiac troponin $T$

DALI

Direkte Adsorption von Lipoproteinen aus Vollblut

DFPP

Double Filtration Plasmapheresis

DSA

Dextran-sulfat-cellulose-adsorption

ELISA

Enzyme linked immunosorbent assay

eNOS

endotheliale NO-Synthase

EP

Endpunkt

FABP

Fatty acid binding protein

FFAu

Free fatty acids

Ges

Gesamt

HDL

High-density-lipoprotein

H.E.L.P.

Heparininduzierte extrakorporale LDL-Präzipitation

$\mathrm{HI}$

Herzinfarkt

HLP

Hyperlipoproteinämie

HTN

Hypertonus

ICAM

Intercellular adhesion molecule

IGF Insulin-like growth factor

IGFBP-4 Insulin-like growth factor binding protein-4 $\lg \mathrm{M}$ Immunglobulin M 


\begin{tabular}{|c|c|}
\hline IL-6/1B & Interleukin-6/1ß \\
\hline IMA & Ischemia-modified albumin \\
\hline ISDM & Isosorbiddinitrat \\
\hline ISMN & Isosorbidmononitrat \\
\hline KHK & Koronare Herzerkrankung \\
\hline $\mathrm{KI}$ & Kontraindikation \\
\hline LDL & Low-density-lipoprotein \\
\hline Lp(a) & Lipoprotein (a) \\
\hline LVF & Linksventrikuläre Funktionsstörung \\
\hline MMP-9 & Matrixmetalloproteinase 9 \\
\hline MPO & Myeloperoxidase \\
\hline n.e.M. & Nur ein Messwert \\
\hline n.n.v. & Nicht normal verteilt \\
\hline n.v. & Normal verteilt \\
\hline NO & Stickstoffmonoxid \\
\hline NT-proANP & $\mathrm{N}$-Terminal proatrial natriuretic peptid \\
\hline NT-proBNP & $N$-Terminal probrain natriuretic peptid \\
\hline PAPP-A & Pregnancy-associated plasma protein $A$ \\
\hline pAVK & Periphere arterielle Verschlusskrankheit \\
\hline PDGF & Platelet-derived growth factor \\
\hline PIGF & Placental growth factor \\
\hline PRIND & Prolongiertes reversibles ischämisch neurologisches Defizit \\
\hline sCD-40L & Soluble CD-40-Ligand \\
\hline sIL-2R & Soluble Interleukin-2R \\
\hline SMC & Smooth muscle cell \\
\hline TIA & Transitorisch ischämische Attacke \\
\hline TIMPs & Tissue inhibitor of metalloproteinases \\
\hline TNF- $\alpha$ & Tumornekrosefaktor- $\alpha$ \\
\hline TG & Triglyzeride \\
\hline TGF- $\alpha / 1 \beta$ & Transforming growth factor- $\alpha / 1 \beta$ \\
\hline (s) VCAM & Human soluble vascular cell adhesion molecule-1 \\
\hline VGF & Vascular endothelial growth factor \\
\hline v.H. & Von Hundert \\
\hline VLDL & Very low density lipoprotein \\
\hline
\end{tabular}




\section{II.2 Abbildungsverzeichnis}

Abb. 1.1 Übersicht der Biomarker für vaskuläre Entzündungsprozesse ................4

Abb. 1.2 Aphereseverfahren................................................................ 14

Abb. 1.3 Schematischer Ablauf des H.E.L.P.-Verfahrens ................................17

Abb. 1.4 Schematischer Ablauf des DFPP-Verfahrens ....................................19

Abb. 1.5 Schematischer Ablauf des DALI-Verfahrens ...................................20

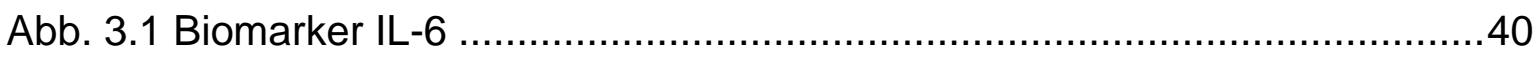

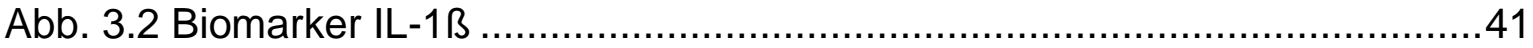

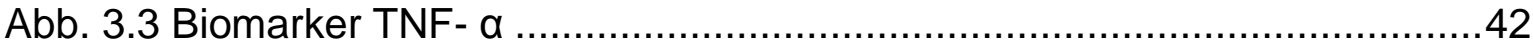

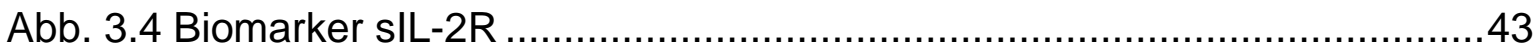

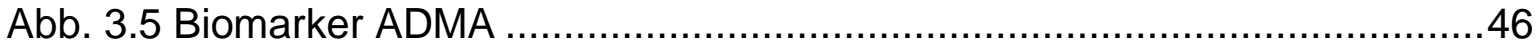

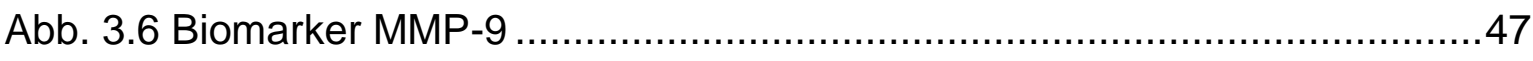

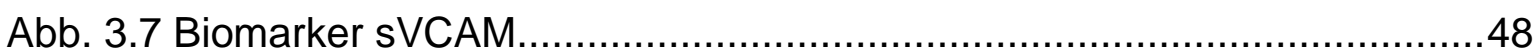

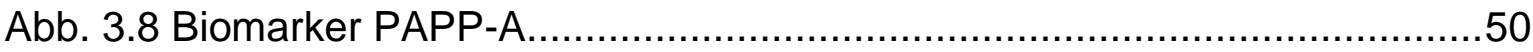

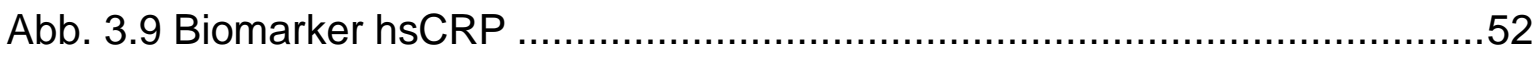

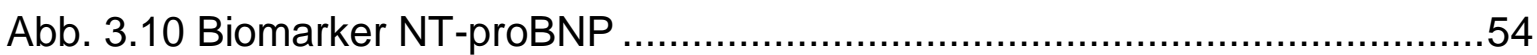

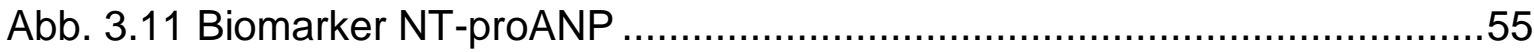

Abb. 3.12 Biomarker ADMA im Vergleich................................................. 58

Abb. 3.13 Biomarker MMP-9 im Vergleich .................................................... 59

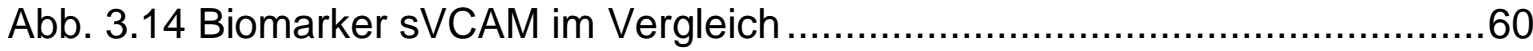

Abb. 3.15 Biomarker PAPP-A im Vergleich .............................................. 61

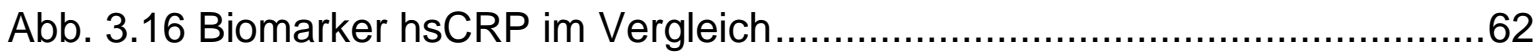




\section{II.3 Tabellenverzeichnis}

Tab. 1.1 Primäre Dyslipoproteinämien (nach Fredrickson) .13

Tab. 3.1 Epidemiologische Daten der Gruppe A (Hauptkollektiv). .33

Tab. 3.2 Epidemiologische Daten der Gruppe B (gesundes Kontrollkollektiv).......34

Tab. 3.3 Epidemiologische Daten der Gruppe C (krankes Kontrollkollektiv) .........35

Tab. 3.4 Summenwerte der Biomarker für proinflammatorische Prozesse ...........37

Tab. 3.5 Differenzwerte der Biomarker für proinflammatorische Prozesse .38

Tab. 3.6 Normalverteilung und p-Werte der Biomarker für proinflammatorische Prozesse 39

Tab. 3.7 Summenwerte der Biomarker für Plaque-Bildung/-Destabililsierung .......44

Tab. 3.8 Differenzwerte der Biomarker für Plaque-Bildung/-Destabililsierung .......44

Tab. 3.9 Normalverteilung und p-Werte der Biomarker für Plaque-Bildung/-Destabilisierung

Tab. 3.10 Summenwerte der Biomarker für Plaqueruptur 49

Tab. 3.11 Differenzwerte der Biomarker für Plaqueruptur .49

Tab. 3.12 Normalverteilung und p-Werte der Biomarker für Plaqueruptur 49

Tab. 3.13 Summenwerte der Biomarker für die Akute-Phase-Reaktion .51

Tab. 3.14 Differenzwerte der Biomarker für die Akute-Phase-Reaktion .51

Tab. 3.15 Normalverteilung und $p$-Werte der Biomarker für die Akute-PhaseReaktion 51

Tab. 3.16 Summenwerte der Biomarker für Myokardiale Dysfunktion. .53

Tab. 3.17 Differenzwerte der Biomarker für Myokardiale Dysfunktion. .53

Tab. 3.18 Normalverteilung und $p$-Werte der Biomarker für Myokardiale Dysfunktion .54

Tab. 3.19 Biomarkervergleich Gruppe A (LDL-Apheresepatienten) .56

Tab. 3.20 Biomarkervergleich Gruppe B und C .57

Tab. 3.21 Biomarker ADMA im Vergleich (MW und STAW) …...........................57

Tab. 3.22 Biomarker MMP-9 im Vergleich (MW und STAW) .............................59

Tab. 3.23 Biomarker sVCAM im Vergleich (MW und STAW) .............................60

Tab. 3.24 Biomarker PAPP-A im Vergleich (MW und STAW) .61 
Tab. 3.25 Biomarker hsCRP im Vergleich (MW und STAW) ..............................62

Tab. 4.1 Vergleichbare Studien zu IL-1B, IL-6, TNF- a....................................66

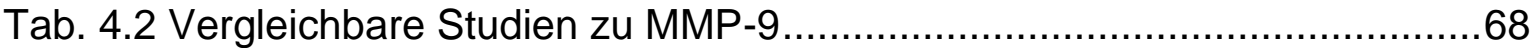

Tab. 4.3 Vergleichbare Studien zu SVCAM .......................................................

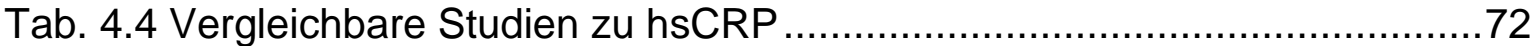




\section{EINLEITUNG}

\subsection{Ausgangssituation}

Die Rolle von mit Cholesterin beladenen Lipoproteinen in der Atherogenese ist mittlerweile gut erforscht. Es kommt unter anderem zu einer Ansammlung von Cholesterin in der Intima, die zu einer endothelialen Dysfunktion und Mikroinflammation führt. Zudem ist belegt, dass low-density-lipoprotein (LDL)Cholesterin wie auch C-reaktives Protein (CRP) das Risiko für Herzinfarkte und Schlaganfälle im Sinne von Endorganschäden deutlich erhöhen (Ridker PM 2001). Cholesterin senkende Therapien haben das Ziel der primären Prävention von Endorganschäden oder der sekundären Prävention des Fortschreitens bereits bestehender Erkrankungen. Bei ausgewählten Patienten mit familiärer Hyperlipoproteinämien, bei denen weder durch diätetische Maßnahmen noch durch eine medikamentöse Therapie der LDL-Cholesterin-Spiegel gesenkt wird, kann die LDL-Apherese als eine ergänzende therapeutische Maßnahme dienen. In der klinischen Praxis konnte bereits gezeigt werden, dass es zu einer Abnahme der kardiovaskulären Ereignisse durch die Behandlung mit einer LDL-Apherese kommt.

\subsection{Atherogenese}

Die Atherogenese ist ein multifaktorielles pathogenes Geschehen, an dem genetische Defekte sowie eine Reihe von Risikofaktoren beteiligt sind. Zu diesen Risikofaktoren zählen vor allem die Hyperlipoproteinämie, Nikotinabusus, arterieller Hypertonus, Diabetes mellitus, genetische Prädisposition und Adipositas.

Im Vordergrund der Atherogenese steht besonders die endotheliale Dysfunktion (Karatzis EN 2005), welche durch oben genannte Risikofaktoren beeinflusst wird. Durch diese Dysfunktion gerät die zunächst physiologische Abwehr in einen pathologischen Zustand im Sinne eines Entzündungsprozesses, der mit einer Proliferation der glatten Muskelzellen (Smooth Muscle Cell $=\mathrm{SMC}$ ), Synthese von 
Bindegewebe, Bildung von Schaumzellen (die oxidiertes bzw. modifiziertes LDLCholesterin speichern) sowie der Ablagerung von Cholesterin und Kalziumsalzen einhergeht (Libby P, Theroux P 2005).

Leukozyten und Thrombozyten lagern sich durch die veränderten Adhäsionseigenschaften an der Endotheloberfläche an und T-Lymphozyten werden aktiviert. Dieses Geschehen beginnt zum Teil bereits in der Kindheit und kann sich über Jahre unbemerkt hinziehen.

Besonders gefährlich ist die Ausbildung von „vulnerablen Plaques“, die plötzlich aufbrechen und eine unmittelbare Plättchenaktivierung und Thrombusbildung auslösen können (Jefferson BK, Topol EJ 2005, Mitra AK et al. 2004). Die Folge ist ein möglicher Gefäßverschluss, welcher einen Herzinfarkt oder Schlaganfall nach sich zieht.

Die endotheliale Dysfunktion führt zu einer gestörten Regulation der Vasomotorik im betroffenen Gefäßabschnitt. Die Stickoxid (NO)-vermittelte endothelabhängige Vasodilatation ist unzureichend. Stattdessen überwiegen vasokonstriktorisch wirkende Mediatoren wie Endothelin, Thromboxan oder Angiotensin II.

Die Stabilität der Plaques hängt von der Menge und Struktur des Kollagens in ihrer fibrösen Kappe ab. Dieses Kollagen wird von glatten Muskelzellen produziert und von spezifischen Kollagenasen, den Matrix-Metalloproteinasen (MMP), abgebaut. Diese stammen aus Makrophagen und glatten Muskelzellen (Libby P, Theroux P 2005).

Grundsätzlich werden drei Formen der Plaqueruptur unterschieden (Mitra AK et al. 2004):

a) Ruptur der fibrösen Kapsel

Hierbei handelt es sich um die häufigste Form der Plaqueruptur, wobei insbesondere Entzündungszellen und -mediatoren eine wichtige Rolle spielen.

b) Oberflächliche Erosion

Dabei kommt es auf einem limitierten Areal über einer atherosklerotischen Läsion zu einer Desquamation (Ablösung).

c) Plaque-Einblutung.

Im Rahmen wachsender atherosklerotischer Läsionen kommt es unter dem Einfluss von Wachstumsfaktoren (Platelet-derived growth factor $=$ PDGF, Vascular endothelial growth factor $=$ VGF) zu einer Neovaskularisation . 
Die Progression der koronaren Durchblutungsstörungen kann man somit in verschiedene Phasen unterteilen, wobei besonders interessant ist, dass im Blut verschiedene Biomarker in den unterschiedlichen Stadien nachweisbar sind.

Das asymmetrische Dimethylarginin (ADMA) konnte als unabhängiger Risikofaktor und neuer Biomarker für das Auftreten kardiovaskulärer Endpunkte identifiziert werden (Schnabel $R$ et al. 2005). Es verhindert unter anderem die bereits erwähnte Stickoxid (NO)-vermittelte endothelabhängige Vasodilatation.

Als Marker der Phase der Plaquedestabilisierung wurden die Myeloperoxidase (MPO), die Matrixmetalloproteinase 9 (MMP-9) und das Adhäsionsmolekül Vascular cell adhesion molecule (VCAM) identifiziert (Güray U et al. 2004, Apple FS et al. 2005, Blankenberg S et al. 2003 a).

In der Phase der Plaqueruptur finden sich erhöhte Werte für den löslichen CD40Liganden (sCD40L) und das Pregnancy associated plasma protein A (PAPP-A) (Cosin-Sales $J$ et al. 2004).

Als Marker der Myokardischämie dienen Choline, die nach einem durch Phospholipase D katalysierten Abbau von Membranphospholipiden freigesetzt werden (Danne O et al. 2003, Roy D et al. 2004).

Als sensitiver und spezifischer Marker der myokardialen Nekrose kann das Fatty acid binding protein (FABP) verwendet werden (Lescuyer $P$ et al. 2005).

Ein kontinuierliches oder diskontinuierliches Wachsen atherosklerotischer Beete ist morphologisch gut belegt. Den glatten Muskelzellen kommt durch Migration, Proliferation und Matrixproduktion bzw. -degradation eine Schlüsselrolle zu. Insbesondere der Zelltod durch Apoptose oder Nekrose der SMC kann zur Destabilisierung eines Plaques und damit zu dessen Ruptur beitragen (Stoneman VE, Bennett MR 2004, Trion A, van der Laarse A 2004).

Die extrazelluläre Matrix besteht aus einem dreidimensionalen Netzwerk von Proteoglykanen, Glykoproteinen und Kollagenfibrillen. Die für die Plaquebildung entscheidende Substanzzunahme resultiert aus einer metabolischen Bilanz, d.h. aus Synthese- und Abbauprozessen. Kollagen stellt den Hauptteil der vaskulären extrazellulären Matrix dar, prädominant sind die Typen I und III.

Die Kollagen-bildenden Zellen (glatte Gefäßmuskelzellen, Myofibroblasten, Endothelzellen) unterliegen einer steuernden Wirkung durch Zytokine. Diese regulieren die Expression Matrix-produzierender und -degradierender Enzymsysteme. 
Die Matrixmetalloproteinasen 1,2 und 9 sind bei der reaktiven Umgestaltung atherosklerotisch veränderter Gefäße (remodelling) wesentlich beteiligt.

Oxidiertes LDL stimuliert die Synthese von MMPs und reduziert die Synthese von Tissue inhibitor of metalloproteinases (TIMPs) (Katsuda S, Kaji T 2003).

In Studien konnte bereits eine Elimination durch die LDL-Apherese einiger dieser Faktoren belegt werden (Bosch T ,Keller C 2003).

\subsection{Biomarker}

Verschiedene Biomarker sind jeweils in bestimmten Phasen vaskulärer Entzündungsprozesse in erhöhter Konzentration festzustellen.

\begin{tabular}{|c|c|c|c|}
\hline $\begin{array}{l}\text { Proin- } \\
\text { flammatorische } \\
\text { Zytokine }\end{array}$ & $\begin{array}{l}\text { Plaque- } \\
\text { Bildung } \\
\text { Destabilisation }\end{array}$ & $\begin{array}{l}\text { Plaque- } \\
\text { Ruptur }\end{array}$ & $\begin{array}{l}\text { Akute-Phase- } \\
\text { Reaktion }\end{array}$ \\
\hline $\begin{array}{l}\text { IL-6 * } \\
\text { IL-1ß* } \\
\text { TNFa * } \\
(\text { sIL-2R *) }\end{array}$ & $\begin{array}{l}\text { ADMA * } \\
\text { MMP-9 * } \\
\text { MPO } \\
\text { ICAM } \\
\text { VCAM * }\end{array}$ & $\begin{array}{l}\text { SCD40L } \\
\text { PIGF } \\
\text { PAPP-A * }\end{array}$ & $\begin{array}{l}\text { CRP } \\
\text { hsCRP* }\end{array}$ \\
\hline
\end{tabular}

\begin{tabular}{|c|c|c|}
\hline Ischämie & Nekrose & $\begin{array}{l}\text { Myokardiale } \\
\text { Dysfunktion }\end{array}$ \\
\hline $\begin{array}{l}\text { IMA } \\
\text { FFAu } \\
\text { Choline }\end{array}$ & $\begin{array}{l}\text { cTnT } \\
\text { cTnl }\end{array}$ & $\begin{array}{l}\text { BNP } \\
\text { NT-proBNP * } \\
\text { NT-proANP* }\end{array}$ \\
\hline
\end{tabular}

Abb. 1.1 Übersicht der Biomarker für vaskuläre Entzündungsprozesse

(Apple FS et al. 2005; S. 811, mit Ergänzungen durch diese Studie) 
(IL-6/1ß = Interleukin-6/1B, TNF- $\alpha=$ Tumornekrosefaktor- $\alpha$, sIL-2R $=$ Soluble Interleukin-2R, ADMA = Asymmetrisches Dimethylarginin, MMP-9 = Matrixmetalloproteinase 9, MPO = Myeloperoxidase, ICAM = Intercellular adhesion molecule, (s)VCAM = Human soluble vascular cell adhesion molecule-1, sCD-40L = Soluble CD-40-Ligand, PIGF = Placental growth factor, PAPP-A = Pregnancy-associated plasma protein $A$, (hs) CRP = (high sensitiv) C-reactiveprotein, IMA = Ischemia-modified albumin, FFAu = Free fatty acids, cTnT = Cardiac troponin $T, \mathrm{cTnl}=$ Cardiac troponin I, BNP $=B$-Type natriuretic peptide, NT-proBNP $=N$-Terminal brain natriuretic peptid, NT-proANP $=N$-Terminal atrial natriuretic peptid)

Der slL-2R steht in Klammern, da es sich hierbei vor allem um einen inflammatorischen Marker handelt, welcher aber zur besseren Übersicht im Verlauf immer mit den proinflammatorischen Markern zusammen beschrieben wird.

Im Folgenden werden nur die im Rahmen der Studie untersuchten Biomarker näher beschrieben. Diese Biomarker sind in vorstehender Abbildung mit “ * “ gekennzeichnet, wobei sich die Anordnung der Biomarker an der jeweiligen Phase ihres Auftretens orientiert.

\subsubsection{Proinflammatorische Zytokine}

Interleukin-6 (IL-6), Interleukin-1ß (IL-1ß), Tumornekrosefaktor- $\alpha$ (TNF- $\alpha$ ), soluble Interleukin-2R (sIL-2R)

Bei den in dieser Studie betrachteten Biomarkern IL-1B, IL-6, sIL-2R und TNF- $\alpha$ handelt es sich um Zytokine.

Zytokine sind eine Gruppe nicht-enzymatischer, löslicher Glykoproteine, die als Mediatoren fungieren und vor allem von Makrophagen, Endothelzellen und natürlichen Killer-Zellen gebildet werden (Ogiwara F et al. 2004, Ikata J et al. 2000).

Sie üben eine regulierende Funktion auf die Proliferation und die Differenzierung von Zielzellen aus, zu denen auch die Kollagen-bildenden Zellen zählen, welche 
inrerseits die Expression Matrix-produzierender und -degradierender Enzymsysteme regulieren.

Diese Biomarker spielen eine wesentliche Rolle sowohl bei der endothelialen Dysfunktion als auch bei der Entstehung und der Progression der Atherogenese (Khuseyinova N, Koenig W 2006, Krishnaswamy G et al. 1999).

IL-1ß wird hauptsächlich von Monozyten gebildet und ist an einer Reihe von Entzündungsprozessen beteiligt. Unter anderem triggert es die IL-6-Freisetzung und die Freisetzung von Prostaglandin E2, welche ihrerseits ebenfalls einen hohen Stellenwert in der Entzündungsreaktion haben.

TNF- $\alpha$ ist als ein Zytokin Bestandteil des Immunsystems. Es wird vor allem von Makrophagen freigesetzt und ist wie die anderen Zytokine an lokalen und systemischen Entzündungsreaktionen beteiligt. Die wichtigste Funktion von TNF- $\alpha$ ist es, die Aktivität verschiedener Immunzellen zu regulieren. Somit kann er Apoptose, Zellproliferation, Zelldifferenzierung und die Ausschüttung anderer Zytokine anregen.

sIL-2R ist ein Marker für die T-Zell-Aktivierung. Er tritt mit erhöhter Konzentration bei entzündlichen Krankheitsprozessen auf und steht in Verbindung mit der fortschreitenden Entwicklung der koronaren Herzerkrankung (KHK) (Simon AD et al. 2001).

\subsubsection{Plaque-Bildung/-Destabilisation}

Asymmetrisches Dimethylarginin = ADMA, Matrixmetalloproteinase-9 (MMP-9), Human soluble vascular cell adhesion molecule-1 = sVCAM

Die Stabilität der Plaques hängt von der Menge und Struktur des Kollagens in ihrer fibrösen Kappe ab. Dieses Kollagen wird von glatten Muskelzellen produziert und von spezifischen Kollagenasen, den Matrix-Metalloproteinasen (MMP), abgebaut, die aus Makrophagen und glatten Muskelzellen stammen (Libby $\mathrm{P}$, Theroux $\mathrm{P}$ 2005). Neben den Matrix-Metalloproteinasen sind auch das Human soluble vascular cell adhesion molecule-1 (sVCAM) und das asymmetrische Dimethylarginin (ADMA) an der Plaquedestabilisation beteiligt. 


\section{Asymmetrisches Dimethylarginin $=$ ADMA}

Bei dem Biomarker asymmetrisches Dimethylarginin (ADMA) handelt es sich um ein Derivat der Aminosäure L-Arginin. L-Arginin ist eine Vorstufe zur Bildung von Stickstoffmonoxid (NO) im menschlichen Körper.

ADMA konnte als unabhängiger Risikofaktor und neuer Biomarker für das Auftreten kardiovaskulärer Endpunkte identifiziert werden (Schnabel $R$ et al. 2005).

Es wird im Gefäßsystem hauptsächlich von der endothelialen NO-Synthase (eNOS) gebildet und ist ein wichtiger physiologischer Mediator im HerzKreislaufsystem, der an der Regulation von Blutdruck und Gefäßwiderstand, Adhäsion und Aggregation von Thrombozyten, Adhäsion von Leukozyten und Monozyten und der Proliferation glatter Gefäßmuskelzellen beteiligt ist (Busse R, Fleming I 1995, Folts JD et al. 1991, Ignarro LJ 1990, Rubanyi GM 1993, Tesfamariam B 1994).

Bei Erkrankungen des Herz-Kreislaufsystems wie der Atherosklerose, der Hypercholesterinämie, der Hypertonie und der chronischen Herzinsuffizienz kommt es zu einer Abschwächung der biologischen Wirkung von NO. Dies führt zu einem Fortschreiten der Erkrankungen und einer Beschleunigung begleitender Gefäßläsionen.

NO kann durch L-Arginin oder Substanzen mit ähnlicher Struktur konzentrationsabhängig gehemmt werden.

Hierzu zählt auch der Biomarker ADMA. Infolge dieser Blockierung sind die NOabhängige Vasodilatation sowie die hemmende Wirkung auf die Thrombozytenaggregation, Monozytenadhäsion, Zellproliferation und Radikalbildung vermindert.

In mehreren klinischen und experimentellen Studien konnte gezeigt werden, dass es bei den genannten Erkrankungen zu einem Anstieg der Konzentration des endogenen L-Arginin-Analogons ADMA im Plasma oder Serum kommen kann, wodurch eine kompetitive Verdrängung von L-Arginin durch ADMA erfolgt.

Durch die Gabe von L-Arginin konnte die Monozytenadhäsion bei hypercholesterinämischen Patienten normalisiert werden (Krempl TK et al. 2005, Schulze F et al. 2004, Schnabel R et al. 2005).

Daher scheint ADMA ein prognostischer Faktor für das Fortschreiten der Erkrankungen zu sein. 


\section{Matrixmetalloproteinase-9 (MMP-9)}

Die Matrixmetalloproteinase ist eine Zink bindende Endopeptidase.

MMP-9 tritt als Marker in der Phase der Plaquedestabilisierung auf (Apple FS et al. 2005, Blankenberg et al. 2003 b) und ist bei der reaktiven Umgestaltung atherosklerotisch veränderter Gefäße (remodelling) wesentlich beteiligt. MMP-9Werte stehen in unmittelbarer Relation zu künftigen kardiovaskulären Endpunkten (Blankenberg et al. 2003 b) wie der Atherosklerose und der Restenosierung (Galis ZS, Khatri JJ 2002).

Somit sind sie an den Mechanismen, die zur Plaqueruptur führen, ursächlich beteiligt und in rupturierten und beschädigten Plaques vermehrt nachweisbar. MMPs konnten bereits in humanen atherosklerotischen Plaques und Regionen von Schaumzell-Akkumulationen identifiziert werden und es ist daher anzunehmen, dass sie zur Plaquevulnerabilität beitragen (Galis ZS et al. 1994, Brown DL et al. 1995).

Pro-MMP-9 wird von vielen verschiedenen Zellen freigesetzt, vor allem aber von glatten Muskelzellen, Monozyten, Makrophagen und Endothelzellen.

Die Freisetzung von Pro-MMP-9 wird erhöht durch Transforming growth factor-1ß (TGF-1ß), IL-1ß, Transforming growth factor- $\alpha$ (TGF- $\alpha$ ), TNF- $\alpha$ und IL-1 $\alpha$ (Lyons JG et al. 1993, Cullen B et al. 1997, Hanemaaijer R et al. 1993).

Eine erhöhte Freisetzung und Aktivität von MMP-9 konnte in verschiedenen pathologischen Prozessen wie Entzündungsreaktionen, Tumormetastasierung, respiratorischen Erkrankungen, Gefäßaneurysmen und Herzerkrankungen festgestellt werden (Creemers EE et al. 2001).

Die MMP-Aktivität wird durch endogene Gewebeinhibitoren von Metalloproteinasen (TIMPs) kontrolliert.

In der Framingham - Herzstudie war das Gesamt-TIMP-1 mit bedeutenden kardiovaskulären Risikofaktoren assoziiert (Sundström J et al. 2004).

Human soluble vascular cell adhesion molecule-1 = sVCAM sVCAM ist ein 100-110 kDa Adhäsionsmolekül. Diese Moleküle vermitteln sowohl das Anheften von Leukozyten an das Endothel und deren Einwandern ins Gewebe als auch die Zellinteraktionen zwischen Immunzellen (Laffón A, González-Amaro R 1995). 
Das Adhäsionsmolekül VCAM konnte bereits als Marker für die Phase der Plaquedestabilisierung identifiziert werden (Güray et al. 2004, Apple FS et al. 2005, Blankenberg et al. 2003 a). Dabei ist vor allem die lösliche Form (sVCAM) verstärkt im Zusammenhang mit einer Plaquedestabilisation anzutreffen (Khuseyinova N, Koenig W 2006).

sVCAM scheint ebenfalls ein Indikator für die Schwere der Atherosklerose zu sein (De Caterina R et al. 1997, Peter K et al. 1997) und wurde als starker Faktor für zukünftig auftretende kardiovaskuläre Erkrankungen identifiziert (Blankenberg $\mathrm{S}$ et al. 2001).

sVCAM wird im Bereich atherosklerotischer Läsionen vermehrt exprimiert und spielt bei dem Adhäsionsprozess von Makrophagen und T-Lymphozyten, die bei der Entstehung der Atherosklerose eine wichtige Rolle haben, mit.

Darüber hinaus bewirken diese zellulären Adhäsionsmoleküle nicht nur eine Adhäsion, sondern sie sind auch verantwortlich für eine Übertragung von Signalen ins Zellinnere. Somit regulieren sie auch die Immunantwort der Zelle im Rahmen eines Entzündungsgeschehens.

Von der Zellmembran abgespaltene Formen der Adhäsionsmoleküle werden in die Extrazellulärflüssigkeit abgegeben, so dass diese auch im Blut nachweisbar sind. Die Konzentration der löslichen Adhäsionsmoleküle in der Extrazellulärflüssigkeit korreliert dabei mit der Expressionsdichte der membran-verankerten Adhäsionsmoleküle.

\subsubsection{Plaque-Ruptur}

\section{Pregnancy-associated plasma protein A = PAPP-A}

Pregnancy-associated plasma protein A (PAPP-A) gehört zu der Familie der Zink bindenden Metalloproteinasen und besitzt ein Molekulargewicht von $187 \mathrm{kDa}$. Es konnnte bereits histochemisch in instabilen menschlichen Plaques nachgewiesen werden.

PAPP-A findet sich mit erhöhten Werten in der Phase der Plaqueruptur (CosinSales $\mathrm{J}$ et al. 2004).

Es spaltet Insulin-like growth factor binding protein-4 (IGFBP-4) und verursacht eine Reduktion der Affinität zu Insulin-like growth factor-I (IGF-I) und II (IGF-II). 
PAPP-A ist somit ein Regulator für die IGF-Bioaktivität in verschiedenen Systemen, einschließlich des kardiovaskulären Systems, und somit ein neuer Marker für das akute koronare Syndrom.

\subsubsection{Akute-Phase-Reaktion}

High sensitive C-reactive-protein = hsCRP

Das hsCRP besteht aus fünf identischen Polypeptideinheiten mit einem Molekulargewicht von $21 \mathrm{kDa}$. Die Synthese erfolgt hauptsächlich in der Leber und wird durch IL-6 und TNF-a reguliert (Kushner I 1993).

Seinen Namen hat das CRP aufgrund seiner Fähigkeit, mit dem C-Polysaccharid von Streptococcus pneumoniae zu reagieren. Es gehört zu den Akute-PhaseProteinen, deren Konzentration im Plasma und Serum bei Gesunden sehr niedrig ist. Bei Infekten oder Verletzungen steigt der Wert im Plasma oder Serum schnell an. Somit stellt das CRP einen hoch sensitiven Entzündungsmarker dar. Geringe Erhöhungen liegen vor allem bei chronischen entzündlichen Prozessen wie der Atherogenese vor.

Eine erhöhte Konzentration des Biomarkers hsCRP ist verbunden mit einem zweibis dreifach erhöhten Risiko für das Auftreten von Myokardinfarkt, Apoplex und peripherer arterieller Verschlusskrankheit (pAVK), unabhängig von bestehenden Vorerkrankungen (De Ferranti SD, Rifai N 2007, Ridker PM 2001).

\subsubsection{Myokardiale Dysfunktion}

\section{Natriuretische Peptide (NT-proANP / NT-proBNP)}

Brain natriuretic peptid (BNP) und atriales natriuretic peptid (ANP) gehören zur Familie der natriuretischen Peptide.

BNP wird als Präpropeptid in Kardiomyozyten der Herzkammern sowie zu einem geringeren Anteil auch in Kardiomyozyten der Herzvorhöfe synthetisiert. Durch Abspaltung einer Signalsequenz vom C-terminalen Ende entsteht zunächst proBNP, welches dann bei der Freisetzung aus den Herzmuskelzellen in ein $\mathrm{N}$ terminales Peptid (NT-proBNP) und das C-terminale BNP gespalten wird. Das Cterminale BNP ist das biologisch aktive Peptid, wohingegen NT-proBNP biologisch 
inaktiv ist. BNP wirkt natriuretisch, diuretisch, vasodilatierend und vermindert die Renin- und Aldosteronsekretion.

Durch eine vermehrte Dehnung der Herzkammern kommt es zur Steigerung der BNP-Freisetzung (Yamamoto K et al. 1996).

Daher kommt es bei Patienten mit einer Herzinsuffizienz zu erhöhten BNP- und NT-proBNP-Konzentrationen im Blut. Dabei korreliert die Höhe der BNP- oder NTproBNP-Konzentration mit dem Schweregrad einer Herzinsuffizienz (Friedl W et al. 1996).

Die natriuretischen Peptide dienen als frühe diagnostische und prognostische Marker der linksventrikulären Funktionsstörung (LVF), wobei NT-pro brain natriuretic peptide (NT-proBNP) und NT-pro atrial natriuretic peptide (NT-proANP) besser als andere natriuretische Peptide für die Diagnose asymptomatischer und symptomatischer LVF geeignet sind (Cowie MR et al. 1997, McDonagh TA et al. 1998). 


\subsection{Dyslipoproteinämien}

Dyslipoproteinämien bezeichnen eine Gruppe von Stoffwechselerkrankungen, bei denen es zu einer Konzentrationserhöhung von Cholesterin, Triglyzeriden und/oder Lipoproteinen kommt.

Man unterscheidet zum einen zwischen primären und sekundären Dyslipoproteinämien sowie bei der primären Dyslipoproteinämie zwischen verschiedenen Typen (Renz-Polster H et al. 2004).

\subsubsection{Primäre Dyslipoproteinämien}

Die primären Dyslipoproteinämien werden nach Fredrickson (Renz-Polster $\mathrm{H}$ et al. 2004) klassifiziert und sind zumeist genetisch bedingt. Zudem sind sie, im Gegensatz zu den sekundären Dyslipoproteinämien, keine Folgeerscheinung anderer Grunderkrankungen, sondern gelten als eigenständige Erkrankungen.

Für diese Arbeit von Bedeutung sind vor allem die familiären Hypercholesterinämien.

Die Hypercholesterinämien sind gekennzeichnet durch eine isolierte Erhöhung von LDL-Cholesterin aufgrund eines Defektes infolge einer Mutation (Chromosom 19) des LDL-Rezeptors. Dieser Defekt führt dazu, dass LDL-Cholesterin nicht (homozygoter Typ) oder nur unzureichend (heterozygoter Typ) von der Leber aufgenommen werden kann und somit die Rückkopplung für die Cholesterinsynthese fehlt.

Dadurch kommt es zu einer massiven Very low density lipoprotein (VLDL)Cholesterin-Bildung, welches die Vorstufe des LDL-Cholesterins darstellt. Mit einer Häufigkeit von 1:500 ist der heterozygot autosomal dominant vererbte Typ am häufigsten. Mit einem koronaren Ereignis ist hier zwischen dem 30. bis 45 . Lebensjahr zu rechnen (LDL-Cholesterin-Spiegel 300-600 mg/dl). Der homozygot vorkommende Typ besitzt dagegen nur eine Häufigkeit von 1:1 Mio und geht mit einem schweren Krankheitsbild schon im Kindes- oder Jugendalter einher (LDLCholesterin Spiegel 600-1000 mg/dl) (Renz-Polster H et al. 2004). 
Tab. 1.1 Primäre Dyslipoproteinämien (nach Fredrickson)

\begin{tabular}{|c|c|c|c|c|c|}
\hline Typ & $\begin{array}{c}\text { Laborwerte } \\
\text { T=Triglyceride } \\
\mathrm{C}=\text { Cholesterin } \\
\text { gesamt }\end{array}$ & $\begin{array}{c}\text { Beteiligte } \\
\text { Lipoproteine }\end{array}$ & Genetik & Häufigkeit & $\begin{array}{l}\text { Besonder- } \\
\text { heit }\end{array}$ \\
\hline I & T erhöht & $\begin{array}{l}\text { Chylomikro- } \\
\text { nen }\end{array}$ & aut.rez. & Sehr selten & $\begin{array}{l}\text { Risiko noch } \\
\text { nicht bekannt }\end{array}$ \\
\hline Ila & C erhöht & LDL & aut.dom. & $\begin{array}{l}10 \% \text { der } \\
\text { HLP }\end{array}$ & $\begin{array}{l}\text { Mutation LDL- } \\
\text { Rezeptor }\end{array}$ \\
\hline IIb & C erhöht & $\begin{array}{l}\text { LDL und } \\
\text { VLDL }\end{array}$ & aut.dom. & $15 \%$ & $\begin{array}{l}\text { ähnlich Typ } \\
\text { Ila }\end{array}$ \\
\hline III & $T+C$ erhöht & $\begin{array}{l}\text { VLDL- } \\
\text { Remnants }\end{array}$ & aut.dom. & $5 \%$ & B-VLDL \\
\hline IV & T erhöht & VLDL & aut.dom. & $70 \%$ & $\begin{array}{l}\text { meist erst } \\
\text { nach 30. LJ }\end{array}$ \\
\hline $\mathbf{V}$ & $T+C$ erhöht & $\begin{array}{l}\text { VLDL und } \\
\text { Chylomikro- } \\
\text { nen }\end{array}$ & unbekannt & selten & $\begin{array}{l}\text { erhöhtes } \\
\text { Risiko wahr- } \\
\text { scheinlich }\end{array}$ \\
\hline
\end{tabular}

$(\mathrm{LDL}=$ Low density lipoprotein, $\mathrm{VLDL}=$ Very low density lipoprotein, aut.-rez. = autosomal-rezessiv, aut.-dom. = autosomal-dominant)

(Renz-Polster H et al. 2004; S. 854, plus eigene Ergänzungen)

\subsubsection{Sekundäre Dyslipoproteinämien}

Heutzutage ist eine Vielzahl von Organ- und Stoffwechselerkrankungen und endokrinen Störungen bekannt, bei denen es sekundär zu einem pathologischen Lipidproteinmuster kommt. Genau wie bei den primären Typen der Dyslipoproteinämien induzieren auch die sekundären Typen ein erhöhtes Atheroskleroserisiko.

Hypercholesterinämie: Ernährung, Cholestase, nephrotisches Syndrom, Hypothyreose, Medikamente (z.B. Thiazide)

Hypertriglyzeridämie: Alkohol, schlecht eingestellter Diabetes mellitus, Adipositas, Gammopathie 
Durch Behandlung der Grundkrankheit ist es möglich eine sekundäre Dyslipoproteinämie zu heilen oder zumindest deutlich zu verbessern.

\subsection{Apherese}

Die Apherese ist ein Behandlungsverfahren, deren Therapieeffekt auf der extrakorporalen Elimination und Modulation pathogener Proteine oder Zellen des Blutes besteht.

Es gibt verschiedene Verfahren. Diese unterscheiden sich in ihrer Methode, in ihren Vor-und Nachteilen sowie in den hauptsächlich von ihnen zu entfernenden Substanzen.

\section{APHERESEVERFAHREN}
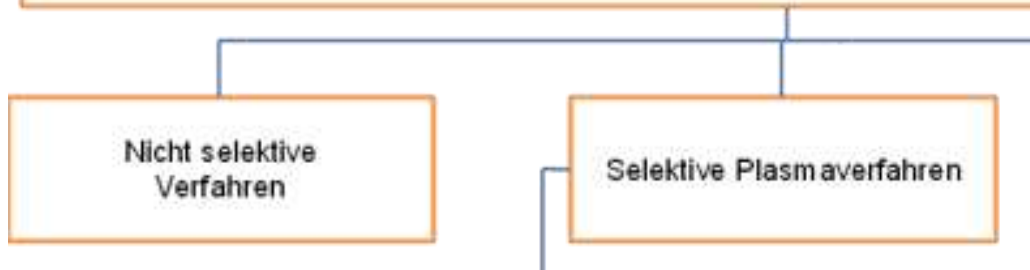

H.E.L.P.

(Heparininduzierte LDLPräzipitation)

Thermo- 1

Doppelmembranfiltration

IA

(Immunabsorption)

DS

Dextransulfatadsorption

Abb. 1.2 Aphereseverfahren

(Koziolek MJ 2005; S. 16, mit eigenen Ergänzungen) 
Insgesamt kann man zwischen drei Grundarten der Apherese unterscheiden:

\section{Nicht selektive Verfahren}

Kommen in dieser Studie nicht zum Einsatz.

\section{Selektive - plasmabehandelnde Verfahren}

Bei diesem Verfahren erfolgt eine extrakorporale Separation von Blutplättchen und Blutplasma. Das Plasma wird mit Hilfe von Adsorption, Präzipitation (Ausfällung) oder Filtern von seinen pathogenen Bestandteilen befreit. Das am Ende verbleibende Plasma kann nun ohne große Volumenverluste dem Patienten reinfundiert werden und erübrigt somit eine zusätzliche Volumensubstitution.

\section{Vollblutverfahren}

Während der Behandlung mit dem Vollblutaphereseverfahren können die pathologischen Bestandteile direkt aus dem Blut adsorbiert werden und machen somit eine vorangehende Trennung des Blutes vom Plasma unnötig. Der Vorteil bei diesem Verfahren ist somit, dass weder eine Separation noch eine Reinfusion nötig werden. Auch eine Substitution von Blut oder Blutbestandteilen erübrigt sich. Insgesamt verlaufen die verschiedenen Apheresearten vereinfacht nach folgendem Schema. Es wird ein extrakorporaler Kreislauf hergestellt, bei dem das Blut aus einer peripheren Vene, einem arteriovenösen Shunt oder einem Vorhofkatheter mittels Blutpumpe entnommen wird. Dieses Blut durchläuft die verschiedenen Geräte mit einem Blutfluss von durchschnittlich 60-120 $\mathrm{ml} / \mathrm{min}$ und wird dem Patienten nach Elimination der pathogenen Bestandteile über einen zweiten Zugang reinfundiert.

Welche Art von pathogenen Bestandteilen und in welcher Menge sie entfernt werden, ist abhängig von dem jeweiligen Verfahren. Die Effektivität der LDLApherese ergibt sich aus folgenden Parametern, die vor und nach der Behandlung gemessen werden: Gesamtcholesterin, LDL-Cholesterin, High-density-lipoprotein (HDL) und Triglyzeriden (TG).

Lipoprotein (a) (Lp(a))-Werte werden nur untersucht, wenn erhöhte Werte als individueller Risikofaktor bekannt sind. 
Es gibt vor Beginn einer LDL-Apheresebehandlung verschiedene Stufen, die durchlaufen werden müssen:

- 1. Diät

- 2. Medikamente (Einzeltherapie)

- 3. Medikamente (Kombinationstherapie).

2003 wurden durch den gemeinsamen Bundesausschuss von Ärzten und Krankenkassen (Kassenärztliche Bundesvereinigung 2003) die Indikationen zur LDL-Apherese gestellt:

- Familiäre Hypercholesterinämie in homozygoter Ausprägung

- Schwere Hypercholesterinämien, bei denen grundsätzlich mit einer über zwölf Monate maximalen diätetischen und medikamentösen Therapie das LDL-Cholesterin (>130 mg/dl) nicht ausreichend gesenkt werden kann

- Im Vordergrund der Abwägung der Indikationsstellung soll dabei das Gesamt-Risikoprofil des Patienten stehen.

Im Jahr 2008 wurde zudem durch den Bundesausschuss die LDL-Apherese bei schwerer isolierter Lipoprotein(a)-Erhöhung mit in die Indikationsstellung aufgenommen. In einigen Studien konnte bereits ein positiver Effekt auf kardiovaskuläre Endpunkte nachgewiesen werden (Stefanutti C et al. 2010).

Über die Jahre wurde die Indikationsstellung immer weiter zugunsten einer frühen LDL-Apheresebehandlung verändert und die Indikationsstellung weiter gefasst.

Auch das Einbeziehen der heterozygot erkrankten Patienten bekommt einen neuen Stellenwert, da in unterschiedlichen Studien, unter anderem in der Hokuriko-Studie, bei diesen Patienten eine deutliche Verbesserung der Sekundärprävention mit weniger organischen Endpunkten beschrieben wird (Mabuchi H. et al. 1998).

In unserer Studie werden die Patienten mit drei verschiedenen Verfahren behandelt. Dies sind aus der Gruppe der selektiven Verfahren die Heparinpräzipitation (H.E.L.P.) und die Thermofiltration (Plasmadifferentialfiltration/DFPP) sowie als Vollblutverfahren die direkte Adsorption (DALI). 


\section{H.E.L.P. (Heparin induzierte Lipoprotein-Präzipitation)}
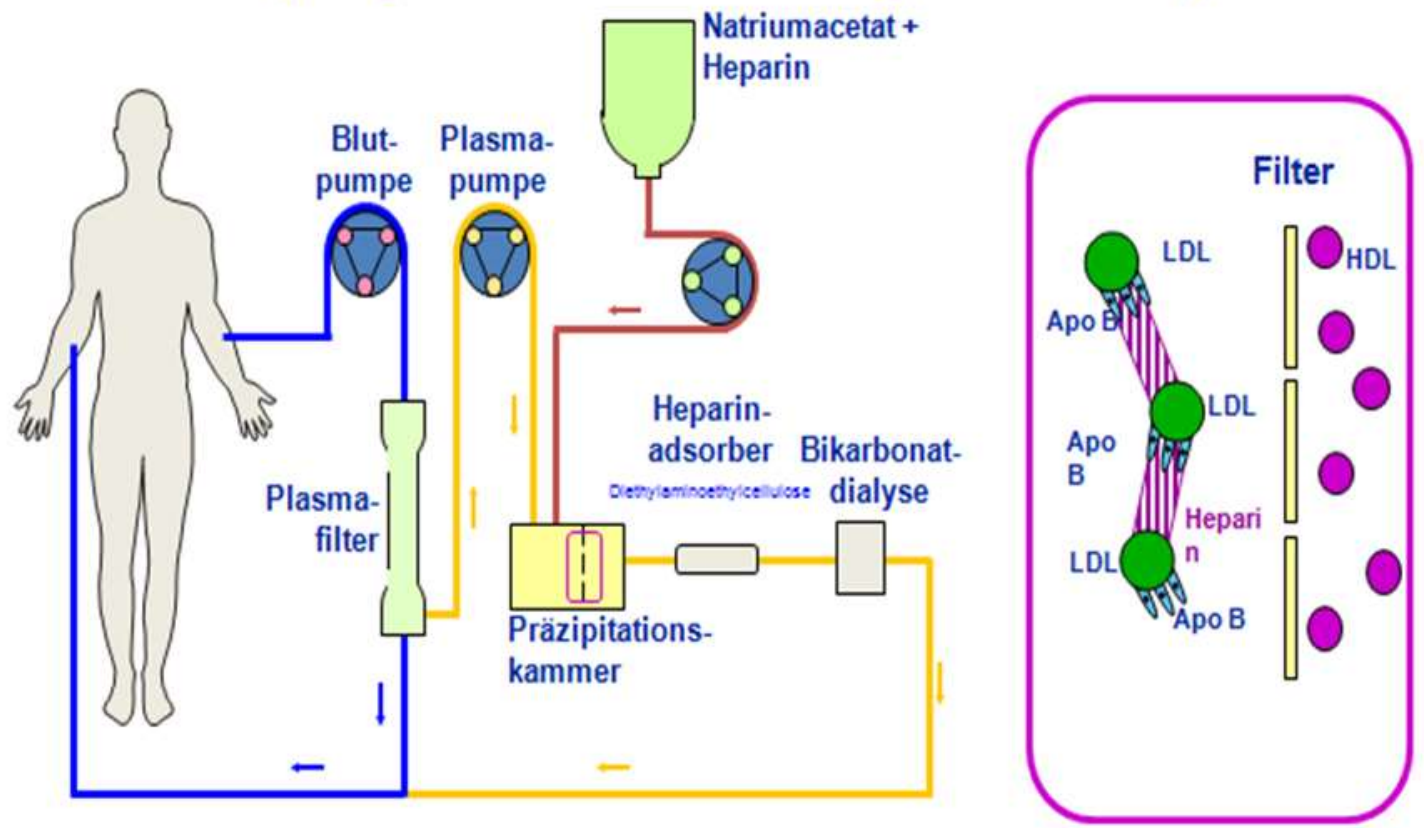

Blutsystem

Plasmasystem

Abb. 1.3 Schematischer Ablauf des H.E.L.P.-Verfahrens

(Koziolek MJ 2005; S. 21)

Zu Beginn der Behandlung steht die Plasmaseparation, die nach der venösen Punktion im Plasmat Secura Gerät (Fa. B.Braun AG, Melsungen) mit Hilfe eines Filters erfolgt. Das Plasma wird im Verhältnis 1:1 mit einem Heparin/Azetatpuffer (Natriumacetat) angereichert und hat dadurch einen $\mathrm{pH}$-Wert von 5,12. Da es sich hierbei um den isoelektrischen Punkt sowohl von Heparin, LDL-Cholesterin, Lp(a) als auch Fibrinogen handelt, kommt es zu einer Ausfällung von Komplexen der genannten Proteine mit Heparin (Armstrong VW et al. 1994).

Diese werden von einem Polycarbonfilter, der auch als Präzipitationsfilter bezeichnet wird, ausgefiltert. Das überschüssige Heparin wird im Anschluss durch einen Heparin-Adsorber chemisch aus dem Plasma entfernt. 
Am Ende muss der pH-Wert wieder normalisiert werden. Dies geschieht durch einen Dialysefilter (Bicarbonat-Dialyse), durch den wieder ein physiologischer $\mathrm{pH}$ Wert von 7,4 hergestellt wird.

Während einer Behandlung mit dem H.E.L.P.- Verfahren können ca. 3000 ml Plasma mit einem Fluss von bis zu $30 \mathrm{ml} / \mathrm{min}$ gereinigt und eine Absenkung der Bluttfettkonzentration von Cholesterin, $L p(a)$ und Fibrinogen um $50 \%$ bis $80 \%$ erreicht werden.

Insgesamt dauert eine Behandlung zwischen 80 und 120 Minuten.

Eine zu starke Fibrinogenabsenkung und eine begrenzte Kapazität des Präzipitationsfilters stellen eine Limitierung des Verfahrens dar.

Grundsätzlich wird dieses Verfahren jedoch als unkompliziert und gut verträglich beschrieben und wird auch schon in anderen Fachbereichen, z.B. bei einem akuten Hörsturz, erfolgreich eingesetzt.

Durch die zusätzliche Einflussnahme auf Gerinnungsfaktoren und Entzündungsparameter kommt es zudem zu einer positiven Veränderung der Plasmaviskosität und Hämorheologie. Dies äußert sich in einer sofortigen Verbesserung der Flusseigenschaften des Blutes, welche auch noch Tage nach der Behandlung besteht (Grützmacher P et al. 1990). 
1.5.2 DFPP = Double Filtration Plasmapheresis (Doppelmembran/Thermofiltration)

\section{Doppelmembran-/Thermofiltration}
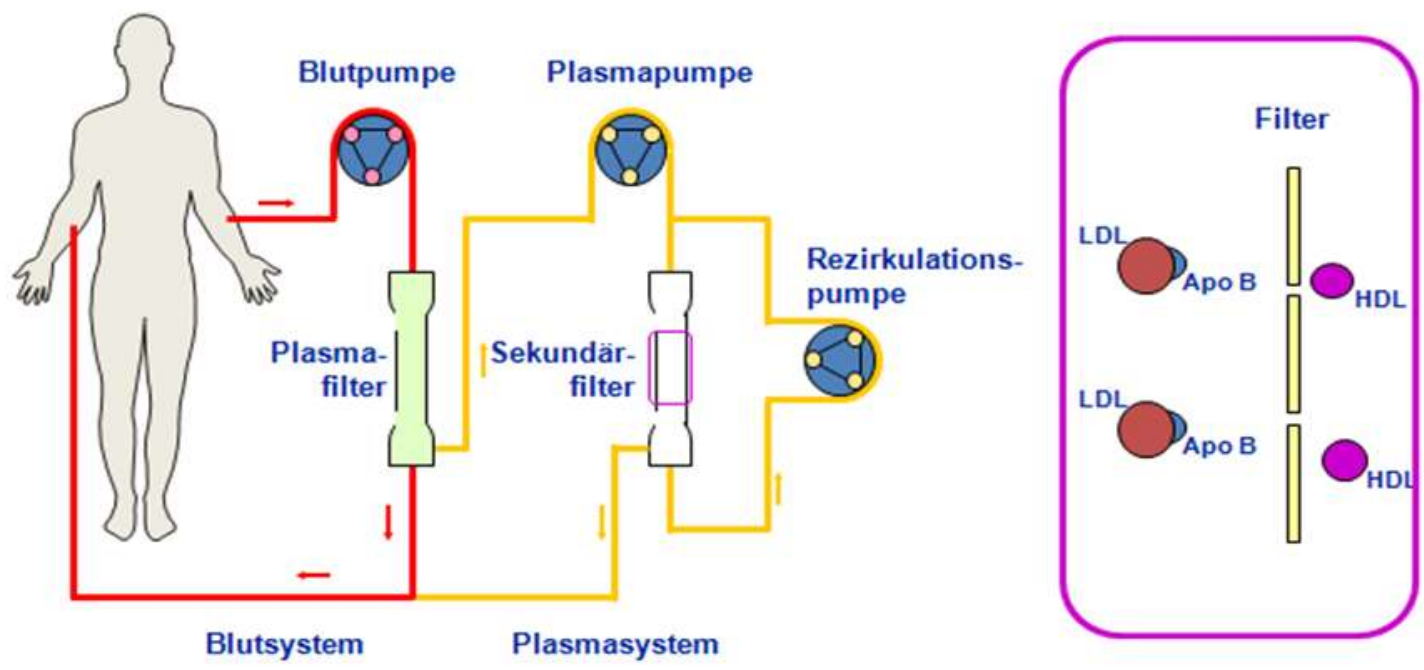

Abb. 1.4 Schematischer Ablauf des DFPP-Verfahrens

(Koziolek MJ 2005; S. 17)

Bei der Thermofiltration handelt es sich um eine Membrandifferentialfiltration. Hierbei wird das OctoNova® - System der Fa. Diamed, Köln mit einem EC50®Filter (Asahi, Japan) eingesetzt. Auch hier erfolgt zuerst eine Plasmaseparation, bevor das Plasma durch einen Sekundärfilter (Lipidfilter) gepresst wird. Die Filter haben eine fest vorgegebene Porengröße, die gerade noch unter der Molekulargröße eines LDL-Cholesterinmoleküls liegt. Eine Porengröße von 0,000015 mm hält neben LDL-Cholesterin auch $\mathrm{Lp}(\mathrm{a})$ und Fibrinogen zurück. So können auch $\operatorname{lgM}$ und a2-Makroglobuline aus dem Plasma gefiltert werden. Aufgrund dieser Tatsache können neben der familiären Hypercholesterinämie auch weitere Erkrankungen, wie z.B. das Hyperviskositätssyndrom, der Morbus Waldenström und die Kryoglobulinämie mit diesem Verfahren behandelt werden. Das Plasma wird dem Patienten fast vollständig, aber gereinigt zurückinfundiert. 
Die Vorteile dieser Methode liegen in der selektiven Entfernung insbesondere der rheologisch aktiven Eiweiße.

Aber auch die Thermofiltration hat ihre Nachteile. Dies ist vor allem die eingeschränkte Kapazität des Sekundärfilters, welcher im sogenannten „deadend“-Modus arbeitet. Bei hohen Ausgangswerten kommt es zu einem Verschluss des distalen Auslasses der Hohlfasern.

Während einer Behandlung mit dem DFPP- Verfahren können ca. 3000-3500 ml Plasma mit einem Fluss von 25-35 ml/min gereinigt werden.

Insgesamt dauert eine Behandlung zwischen 110 und 130 Minuten.

1.5.3 DALI = Direkte Adsorption von Lipoproteinen aus Vollblut

\section{DALI (Direkte Adsorption von Lipoproteinen)}

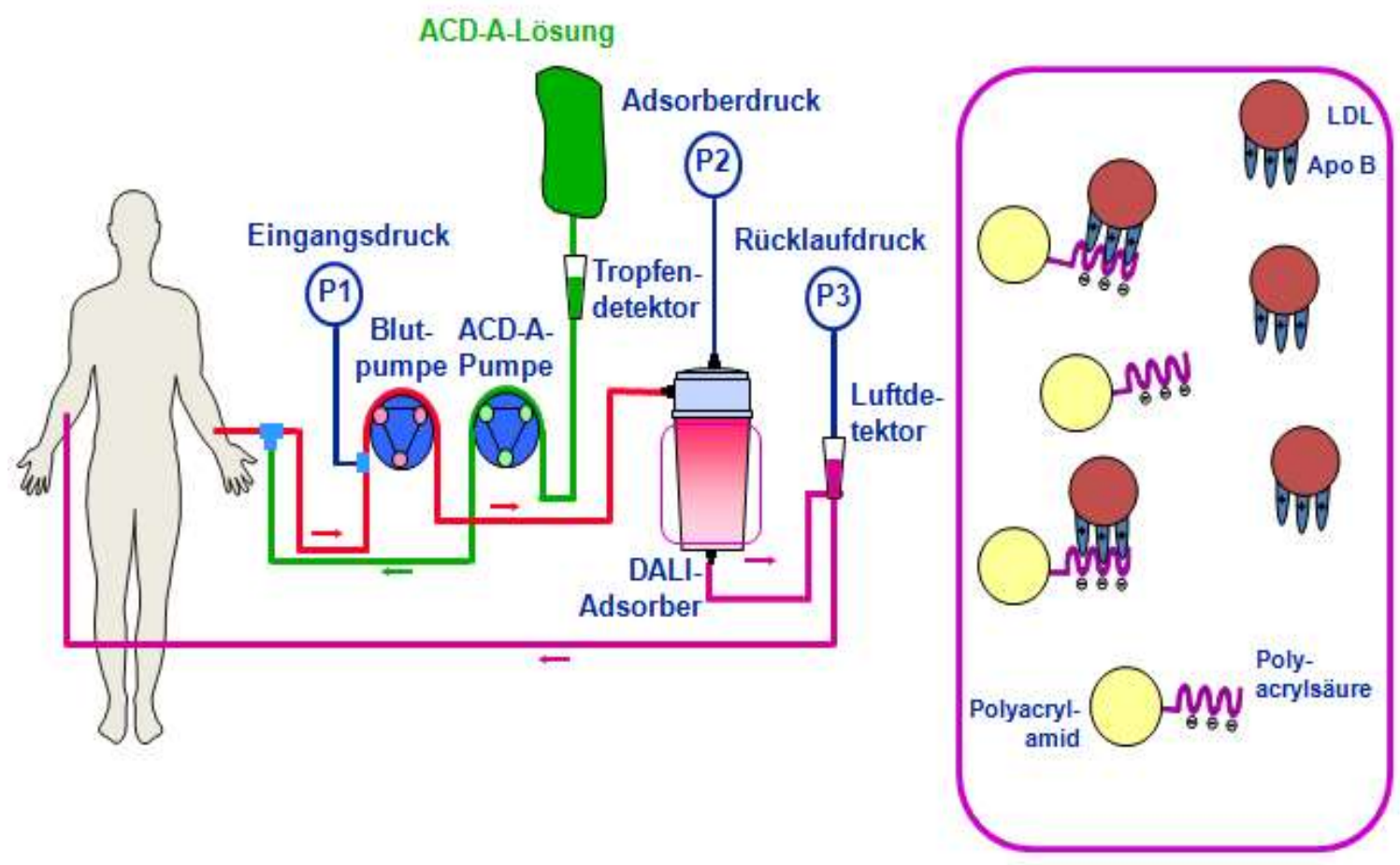

Abb. 1.5 Schematischer Ablauf des DALI-Verfahrens

(Koziolek MJ 2005; S. 22)

Das DALI-Verfahren (Fa. Fresenius AG, St. Wendel) unterscheidet sich von den vorstehend beschriebenen Verfahren, da hier LDL-Cholesterin und Lp(a) direkt 
aus dem Vollblut entfernt werden. Eine vorangehende Separation des Plasmas ist somit nicht erforderlich.

Nach H.E.L.P. ist DALI das insgesamt am zweithäufigsten angewandte Verfahren. Das Blut wird direkt nach der Entnahme auf eine Adsorberpatrone geleitet, in der sich mit polyanionischem Polyacrylamid beladene poröse Kügelchen mit negativer Ladung befinden.

Die beiden positiv geladenen atherogenen Lipoproteine LDL-Cholesterin und Lp(a) bleiben im Filter hängen und werden somit dem Plasma entzogen. Die Bindung ähnelt der von LDL-Cholesterin an dem LDL-Rezeptor.

Die restlichen Blutbestandteile laufen durch den Adsorber und werden dem Patienten reinfundiert.

Um den Blutgerinnungsprozess während der Behandlung zu unterbrechen, wird dem Blut direkt nach der Entnahme eine sogenannte ACD-Lösung zugemischt. Hierbei handelt es sich um Citrat, welches das freie Serumkalzium im Blut bindet.

Vorteile dieser Behandlung sind der einfache Systemaufbau durch Wegfall der Plasmaseparation und die Möglichkeit, höhere Flussraten zu fahren (z.T. bis 160 $\mathrm{ml} / \mathrm{min}$ ) mit verkürzter Behandlungszeit. Neuere Studien zeigen jedoch, dass höhere Flussraten insgesamt weniger effektiv sind (Wendler T. et al. 2003).

Bei der DALI-Apherese gibt es jedoch auch einige Einschränkungen. Durch die negative Ladung, die im Adsorber herrscht, kommt es zu einer Aktivierung des Bradykinins. Daher ist eine gleichzeitige Gabe von ACE-Hemmern kontraindiziert. Zudem kann es durch die Bindung des freien Serumkalziums zu einer Hypokalziämie kommen.

Während einer Behandlung mit dem DALI - Verfahren können ca. 5000-8000 ml Blut mit einem Fluss von 60-80 ml/min gereinigt und eine Absenkung der LDLKonzentration von bis zu $60 \%$ erreicht werden.

Insgesamt dauert eine Behandlung zwischen 80 und 110 Minuten.

In der nachfolgenden Tabelle sind die wesentlichen Parameter der betrachteten Verfahren vergleichend dargestellt. 
Tab. 1.2 Eliminationsparameter der verwendeten Aphereseverfahren

\begin{tabular}{|l|l|l|l|}
\hline Verfahren & H.E.L.P. & DFPP & DALI \\
\hline Zeit & $80-120 \mathrm{~min}$ & $110-130 \mathrm{~min}$ & $80-110 \mathrm{~min}$ \\
\hline Fluss & $30 \mathrm{ml} / \mathrm{min}$ & $25-35 \mathrm{ml} / \mathrm{min}$ & $60-80 \mathrm{ml} / \mathrm{min}$ \\
\hline Volumen & $2800-3200 \mathrm{ml}$ & $3000-3500 \mathrm{ml}$ & $5000-8000 \mathrm{ml}$ \\
\hline Elimination & Ges-Chol: $-49 \%$ & Ges-Chol: $-54 \%$ & Ges-Chol: -45 bis-58\% \\
& LDL-Chol: $-61 \%$ & LDL-Chol: $-65 \%$ & LDL-Chol: -52 bis-71\% \\
& HDL-Chol: $-15 \%$ & HDL-Chol: $-9 \%$ & HDL-Chol: -2 bis-10\% \\
& TG: $-57 \%$ & TG: $-40 \%$ & TG: -27 bis-31\% \\
& Lp(a): $-62 \%$ & Lp(a): $-60 \%$ & Lp(a): -55 bis-68\% \\
\hline Besonderheit & Fibrinogenabsen- & Dead-end-Modus & KI:ACE-Hemmer \\
& kung & & \\
\hline
\end{tabular}

(Ges-Chol = Gesamt-Cholesterin, LDL-Chol = LDL-Cholesterin, HDL-Chol = HDLCholesterin, $\mathrm{TG}=$ Triglyzeride, $\mathrm{Lp}(\mathrm{a})=$ Lipoprotein $(\mathrm{a}), \mathrm{KI}=$ Kontraindikation)

(Horstkotte D, Mellwig KP 2003, Mellwig KP 2003, Parhofer KG et al. 2000, Koziolek MJ et al. 2010) 


\subsection{Ziel der Arbeit}

Ziel dieser Arbeit ist es in erster Linie den Einfluss der LDL-Apherese auf proatherogene und plaquestabilisierende bzw. -destabilisierende Mechanismen zu analysieren.

In den verschiedenen Phasen der koronaren Herzkrankheit werden unterschiedliche Biomarker exprimiert. Der Einfluss der LDL-Apherese auf die Expression von Biomarkern wird durch Bestimmung dieser Surrogatparameter systemisch unter der Behandlung vor und nach dem LDL-Apherese-relevanten Filter durchgeführt.

Als Methodenkontrolle dienen Gesamteiweiß, LDL-Cholesterin und hsCRP. Zur weiteren Kontrolle werden die Werte bei dem Hauptkollektiv sowie bei den beiden Kontrollkollektiven, bestehend aus einem gesunden Kollektiv und einem Kollektiv unter LDL-senkender Therapie (Statin + Ezetrol) und mit anamnestischen Endorganschäden, bestimmt.

Als Hypothese wird eine protektive Wirkung der LDL-Apherese auf die Plaqueentstehung und-stabilität angenommen.

Des Weiteren werden die zu erzielenden Effekte bei den unterschiedlichen LDLApheresemethoden, bestehend aus H.E.L.P., DFPP und DALI, verglichen. 


\section{PATIENTEN UND METHODEN}

\subsection{Patienten}

Die Studie wurde durch das Ethikkomitee der Universität Göttingen geprüft und genehmigt (Ethikantrag Nr. 39/12/05). Die Einwilligung aller Probanden oder ihrer Eltern lag vor.

\subsubsection{Probandenpopulation}

Für die vorliegende Arbeit werden Probanden aus drei verschiedenen Kollektiven rekrutiert.

Bei der ersten Gruppe (Gruppe A) handelt es sich um das Hauptkollektiv. Dieses besteht aus 22 LDL-Apherese-Patienten der LDL-Apheresestation der Universitätsmedizin Göttingen (UMG).

Die zweite Gruppe (Gruppe B) beinhaltet das erste Kontrollkollektiv mit 15 gesunden Probanden.

Das zweite Kontrollkollektiv bildet die Gruppe C mit 20 Patienten, bei denen eine medikamentös behandelte Hyperlipoproteinämie und Endorganschäden vorliegen, aber die Indikationen für eine LDL-Apherese nicht erfüllt sind.

Insgesamt umfasst die Studie 57 Probanden.

\section{Gruppe A}

Das Hauptkollektiv bilden 22 Patienten, die sich regelmäßig und seit mindestens zwei Jahren einer teilstationären LDL- Apheresebehandlung unterziehen.

Sie leiden unter einer schweren Hyperlipoproteinämie (HLP), die sich trotz medikamentöser Therapie und strenger Diät nicht auf die gewünschten Zielwerte für die Lipidwerte LDL-Cholesterin, Cholesterin und Triglyzeride (LDL, CHOL, TG) einstellen lässt.

Die LDL-Apheresebehandlung findet im Apheresezentrum des Universitätsklinikums Göttingen unter Beachtung der geltenden nationalen Richtlinien (Schettler V et al. 2002, Kassenärztliche Bundesvereinigung 2003) statt. 


\section{Gruppe B}

Bei dieser Gruppe handelt es sich um das gesunde Normalkollektiv.

Es umfasst Probanden, die aus dem Bekanntenkreis rekrutiert werden und Patienten diverser Stationen der UMG, die sich aufgrund elektiver Eingriffe in stationärer Behandlung befinden. Keiner dieser Patienten nimmt für die Studie relevante Medikamente oder leidet an einer chronischen Erkrankung, insbesondere an einer Hyperlipoproteinämie mit kardialen oder vaskulären Endorganschäden.

\section{Gruppe C}

Die Probanden für das zweite Kontrollkollektiv entstammen hauptsächlich der kardiologischen Ambulanz und den vier kardiologischen Stationen der UMG. Bei dieser Gruppe liegen ebenfalls wie bei Gruppe A kardiale oder vaskuläre Endorganschäden und HLP vor, jedoch ohne Indikation zur Durchführung einer LDL-Apherese. Behandelt werden diese Patienten medikamentös ebenfalls mit einem Statin und Ezetimib.

Die Alters- und Geschlechtsverteilung der Gruppen B und C wird im Sinne einer „matched-pairs“-Technik zu den LDL-Apheresepatienten gewählt. Bei der „matchpairs"-Technik werden jedem Patienten des zu untersuchenden Hauptkollektivs aus der Gruppe B und C jeweils ein Proband zugeordnet, der in gewissen Kriterien mit diesem übereinstimmt. In dieser Arbeit werden das Alter und das Geschlecht als Kriterien festgelegt.

\subsubsection{Einschlusskriterien}

Für alle Kollektive (Gruppe A, B und C) gelten folgende Einschlusskriterien:

- Aufklärung der Probanden

- Einverständniserklärung des Probanden

- Volljährigkeit des Probanden bzw. Einverständniserklärung eines Elternteils.

Sind sämtliche Einschlusskriterien erfüllt, erfolgt die Aufnahme in die Studie durch die jeweiligen Prüfärzte.

In der Gruppe B sind zusätzliche Voraussetzungen für den Einschluss in dieses Kollektiv eine unauffällige Anamnese, einschließlich Medikamentenanamnese und 
klinischer und laborchemischer Ausschluss einer Infektionskrankheit sowie einer HLP.

Einschlusskriterien für die Gruppe $\mathrm{C}$ sind eine positive Anamnese in Bezug auf Endorganschäden (koronare Herzerkrankung=KHK, Herzinfarkt=HI, periphere arterielle Verschlusskrankheit=pAVK, transitorisch ischämische Attacke=TIA, prolongiertes reversibles ischämisch neurologisches Defizit=PRIND, Apoplex), eine HLP sowie eine medikamentöse fettsenkende Therapie mit einem Statin (HMG-CoA-Reduktase-Hemmer) und Ezetimib (Cholesterol-ResorptionsHemmer).

\subsubsection{Ausschlusskriterien}

Kriterien zum Ausschluss aus der Studie sind für alle Gruppen:

- Fehlende Einwilligungsfähigkeit

- Drogen- oder Arzneimittelmissbrauch

- Gleichzeitige Teilnahme an einer anderen klinischen Studie gemäß §40 AMG (Gesetz über den Verkehr mit Arzneimitteln)

- Klinische oder laborchemische Zeichen eines Infekts

- $\quad$ Eine bestehende Schwangerschaft sowie eine nicht beendete Stillperiode.

Für das Normalkollektiv führt zudem eine Hypercholesterinämie oder Lp(a)Erhöhung zum Ausschluss aus der Studie.

Ein zusätzliches Screening aller Probanden dient der Bestimmung von Infektparameter und dem jeweiligen Lipidstatus. Hierfür werden bei jedem Probanden folgende Laborparameter bestimmt: Blutbild, BSG, CRP, GesamtCholesterin, LDL-Cholesterin, HDL-Cholesterin, Lp(a) und Triglyzeride. 


\subsection{Diagnostik}

\subsubsection{Probengewinnung}

Für die Studie werden von jedem Probanden je eine Serummonovette und eine Heparinatmonovette benötigt.

Für die Gruppe A werden die entsprechenden Monovetten zu zwei Zeitpunkten abgenommen. Die Blutentnahmen erfolgen vor (Anfangspunkt=AP) und nach (Endpunkt=EP) dem Filter zu Beginn der LDL-Apherese aus einer Kubitalvene, einem Dialysekatheter oder einer arteriovenösen Fistel (Shunt).

Bei den Gruppen B und C handelt es sich um eine einmalige Blutentnahme.

In allen Fällen ist zur Gewinnung der Proben keine zusätzliche Venenpunktion nötig, da die benötigten Monovetten bei den routinemäßig durchgeführten Blutabnahmen mit abgenommen werden.

Die zur Durchführung der Studie entnommenen Blutmengen sind von geringer Menge.

\subsubsection{Probenbearbeitung}

Innerhalb von zwei Stunden, meist unmittelbar nach der Blutabnahme, werden die Proben abgeholt und im Labor bearbeitet.

Erst werden die Monovetten bei $3000 \mathrm{U} / \mathrm{min} 15$ Minuten zentrifugiert, um dann im Anschluss in Mengen von $250 \mu \mathrm{l}$ aliquotiert zu werden. Dadurch wird verhindert, dass die einzelnen Proben mehrmals aufgetaut werden müssen und so mögliche Fehlmessungen vermieden.

Die Proben werden nach dem jeweiligen Probanden durchnummeriert. Zudem werden sie mit dem Zeitpunkt der Entnahme (im Falle der LDL-Apheresepatienten mit den Zeitpunkten AP und EP) und der jeweiligen Gruppe (A-C) beschriftet. Um einen Überblick über die Proben zu bekommen, wird eine Datenbank angelegt. Hier wird festgehalten, wie viele Aliquots es pro Patient gibt und welche Menge sie enthalten. 


\subsubsection{Probenlagerung}

Die Aliquots werden für die ersten Tage bis zu 2 Wochen bei $-8^{\circ} \mathrm{C}$ und später für die Lagerung über Monate und Jahre bei $-80^{\circ} \mathrm{C}$ eingefroren. So wird verhindert, dass die zu messenden Marker ihre Konzentrationen über die Zeit verändern.

Für die Lagerung steht ein Gefrierschrank der nephrologischen Abteilung zur Verfügung.

\subsection{Versuche zur Bestimmung der Biomarker}

\section{Serum}

Bei der quantitativen Messung der Biomarker sVCAM, MMP-9 und NT-proANP werden standardisierte ELISA (Enzyme linked immunosorbent assay) - Verfahren der Firma R\&D systems (Minneapolis, USA) eingesetzt.

Die dazu vorliegenden Herstellerangaben werden beachtet. Als untere Grenzwerte (Sensitivität) ergeben sich bei sVCAM 0,17 ng/ml und bei MMP-9 0,156 ng/ml.

ADMA wird mit einem ELISA der Fa. DLD (Gesellschaft für Diagnostika und medizinische Geräte $\mathrm{mbH}$, Hamburg) mit einem unteren Grenzwert von 0,05 $\mu \mathrm{mol} / \mathrm{l}$ ausgewertet.

PAPP-A wird mit einem ELISA der Fa. DSL (Diagnostic systems laboratories Inc., Texas, USA) bei einem unteren Grenzwert von $0,06 \mu \mathrm{lU} / \mathrm{ml}$ gemessen.

Die Biomarker Interleukin IL-1B, IL-6, TNFa und sIL-2R werden über eine "chemiluminiscence“-Methode in einem Immulightsystem der Fa. Siemens bestimmt, wobei die unteren Grenzwerte bei $5 \mathrm{pg} / \mathrm{ml}$ (IL-1ß), $2 \mathrm{U} / \mathrm{ml}$ (IL-6), 3 $\mathrm{pg} / \mathrm{mL}$ (TNF- $\alpha$ ) und $50 \mathrm{U} / \mathrm{ml}$ (slL-2R) liegen.

\section{Plasma}

Die Konzentration des Markers NT-proBNP wird bestimmt mit dem Cobas 6000 System der Fa. Roche Diagnostics, Mannheim mit einem unteren Grenzwert von 5 $\mathrm{pg} / \mathrm{mL}$.

Zur Messung des Markers hsCRP wird das Integra 800 System der Fa. Roche Diagnostics, Mannheim mit einem unteren Grenzwert von $0,1 \mathrm{ng} / \mathrm{mL}$ eingesetzt. 


\section{Klinische Chemie}

Zusätzlich zu den bereits genannten Biomarkern werden folgende Laborwerte durch validierte Messmethoden zum Vergleich bestimmt: Gesamt-Cholesterin, LDL-Cholesterin, HDL-Cholesterin, Triglyzeride und Lp(a).

\subsection{Datenbank}

Um eine Vergleichbarkeit der einzelnen Patientendaten zu erreichen, wird eine Datenbank in standardisierter Form angelegt.

Gegliedert wird diese Datenbank in verschiedene Bereiche, die aus den jeweiligen Anamnesen der Probanden entnommen werden:

\section{Patientenbezogene Daten}

- $\quad$ Geburtsdatum (mit Lebensalter in Jahren)

- Geschlecht

- Körpergewicht in Kilogramm

- Körpergröße in Zentimeter

- Körpermassenindex (BMI)

\section{Klinische Daten}

- Endorganschäden

- $\quad$ Koronare Herzerkrankung (KHK)

- Herzinfarkt

- $\quad$ Periphere Verschlusskrankheit (pAVK), Einteilung nach Fontaine

- Transitorischischämische Attacke (TIA)

- Prolongiert reversibles ischämisches neurologisches Defizit (PRIND)

- Apoplex

- Therapien der Endorganschäden

- Herzkatheteruntersuchung (Anzahl)

- Stentimplantation

- $\quad$ ACVB-Operation (Datum) 


\section{Risikofaktoren}

- $\quad$ Arterieller Hypertonus (HTN)

- Hyperlipoproteinämie (HLP)

- Nikotinabusus

- Insulinpflichtiger und nicht insulinpflichtiger Diabetes mellitus

Medikamente

- $\quad$ Lipidsenker (Statine, Ezetimib)

- $\quad$ Koronarmittel $($ Molsidomin, Isosorbidmononitrat $=$ ISMN, Isosorbiddinitrat $=$ ISDN)

- $\quad$ Gerinnungshemmer (Acetylsalicylsäure = ASS, Clopidogrel, Macumar)

- Diuretika

- $\quad$ Antihypertensiva

- $\quad$ Antidiabetika

Laborwerte

- $\quad$ kleines Blutbild (BB)

- $\quad$ Lipidstatus (LDL-Chol., HDL-Chol., Gesamt-Chol., Triglyceride, Lp(a))

- $\quad$ CRP, hsCRP

- $\quad$ CK, CK-MB

- Protein

\section{Apheresedaten}

- $\quad$ Lipidaphereseverfahren (DALI, H.E.L.P., Thermofiltration)

- $\quad$ Zeitraum der Behandlung

- Behandeltes Blut-/Plasmavolumen

- Verträglichkeit.

\subsection{Statistik / Datenerfassung und Auswertung}

Bei der statistischen Datenanalyse wird als Software MedCalc Version 11.3.6.0 (MedCalc Software bvba Belgium) eingesetzt.

Um eine Gauß'sche Normalverteilung nachzuweisen, verwenden wir den Kolmogorov-Smirnov-Test. 
Hierdurch wird bei einigen Markern eine Normalverteilung ausgeschlossen, so dass im Verlauf für die graphische Darstellung nicht parametrische Methoden eingesetzt werden.

Es wird angenommen, dass der Zeitpunkt und die LDL-Apherese-Methode fixe Parameter sind und der Patient die zufällige Wirkung ist.

Um die AP- mit den EP-Werten für die einzelnen Methoden zu vergleichen, wird der Matched pair-Test von Wilcoxon bzw. der Student's t-Test verwendet.

Beide Tests ermitteln, mit welcher Irrtumswahrscheinlichkeit $p$ die Nullhypothese, nämlich dass die Werte in beiden Stichproben nicht unterschiedlich sind, verworfen werden kann. Für normalverteilte Stichproben kommt der Student's tTest zum Einsatz, während nicht normalverteilte Stichproben mit dem WilcoxonTest untersucht werden.

Darüber hinaus wird mittels Man-Whitney Test die quantitative Reduktion der Biomarker durch die drei verschiedenen Aphereseverfahren miteinander verglichen, indem die Differenzen der Biomarker-Konzentrationen vor und nach dem Aphereseverfahren berechnet wurden. Ein p-Wert von $<0.05$ wird als statistisch signifikant betrachtet. 


\section{Ergebnisse}

\subsection{Epidemiologie und demographische Daten der gemessenen Probanden}

Im Folgenden werden die wichtigsten Eckdaten der teilnehmenden Probanden, unterteilt nach den jeweiligen Gruppen erläutert und tabellarisch dargestellt.

\subsubsection{Patientengruppe A (Hauptkollektiv)}

Die Patienten der LDL-Apheresegruppe kommen im Regelfall einmal pro Woche, bei entsprechendem Lipoproteinstatus auch in vierzehntägigen Abständen zur teilstationären Therapie. Alle Patienten erhalten eine individuelle, der Erkrankung angepasste medikamentöse Behandlung. Dies beinhaltet eine medikamentöse Therapie der Risikofaktoren mit Blutverdünner, Beta-Blocker, ACE-Hemmer oder Angiotensin-Blocker sowie eine lipidsenkende Kombinationsbehandlung mit einem Statin und Ezetimib. Bei zwei der Patienten besteht eine Unverträglichkeit gegen Statine, so dass auf eine lipidsenkende Therapie verzichtet werden musste.

Bei allen Patienten dieser Gruppe liegen zum Zeitpunkt der Studie bereits kardiale oder vaskuläre Endorganschäden vor.

In Tabelle 3.1 werden die Charakteristika der Patienten, ihre aufgrund der Hyperlipoproteinämie entstandenen Endorganschäden und ihre medikamentöse Therapie sowie ihr jeweiliges Aphereseverfahren dargestellt. 
Tab. 3.1 Epidemiologische Daten der Gruppe A (Hauptkollektiv)

\begin{tabular}{|c|c|c|c|c|}
\hline & Gesamt & DFPP & DALI & H.E.L.P. \\
\hline \multicolumn{5}{|l|}{ Demografische Daten } \\
\hline Anzahl & 22 & 10 & 6 & 6 \\
\hline Alter (Jahre) & $\begin{array}{c}49,2 \pm \\
15.8\end{array}$ & $\begin{array}{c}55,9 \pm \\
12,5\end{array}$ & $\begin{array}{c}50,2 \pm \\
17,0\end{array}$ & $\begin{array}{c}42,0 \pm \\
19,9\end{array}$ \\
\hline Geschlecht (m/w) & $14 / 8$ & $7 / 3$ & $3 / 3$ & $4 / 2$ \\
\hline \multicolumn{5}{|l|}{$\begin{array}{l}\text { Vorliegende } \\
\text { Erkrankungen }\end{array}$} \\
\hline $\begin{array}{l}\text { Homozygote familiäre } \\
\text { Hyperlipoproteinämie }\end{array}$ & $3 / 22$ & $0 / 10$ & $1 / 6$ & $2 / 6$ \\
\hline Erhöhte LDL-Chol.-Werte & $16 / 22$ & $5 / 10$ & $4 / 6$ & $5 / 6$ \\
\hline Erhöhte TG-Werte & $6 / 22$ & $4 / 10$ & $1 / 6$ & $2 / 6$ \\
\hline $\begin{array}{l}\text { Erhöhte Lp(a)-Werte } \\
>0,3 \mathrm{~g} / \mathrm{L}\end{array}$ & 16 / 22 & $3 / 10$ & $4 / 6$ & $3 / 6$ \\
\hline $\begin{array}{l}\text { Mittlerer LDL- Chol. -Wert } \\
(\mathrm{mg} / \mathrm{dL})\end{array}$ & $\begin{array}{c}108,4 \pm \\
26,4\end{array}$ & $\begin{array}{c}106,9 \pm \\
21,5\end{array}$ & $\begin{array}{c}102,3 \pm \\
24,7\end{array}$ & $\begin{array}{c}116,4 \pm \\
42,0\end{array}$ \\
\hline \multicolumn{5}{|l|}{ Organerkrankungen } \\
\hline KHK & $18 / 22$ & $8 / 10$ & $5 / 6$ & $5 / 6$ \\
\hline $\begin{array}{llll}\text { pAVK (Stadium } & 1 & \text { oder } \\
\text { höher) } & & & \end{array}$ & $4 / 22$ & $2 / 10$ & $0 / 6$ & $2 / 6$ \\
\hline $\begin{array}{l}\text { Zerebrovaskuläre Erkr. } \\
\text { (TIA, PRIND, Apoplex) }\end{array}$ & $1 / 22$ & $1 / 10$ & $0 / 6$ & $0 / 6$ \\
\hline \multicolumn{5}{|l|}{$\begin{array}{l}\text { Lipidsenkende } \\
\text { Begleittherapie }\end{array}$} \\
\hline Statine & $20 / 22$ & $9 / 10$ & $5 / 6$ & $6 / 6$ \\
\hline Ezetimib & $20 / 22$ & $9 / 10$ & $5 / 6$ & $6 / 6$ \\
\hline \multicolumn{5}{|l|}{ Apheresedaten } \\
\hline $\begin{array}{l}\text { Behandlungsintervall } \\
\text { (wöchentl./zweiwöchentl.) }\end{array}$ & $21 / 1$ & $10 / 0$ & $5 / 1$ & $6 / 0$ \\
\hline
\end{tabular}




\begin{tabular}{|c|c|c|c|c|}
\hline & Gesamt & DFPP & DALI & H.E.L.P. \\
\hline \multicolumn{5}{|l|}{ Laborwerte } \\
\hline LDL-Chol. (mg/dl) AP & $\begin{array}{c}153,3 \pm \\
39,7\end{array}$ & $\begin{array}{c}148,8 \pm \\
26,3\end{array}$ & $\begin{array}{c}148,6 \pm \\
33,7\end{array}$ & $\begin{array}{c}165,5 \pm \\
63,8\end{array}$ \\
\hline LDL-Chol. (mg/dl) EP & $\begin{array}{c}55,8 \pm \\
15,6\end{array}$ & $\begin{array}{c}57,7 \pm \\
15,9\end{array}$ & $\begin{array}{c}48,0 \pm \\
14,7\end{array}$ & $\begin{array}{c}58,7 \pm \\
16,4\end{array}$ \\
\hline
\end{tabular}

$($ LDL-Chol. $=$ LDL-Cholesterin, $\mathrm{TG}=$ Triglyzeride, $\mathrm{KHK}=$ Koronare Herzerkrankung, $\mathrm{PAVK}=$ Periphere arterielle Verschlusskrankheit, $\mathrm{TIA}=$ Transitorisch ischämische Attacke, PRIND = Prolongiertes reversibles ischämisches neurologisches Defizit, AP = Anfangspunkt, EP = Endpunkt) Anmerkung zur Berechnung von Mean LDL:

LDL-Chol (AP) + 3,78 * (LDL-Chol (EP) - LDL-Chol(AP))/d

\subsubsection{Patientengruppe B (gesundes Kontrollkollektiv)}

Die Patienten der Gruppe B leiden weder an einer Hyperlipoproteinämie, noch bestehen zu dem Zeitpunkt der Probengewinnung laborchemische oder klinische Hinweise auf eine kardiovaskuläre Erkrankung. Zudem nehmen diese Patienten keine für diese Studie relevanten Medikamente ein.

Tab. 3.2 Epidemiologische Daten der Gruppe B (gesundes Kontrollkollektiv)

\begin{tabular}{|c|c|}
\hline & Gesamt \\
\hline \multicolumn{2}{|c|}{ Demografische Daten } \\
\hline Anzahl & 15 \\
\hline Alter (Jahre) & $41,9 \pm 12,5$ \\
\hline Geschlecht (m/w) & $5 / 10$ \\
\hline \multicolumn{2}{|l|}{ Laborwerte } \\
\hline LDL-Chol. (mg/dl) & $119,1 \pm 25,2$ \\
\hline
\end{tabular}


3.1.3 Patientengruppe C (krankes Kontrollkollektiv)

Die Patienten der Gruppe C haben wie die Gruppe A schon kardiovaskuläre Ereignisse und eine Hyperlipoproteinämie in ihrer Krankengeschichte. Sie erhalten eine lipidsenkende Begleittherapie, bestehend aus einem Statin und Ezetimib, sowie Medikamente zur Blutverdünnung und zur Bluthochdruckbehandlung (BetaBlocker, ACE-Hemmer oder Angiotensin-Blocker).

Im Unterschied zu der ersten Gruppe erfüllen diese Patienten jedoch nicht die Indikation für eine LDL-Apheresebehandlung.

Tab. 3.3 Epidemiologische Daten der Gruppe C (krankes Kontrollkollektiv)

\begin{tabular}{|l|c|}
\hline & Gesamt \\
\hline Demografische Daten & 22 \\
\hline Anzahl & $59,4 \pm 9,6$ \\
\hline Alter (Jahre) & $18 / 4$ \\
\hline Geschlecht (m/w) & $17 / 22$ \\
\hline Organerkrankungen & $3 / 22$ \\
\hline KHK & $2 / 22$ \\
\hline pAVK (Stadium 1 oder höher) & \\
\hline $\begin{array}{l}\text { Zerebrovaskuläre Erkr. } \\
\text { (TIA, PRIND, Apoplex) }\end{array}$ & $22 / 22$ \\
\hline Lipidsenkende Begleittherapie & $22 / 22$ \\
\hline Statine & $93,5 \pm 21,9$ \\
\hline Ezetimib & \\
\hline Laborwerte & \\
\hline LDL-Chol. (mg/dl) & \\
\hline
\end{tabular}




\subsection{Analyse der gemessenen Werte (Hauptkollektiv)}

Die Biomarker ADMA, MMP-9, VCAM und PAPP-A werden im Rahmen dieser Arbeit mittels ELISA analysiert.

Die Werte für die Biomarker IL-1ß, IL-6, TNF- $\alpha$, hsCRP, sIL-2R, NT-proBNP und NT-proANP werden durch weitere im Rahmen der Gesamtuntersuchung beteiligte Doktoranden und Laborkräfte ermittelt.

Die Werte sind jeweils für den Zeitpunkt vor dem Filter (Anfangspunkt $=$ AP) und nach dem Filter (Endpunkt $=E P)$ ermittelt. Die Differenz $(E P-A P)$ ist absolut (abs.) und prozentual (von Hundert = v.H.) errechnet. Soweit Messwerte unterhalb der Nachweisgrenze liegen, wird bei den Berechnungen der Grenzwert zu Grunde gelegt.

Die gemessenen Werte sind tabellarisch in der Anlage zu dieser Arbeit dargestellt. Für die weitere Analyse wurden Summenwerte für alle Biomarker differenziert nach Anfangspunkt (AP) und Endpunkt (EP) sowie nach dem jeweiligen LDLApherese-Verfahren ermittelt.

Anschließend werden die Differenzwerte absolut (= WertEP - WertAP) und prozentual $(=($ WertEP - WertAP $) /$ WertAP $)) \times 100)$ bezogen auf das Gesamtkollektiv und auf die jeweiligen Biomarker ermittelt.

Zudem werden in einer Tabelle jeweils die Normalverteilung und die daraus zu errechnende statistische Signifikanz dargestellt, bezogen auf den Messwert vor und nach dem Filter.

Bei statistisch signifikant fallenden Biomarkern werden darüber hinaus die jeweiligen LDL-Aphereseverfahren nochmals miteinander verglichen, um eine eventuelle Überlegenheit eines dieser Verfahren hervorzuheben.

Die ermittelten Werte werden nachfolgend für jeden Biomarker angeordnet nach den Phasen der vaskulären Prozesse dargestellt und bewertet. 


\subsection{Auswertung der Ergebnisse bezogen auf den Zeitpunkt der Atherosklerose}

Bei allen untersuchten LDL-Apherese-Verfahren ist eine deutliche Reduzierung der Werte für LDL-Cholesterin und $L p(a)$ festzustellen (s. Tabelle 3.1), welches dem primären Ziel der LDL-Apherese entspricht.

Im Verlauf werden nun die beschriebenen Biomarker gegenübergestellt und miteinander verglichen. In den folgenden Tabellen werden jeweils die Mittelwerte und Standardabweichungen aufgelistet.

3.3.1 Biomarker für proinflammatorische Prozesse (IL-6, IL-1ß, TNF-a, sIL-2R)

Tab. 3.4 Summenwerte der Biomarker für proinflammatorische Prozesse

\begin{tabular}{|l|l|c|c|c|c|}
\hline $\begin{array}{l}\text { Bio- } \\
\text { marker }\end{array}$ & Zeit & Gesamt & DFPP & DALI & H.E.L.P. \\
\hline $\begin{array}{l}\text { IL-6 } \\
\mathbf{( U / m l )}\end{array}$ & AP & $2,64 \pm 1,02$ & $2,72 \pm 1,26$ & $2,57 \pm 1,20$ & $2,57 \pm 0,27$ \\
\cline { 2 - 6 } & EP & $2,61 \pm 0,95$ & $2,68 \pm 1,18$ & $2,55 \pm 1,12$ & $2,55 \pm 0,18$ \\
\hline IL-1B & AP & $5,37 \pm 0,21$ & $5,34 \pm 0,23$ & $5,38 \pm 0,21$ & $5,40 \pm 0,20$ \\
\cline { 2 - 6 }$(\mathbf{p g} / \mathbf{m l})$ & EP & $5,38 \pm 0,16$ & $5,33 \pm 0,19$ & $5,42 \pm 0,12$ & $5,42 \pm 0,15$ \\
\hline TNFa & AP & $4,81 \pm 1,34$ & $4,48 \pm 1,58$ & $5,02 \pm 1,31$ & $5,15 \pm 0,97$ \\
\cline { 2 - 6 }$(\mathbf{p g} / \mathbf{m l})$ & EP & $5,16 \pm 2,57$ & $4,50 \pm 1,57$ & $4,42 \pm 1,02$ & $7,02 \pm 4,08$ \\
\hline \multirow{2}{*}{$\mathbf{s l L - 2 R}$} & AP & $446,55 \pm 152,20$ & $422,30 \pm 131,85$ & $561,17 \pm 177,75$ & $372,33 \pm 104,20$ \\
\cline { 2 - 6 } $\mathbf{( U / m l )}$ & EP & $357,05 \pm 157,55$ & $353,60 \pm 157,59$ & $473,17 \pm 157,44$ & $246,67 \pm 62,70$ \\
\hline
\end{tabular}


Tab. 3.5 Differenzwerte der Biomarker für proinflammatorische Prozesse

\begin{tabular}{|l|l|c|c|c|c|}
\hline $\begin{array}{l}\text { Bio- } \\
\text { marker }\end{array}$ & Abw & Gesamt & DFPP & DALI & H.E.L.P. \\
\hline \multirow{2}{*}{ IL-6 } & abs. & $-0,03 \pm 0,14$ & $-0,04 \pm 0,08$ & $-0,02 \pm 0,10$ & $-0,02 \pm 0,24$ \\
\cline { 2 - 6 } & $\%$ & $-0,37 \pm 4,77$ & $-0,80 \pm 1,69$ & $0,03 \pm 2,58$ & $-0,04 \pm 9,11$ \\
\hline \multirow{2}{*}{ IL-1B } & abs. & $0,01 \pm 0,12$ & $-0,01 \pm 0,12$ & $0,03 \pm 0,12$ & $0,02 \pm 0,13$ \\
\cline { 2 - 6 } & $\%$ & $0,22 \pm 2,25$ & $-0,14 \pm 2,27$ & $0,69 \pm 2,28$ & $0,36 \pm 2,51$ \\
\hline \multirow{2}{*}{ TNF- $\boldsymbol{\alpha}$} & abs. & $0,35 \pm 2,46$ & $0,02 \pm 1,18$ & $-0,60 \pm 1,60$ & $1,87 \pm 4,04$ \\
\cline { 2 - 6 } & $\%$ & $9,12 \pm 45,95$ & $2,92 \pm 19,84$ & $-8,53 \pm 23,71$ & $37,10 \pm 78,78$ \\
\hline \multirow{2}{*}{ sIL-2R } & abs. & $-89,50 \pm 55,19$ & $-68,70 \pm 53,66$ & $-88,00 \pm 40,19$ & $-125,67 \pm 59,66$ \\
\cline { 2 - 6 } & $\%$ & $-21,40 \pm 13,09$ & $-17,82 \pm 14,10$ & $-15,85 \pm 6,29$ & $-32,92 \pm 10,01$ \\
\hline
\end{tabular}

(Abw $=$ Abweichung, abs. $=$ absolut $)$

Es wird nun der $p$-Wert mittels Student's t-Test und mittels Wilcoxon-Test ermittelt. Bei den Proben, welche nicht einer Normalverteilung entsprechen, wird der Wert des t-Testes in Klammern dargestellt, da dieser bei diesem Kollektiv formal nicht angewendet werden sollte. Die statistisch signifikanten $\mathrm{p}$-Werte sind fett gedruckt. Statistisch signifikant ist ein Wert mit $p<0,05$.

Bei dem Biomarker IL-6 ist das gemessene Kollektiv zu klein, um einen sicheren p-Wert ermitteln zu können. Zudem sind die Werte vor und nach dem Filter fast identisch. 
Tab. 3.6 Normalverteilung und p-Werte der Biomarker für proinflammatorische Prozesse

\begin{tabular}{|c|c|c|c|c|}
\hline Marker & AP & EP & t-Test & WilcoxonTest \\
\hline IL-6 Kollektiv & n.v. & n.v. & $p=0,3667$ & $P=0,3594$ \\
\hline IL-6 DFPP & n.n.v. & n.n.v. & $(p=0,1679)$ & zu klein \\
\hline IL-6 DALI & n.v. & n.v. & $\mathrm{p}=0,6952$ & zu klein \\
\hline IL-6 H.E.L.P. & n.v. & n.v. & $p=0,8717$ & $p=1$ \\
\hline IL-1ß Kollektiv & n.v. & n.v. & $\mathrm{p}=0,7240$ & $p=0,9308$ \\
\hline IL-1ß DFPP & n.v. & n.v. & $p=0,7976$ & $p=0,8457$ \\
\hline IL-1ß DALI & n.v. & n.v. & $p=0,5301$ & $p=0,8125$ \\
\hline IL-1ß H.E.L.P. & n.v. & n.v. & $p=0,7711$ & $p=1$ \\
\hline TNF- $\alpha$ Kollektiv & n.v. & n.v. & $p=0,5067$ & $p=0,8900$ \\
\hline TNF- $\alpha$ DFPP & n.v. & n.v. & $p=0,9583$ & $p=0,8438$ \\
\hline TNF- $\alpha$ DALI & n.v. & n.v. & $p=0,4015$ & $p=0,4375$ \\
\hline TNF- $\alpha$ H.E.L.P. & n.v. & n.v. & $p=0,3092$ & $p=0,3092$ \\
\hline slL-2R Kollektiv & n.v. & n.v. & $\mathrm{p}<0,0001$ & $p<0,0001$ \\
\hline sIL-2R DFPP & n.v. & n.v. & $p=0,0029$ & $p=0,0020$ \\
\hline sIL-2R DALI & n.v. & n.v. & $p=0,0030$ & $p=0,0312$ \\
\hline sIL-2R H.E.L.P. & n.v. & n.v. & $p=0,0036$ & $p=0,0312$ \\
\hline
\end{tabular}

(n.v. = normal verteilt, n.n.v. = nicht normal verteilt)

Im Folgenden werden die Daten mit Hilfe einer Box-and-whisker-Graphik mittels Boxplot dargestellt.

Die Box entspricht dem Bereich, in dem die mittleren 50 \% der Daten liegen. Sie wird durch das obere und das untere Quartil begrenzt. Das obere Quartil bedeutet, dass 75\% der Messwerte kleiner oder gleich diesem Wert sind, das untere Quartil zeigt dies für die kleinsten 25\% der Messwerte, welche gleich oder kleiner diesem Messwert sind.

Der Median wird als durchgehender Strich in der Box eingezeichnet. Dieser Strich teilt das gesamte Diagramm in zwei Hälften, in denen jeweils $50 \%$ der Daten liegen. 
Die Whisker stellen die außerhalb der Box liegenden Werte dar. Die Punkte stehen für die Ausreißer, welche aufgrund ihrer starken Abweichung nicht mit in die Berechnung eingehen.

Diese Form wird gewählt, da in allen Graphiken für eine bessere Vergleichbarkeit von einer nicht parametrischen Verteilung ausgegangen wird.

In den Graphiken werden jeweils der AP- und der EP-Wert der einzelnen LDLAphereseverfahren für den jeweiligen Biomarker miteinander verglichen.

Hierbei steht Ges für das Gesamtkollektiv bestehend aus allen gemessenen Probanden. DFPP, DALI und H.E.L.P. stellen nochmals die jeweiligen Verfahren im Vergleich zueinander dar.

Biomarker IL-6

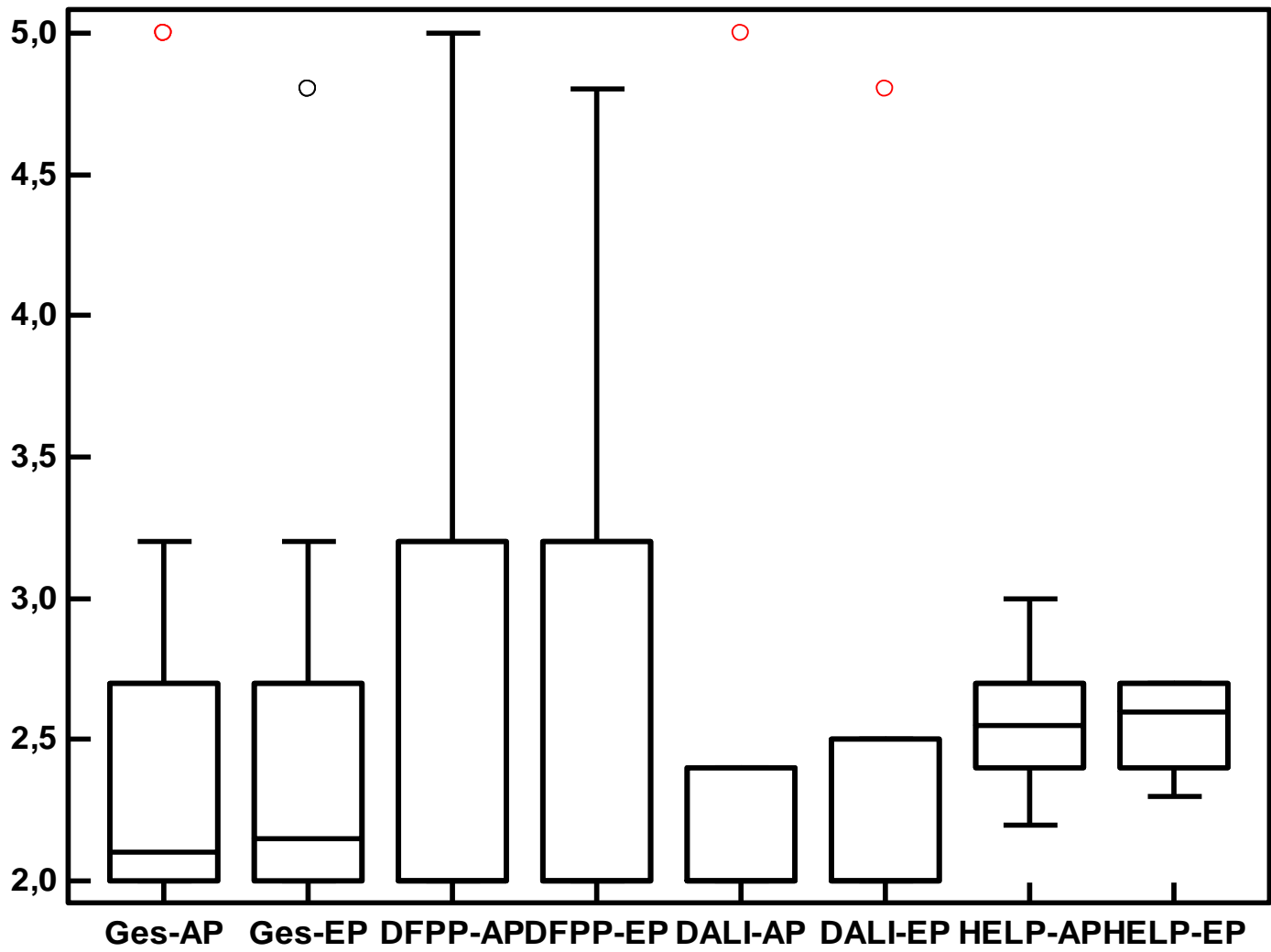

Abb. 3.1 Biomarker IL-6

(Ges-Ap = Gesamtkollektiv-Anfangspunkt, Ges-EP = Gesamtkollektiv Endpunkt) 
Bezüglich des proinflammatorischen Zytokin IL-6 zeigen die Auswertungen der Messergebnisse sowie deren graphische Darstellung mit einem p-Wert von 0,367 keine signifikante Veränderung durch die untersuchten LDL-Aphereseverfahren. Die Werte nach der LDL-Apherese sind weitestgehend identisch zu den Werten vor der LDL-Apherese unabhängig vom jeweiligen LDL-Aphereseverfahren.

Aufgrund der fehlenden Signifikanz wird bei diesem Marker von einem Vergleich der einzelnen Verfahren abgesehen.

\section{Biomarker IL-1ß}

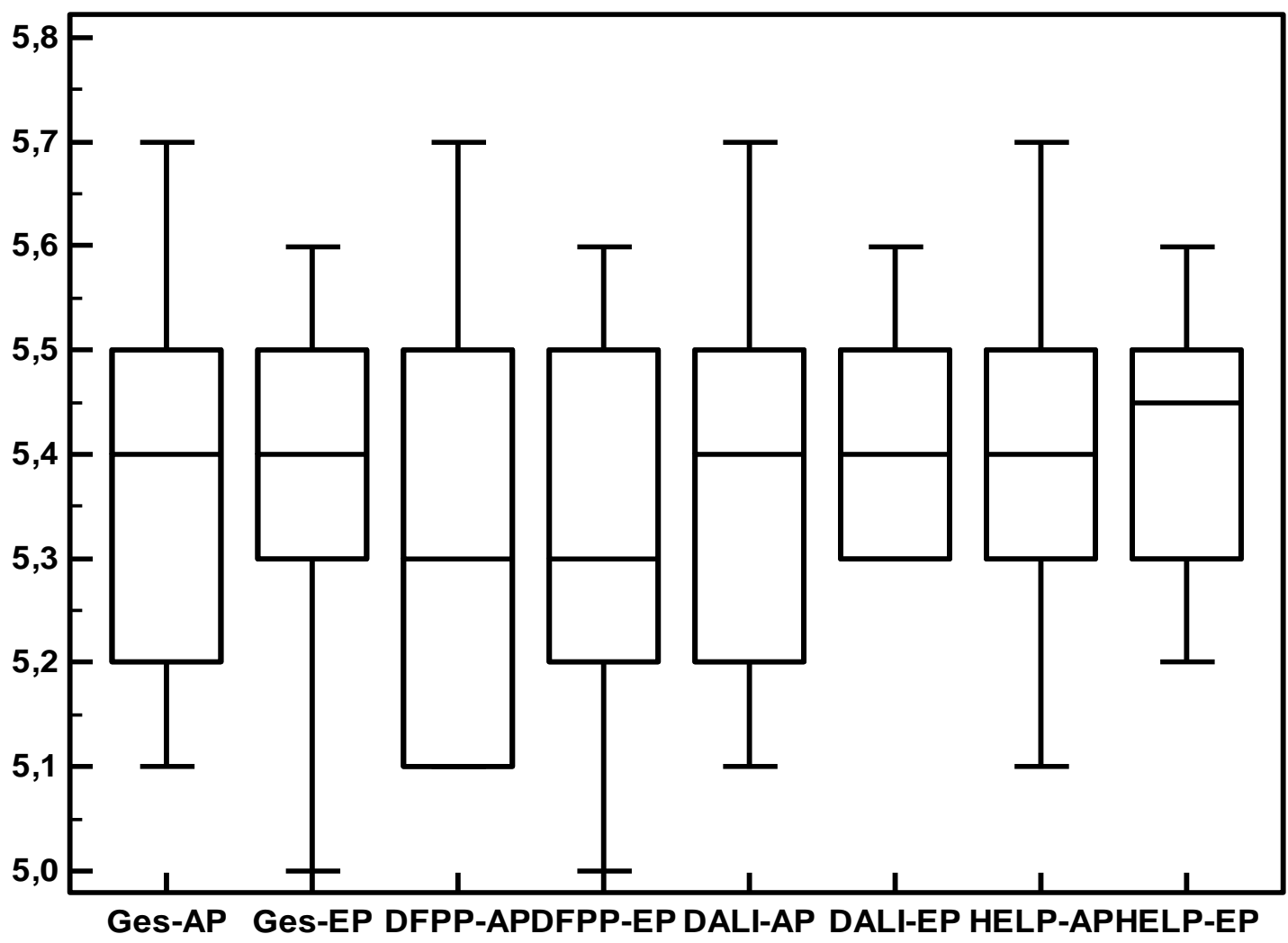

Abb. 3.2 Biomarker IL-1ß

Ebenso wie bei IL-6 kommt es auch bei dem proinflammatorischem Zytokin IL-1ß zu keiner nennenswerten Absenkung durch eines der Verfahren während der LDL-Apherese. Mit einem p-Wert von 0,7240 im t-Test wird auch dieser Marker nicht signifikant reduziert, so dass wir von einem weiteren Vergleich der einzelnen Verfahren absehen. 
Biomarker TNF- $\alpha$

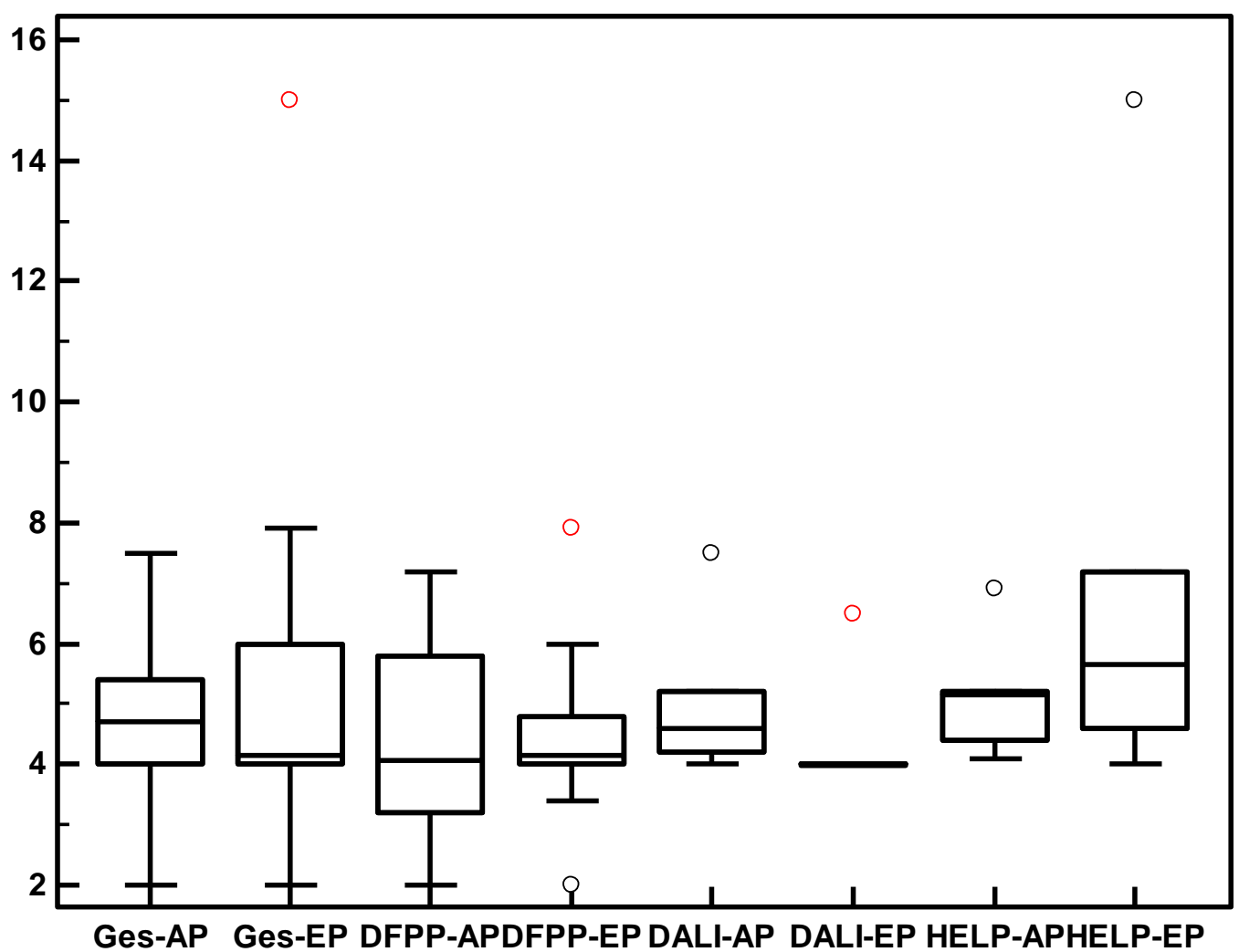

Abb. 3.3 Biomarker TNF- $\alpha$

Die nachweisbare Konzentration von TNF- $\alpha$ wird während keines der untersuchten Verfahren signifikant gesenkt ( $p$-Wert $=0,5067$ ) und schließt sich somit den beiden vorangegangenen Zytokinen an. Bei dem Marker IL-6 und TNF- $\alpha$ kommt es bei zwei der drei untersuchten Verfahren sogar eher zu einem diskreten Ansteigen der gemessenen Konzentrationen. 
Biomarker sIL-2R

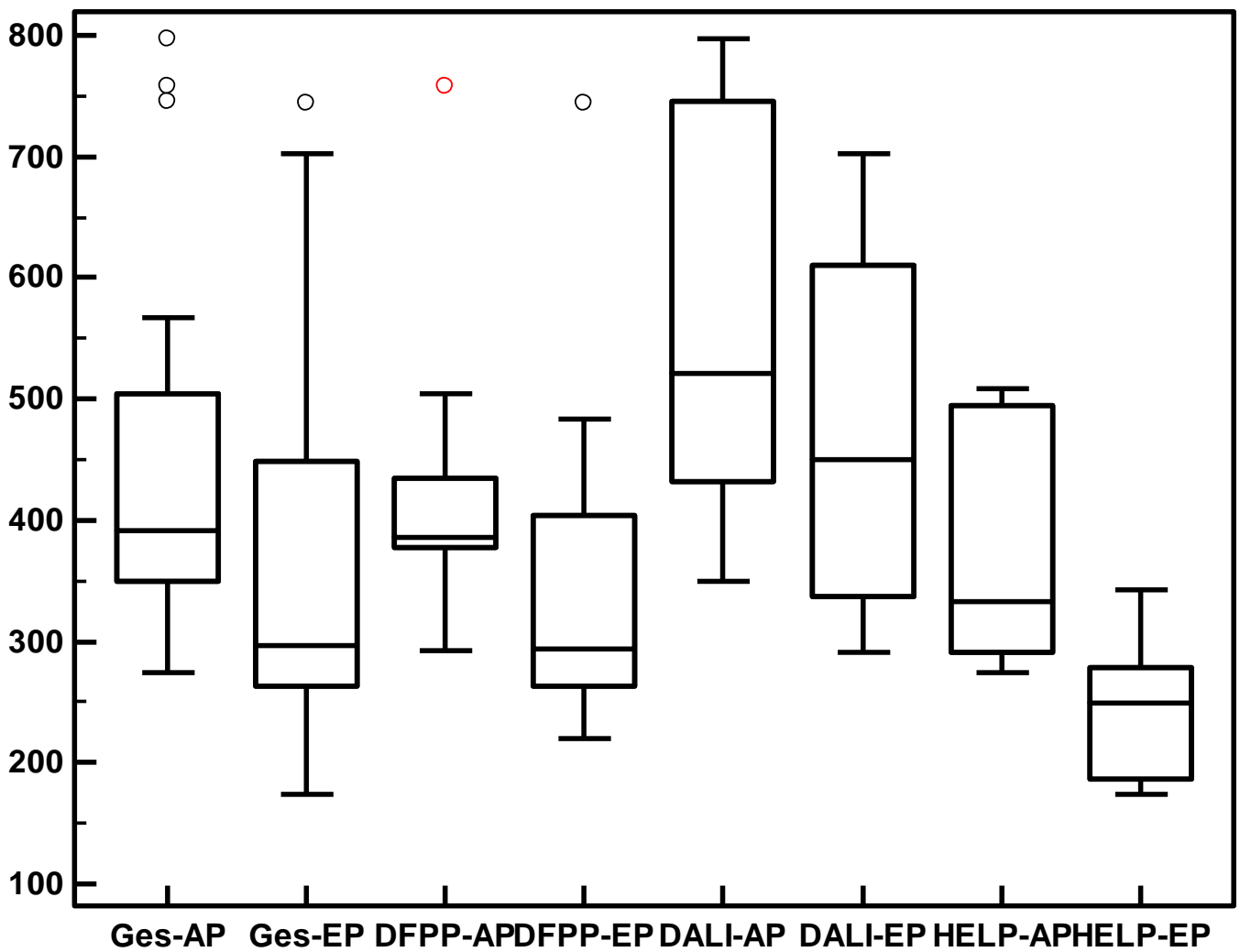

Abb. 3.4 Biomarker sIL-2R

Bezüglich des Biomarkers sIL-2R ist aus dem Vergleich der AP- und EP-Werte insgesamt eine leichte, aber durchaus signifikante Reduzierung von $-21,4 \pm 13,1 \%(p<0,0001)$ festzustellen. Die größte Reduzierung ist im HELPVerfahren zu erkennen. Hier ergibt sich eine Verringerung von $-32,9 \pm 10,0 \%$ und ein $\mathrm{p}$-Wert von 0,0036 .

Schwächer fallen die Reduzierungen beim DFPP-Verfahren (-17,8 \pm 14,1\%;

$p=0,0029)$ und beim DALI-Verfahren $(-15,9 \pm 6,3 \% ; p=0,0030)$.

Im Folgenden sollen nun diese drei Verfahren nochmals miteinander verglichen werden, da bislang nur ein Vergleich über die Zeit stattgefunden hat.

Hierzu werden die Differenzen von den AP- zu den EP-Werten der einzelnen Verfahren einander gegenübergestellt und die statistische Signifikanz ermittelt.

Verwendet wird hierzu der Man-Whitney Test, welcher einen Vergleich von unabhängigen Kollektiven ermöglicht. 
DFPP vs. DALI: $p=1$

DFPP vs. H.E.L.P.: $p=0,0344$ (signifikant)

DALI vs. H.E.L.P.: $p=0,025$ (signifikant)

Hieran ist zu erkennen, dass der Biomarker sIL-2R im HELP-Verfahren signifikant stärker reduziert wird als in den beiden anderen Verfahren.

\subsubsection{Biomarker für Plaque-Bildung/Destabilisierung (ADMA, sVCAM, MMP-9)}

Tab. 3.7 Summenwerte der Biomarker für Plaque-Bildung/-Destabililsierung

\begin{tabular}{|l|l|c|c|c|c|}
\hline $\begin{array}{l}\text { Bio- } \\
\text { marker }\end{array}$ & Abw & Gesamt & DFPP & DALI & H.E.L.P. \\
\hline $\begin{array}{l}\text { ADMA } \\
(\boldsymbol{\mu m m o l} / \mathbf{l})\end{array}$ & AP & $0,70 \pm 0,12$ & $0,67 \pm 0,09$ & $0,73 \pm 0,09$ & $0,72 \pm 0,18$ \\
\cline { 2 - 6 } & EP & $0,21 \pm 0,12$ & $0,21 \pm 0,11$ & $0,08 \pm 0,00$ & $0,33 \pm 0,04$ \\
\hline \multirow{2}{*}{$\begin{array}{l}\text { MMP-9 } \\
\text { (ng/ml) }\end{array}$} & AP & $44,40 \pm 25,40$ & $46,47 \pm 28,80$ & $40,84 \pm 28,86$ & $44,53 \pm 18,95$ \\
\cline { 2 - 6 } & EP & $52,72 \pm 76,16$ & $38,42 \pm 41,79$ & $51,22 \pm 64,20$ & $78,05 \pm 126,15$ \\
\hline \multirow{2}{*}{$\begin{array}{l}\text { sVCAM } \\
\text { (ng/ml) }\end{array}$} & AP & $605,68 \pm 295,85$ & $684,40 \pm 373,61$ & $533,30 \pm 73,73$ & $546,84 \pm 296,82$ \\
\cline { 2 - 6 } & EP & $161,17 \pm 66,65$ & $116,53 \pm 25,41$ & $182,41 \pm 81,50$ & $214,34 \pm 54,17$ \\
\hline
\end{tabular}

Tab. 3.8 Differenzwerte der Biomarker für Plaque-Bildung/-Destabililsierung

\begin{tabular}{|l|l|c|c|c|c|}
\hline $\begin{array}{l}\text { Bio- } \\
\text { marker }\end{array}$ & Abw & Gesamt & DFPP & DALI & H.E.L.P. \\
\hline ADMA & abs. & $-0,49 \pm 0,16$ & $-0,46 \pm 0,14$ & $-0,65 \pm 0,09$ & $-0.39 \pm 0,16$ \\
\cline { 2 - 6 }$(\boldsymbol{\mu} \mathrm{mol} / \mathbf{l})$ & $\%$ & $-69,69 \pm 18,44$ & $-68,63 \pm 17,30$ & $-88,60 \pm 1,60$ & $-52,56 \pm 10,18$ \\
\hline MMP-9 & abs. & $8,32 \pm 68,95$ & $-8,05 \pm 53,20$ & $10,38 \pm 40,08$ & $33,53 \pm 109,36$ \\
\cline { 2 - 6 } (ng/ml) & $\%$ & $10,62 \pm 115,00$ & $3,97 \pm 120,70$ & $6,89 \pm 68,63$ & $25,42 \pm 155,72$ \\
\hline \multirow{2}{*}{$\mathbf{s V C A M}$} & abs. & $-444,50 \pm$ & $-567,87 \pm$ & $-350,89 \pm$ & $-332,50 \pm$ \\
(ng/ml) & $\%$ & $-69,62 \pm 13,95$ & $-79,63 \pm 7,90$ & $-66,28 \pm 12,77$ & $-56,27 \pm 10,70$ \\
\cline { 2 - 6 } & $\%$ & 366,48 & 72,71 & 247,10 \\
\hline
\end{tabular}


Tab. 3.9 Normalverteilung und p-Werte der Biomarker für Plaque-Bildung/-Destabilisierung

\begin{tabular}{|l|c|c|c|c|}
\hline Marker & AP & EP & t-Test & WilcoxonTest \\
\hline ADMA Kollektiv & n.v. & n.v. & $p<0,0001$ & $p<0,0001$ \\
\hline ADMA DFPP & n.v. & n.v. & $p<0,0001$ & $p=0,002$ \\
\hline ADMA DALI & n.n.v. & n.n.v. & $(p<0,0001)$ & $p=0,0312$ \\
\hline ADMA H.E.L.P. & n.v. & n.v. & $p=0,0021$ & $p=0,0312$ \\
\hline MMP-9 Kollektiv & n.v. & n.n.v. & $(p=0,5774)$ & $p=0,4852$ \\
\hline MMP-9 DFPP & n.v. & n.v. & $p=0,6439$ & $p=0,3750$ \\
\hline MMP-9 DALI & n.v. & n.v. & $p=0,5536$ & $p=0,6875$ \\
\hline MMP-9 H.E.L.P. & n.v. & n.v. & $p=0,4865$ & $p=0,8438$ \\
\hline sVCAM Kollektiv & n.n.v. & n.v. & $(p<0,0001)$ & $p<0,0001$ \\
\hline sVCAM DFPP & n.v. & n.n.v. & $(p=0,0008)$ & $p=0,002$ \\
\hline sVCAM DALI & n.v. & n.v. & $p=0,0001$ & $p=0,0312$ \\
\hline sVCAM H.E.L.P. & n.v. & n.v. & $p=0,0216$ & $p=0,0312$ \\
\hline
\end{tabular}


Biomarker ADMA

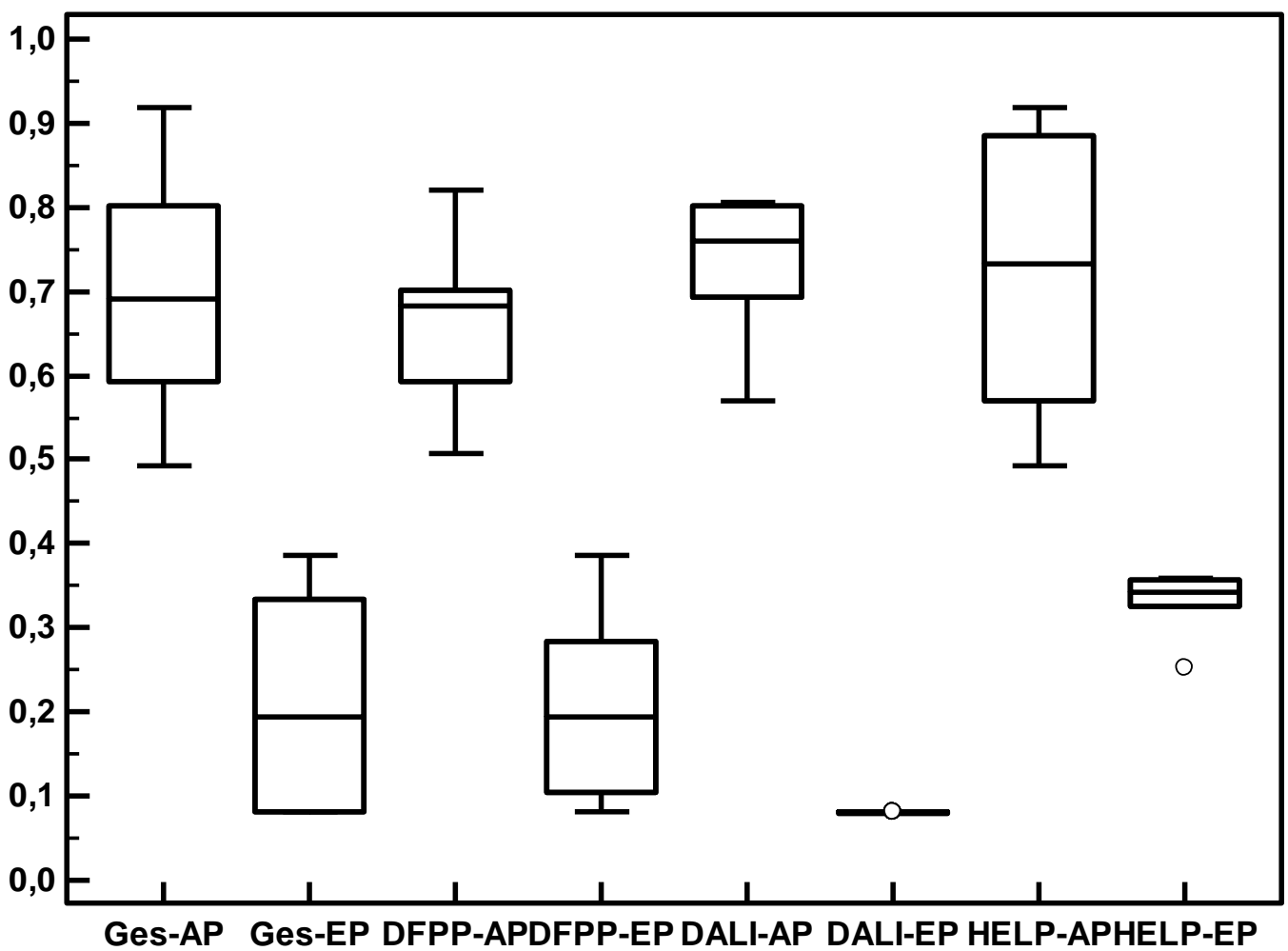

Abb. 3.5 Biomarker ADMA

Beim Biomarker ADMA ist eine signifikante Reduzierung $(p<0,0001)$ um $-69,69 \pm 18,44 \%$ festzustellen. Eine Reduzierung des Biomarkers ist bei allen drei Verfahren zu verzeichnen.

Bei dem DALI-Verfahren liegen die Konzentrationen von ADMA nach der LDLApherese sogar unterhalb der Nachweisgrenze. Insgesamt wird der Marker in allen drei Verfahren um mehr als die Hälfte reduziert.

DFPP vs. DALI: $p=0,0020$ (signifikant)

DFPP vs. H.E.L.P.: $p=0,0652$

H.E.L.P. vs. DALI: $p=0,0039$ (signifikant)

Im Vergleich der drei Verfahren senkt das DALI-Verfahren den Biomarker ADMA auch statistisch signifikant, so dass eine Überlegenheit der DALI-Apherese gegenüber der beiden anderen LDL-Apherese-Verfahren vorzuliegen scheint. 
$\underline{M M P-9}$

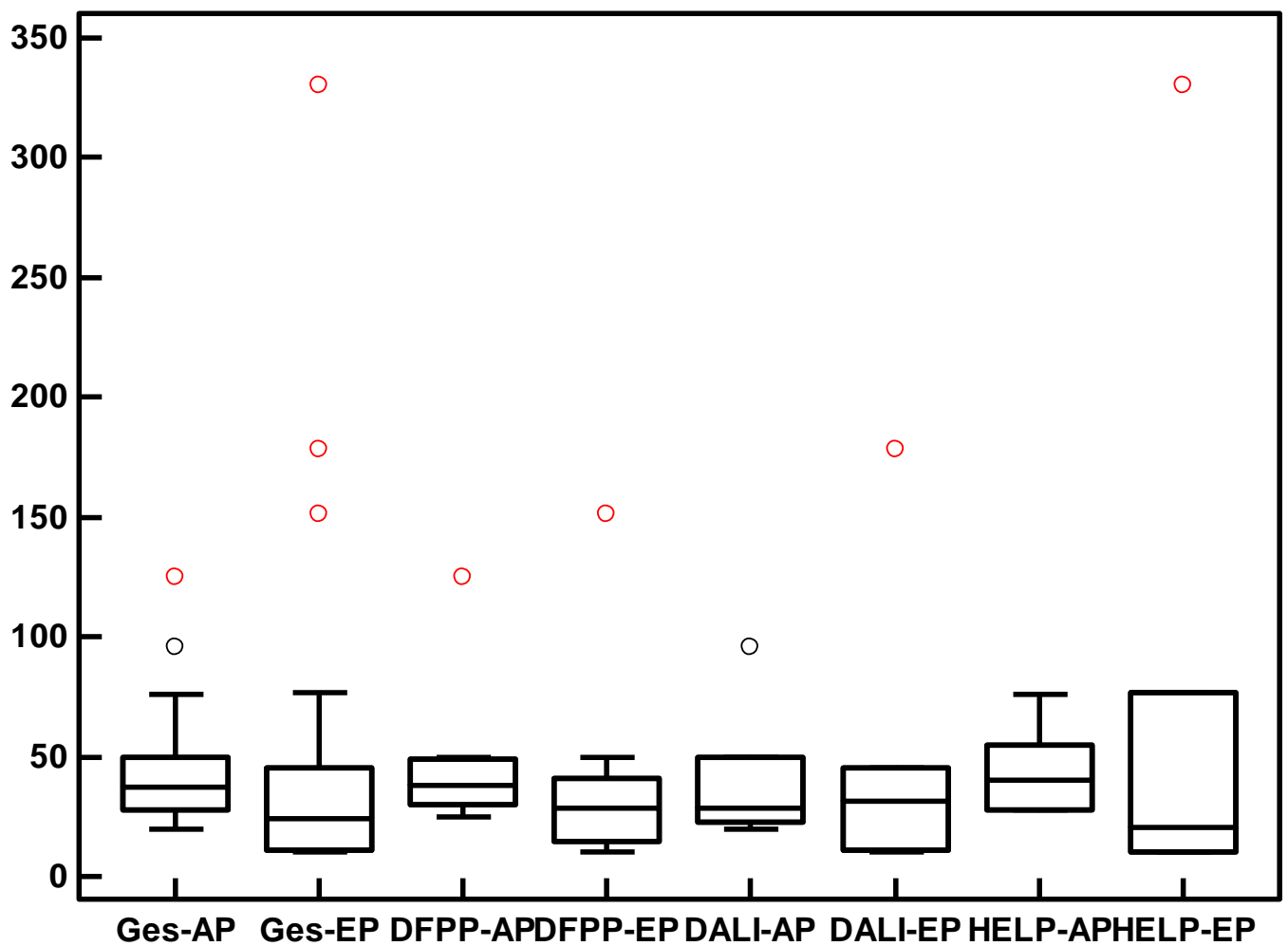

Abb. 3.6 Biomarker MMP-9

Bei dem Biomarker MMP-9 kommt es zu einem Anstieg der Werte. Vor allem beim DALI- und H.E.L.P.-Verfahren ist eine Steigerung der Werte nach dem LDLAphereseverfahren zu verzeichnen. Beim DALI-Verfahren steigt der Marker von $40,84 \mathrm{ng} / \mathrm{ml} \pm 28,86 \mathrm{ng} / \mathrm{ml}$ auf $51,22 \mathrm{ng} / \mathrm{ml} \pm 64,20 \mathrm{ng} / \mathrm{ml}(6,89 \pm 68,63 \%)$, beim H.E.L.P.-Verfahren von $44,53 \mathrm{ng} / \mathrm{ml} \pm 18,95 \mathrm{ng} / \mathrm{ml}$ auf $78,05 \mathrm{ng} / \mathrm{ml} \pm 126,15 \mathrm{ng} / \mathrm{ml}$ $(25,42 \pm 155,72 \%)$. Auffallend sind hier die großen Standardabweichungen, welche auf stark schwankende Werte hinweisen.

Dagegen kommt es bei der DFPP-Apherese zu einer Absenkung der Werte von $46,47 \mathrm{ng} / \mathrm{ml} \pm 28,80 \mathrm{ng} / \mathrm{ml}$ auf $38,42 \mathrm{ng} / \mathrm{ml} \pm 41,79 \mathrm{ng} / \mathrm{ml}$, welche mit einer Abweichung von $3,97 \pm 120,70 \%$ und einem $p=0,6439$ jedoch nicht signifikant reduziert werden. 
Biomarker SVCAM

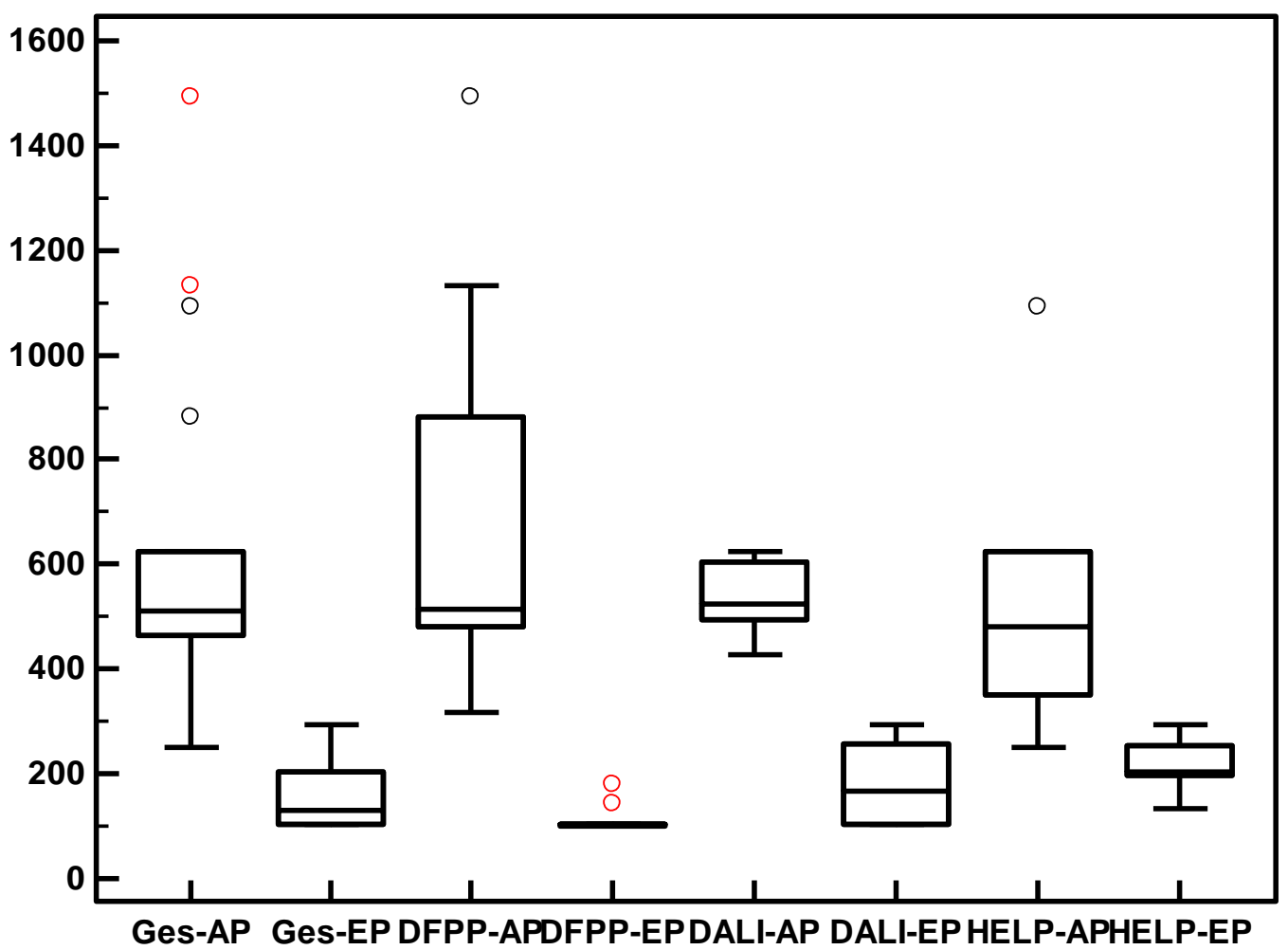

Abb. 3.7 Biomarker sVCAM

Bei der Analyse zeigt sich eine Reduzierung der sVCAM-Werte von 605,68 ng/ml $\pm 295,85 \mathrm{ng} / \mathrm{ml}$ auf $161,17 \mathrm{ng} / \mathrm{ml} \pm 66,65 \mathrm{ng} / \mathrm{ml}$. Daraus ergibt sich eine statistisch signifikante Differenz von $-69,9 \pm 14,0 \%(p<0,0001)$. Dabei liegt der höchste Wert beim DFPP-Verfahren $(-79,6 \pm 7,9 \%$; $p<0,002)$. Es folgen DALI mit $-66,3 \pm 12,8 \%$ $(p=0,0001)$ und H.E.L.P. mit $-56,3 \pm 10,7 \%(p=0,0216)$.

DFPP vs. DALI: $p=0,0644$

DFPP vs. H.E.L.P.: $p=0,0034$ (signifikant)

DALI vs. H.E.L.P.: $p=0,2623$

Statistisch signifikant gesenkt im Vergleich der drei Verfahren wird der Biomarker sVCAM nur im DFPP-Verfahren gegenüber dem HELP-Verfahren. 
3.3.3 Biomarker für Plaqueruptur (PAPP-A)

Tab. 3.10 Summenwerte der Biomarker für Plaqueruptur

\begin{tabular}{|l|c|c|c|c|c|}
\hline $\begin{array}{l}\text { Bio- } \\
\text { marker }\end{array}$ & Zeit & Gesamt & DFPP & DALI & H.E.L.P. \\
\hline $\begin{array}{l}\text { PAPP-A } \\
(\mu \mathrm{l} / \mathrm{ml})\end{array}$ & AP & $5,81 \pm 3,43$ & $5,45 \pm 3,01$ & $2,72 \pm 0,00$ & $10,73 \pm 0,00$ \\
\cline { 2 - 6 } & EP & $1,10 \pm 2,09$ & $0,45 \pm 1,00$ & $0,00 \pm 0,00$ & $5,45 \pm 0,00$ \\
\hline
\end{tabular}

Tab. 3.11 Differenzwerte der Biomarker für Plaqueruptur

\begin{tabular}{|l|c|c|c|c|c|}
\hline $\begin{array}{l}\text { Bio- } \\
\text { marker }\end{array}$ & Abw & Gesamt & DFPP & DALI & H.E.L.P. \\
\hline $\begin{array}{l}\text { PAPP-A } \\
(\boldsymbol{\mu l} \mathbf{l} / \mathbf{m l})\end{array}$ & abs. & $-4,71 \pm 2,39$ & $-5,00 \pm 2,71$ & $-2,72 \pm 0,00$ & $-5,28 \pm 0,00$ \\
\cline { 2 - 6 } & $-88,68 \pm 20,38$ & $-94,31 \pm 12,71$ & $-100,00 \pm 0,00$ & $-49,20 \pm 0,00$ \\
\hline
\end{tabular}

Tab. 3.12 Normalverteilung und p-Werte der Biomarker für Plaqueruptur

\begin{tabular}{|l|c|c|c|c|}
\hline Marker & AP & EP & t-Test & WilcoxonTest \\
\hline PAPP-A Kollektiv & n.v. & n.v. & $\mathrm{p}=0,002$ & $\mathrm{p}=0,0156$ \\
\hline PAPP-A DFPP & n.v. & n.v. & $\mathrm{p}=0,0146$ & $\mathrm{p}=0,062$ \\
\hline PAPP-A DALI & n.e.M. & n.e.M. & n.e.M. & n.e.M. \\
\hline PAPP-A H.E.L.P. & n.e.M. & n.e.M. & n.e.M. & n.e.M. \\
\hline
\end{tabular}

(n.e.M. = nur ein Messwert, ELISA von Firma nicht mehr lieferbar) 


\section{Biomarker PAPP-A}

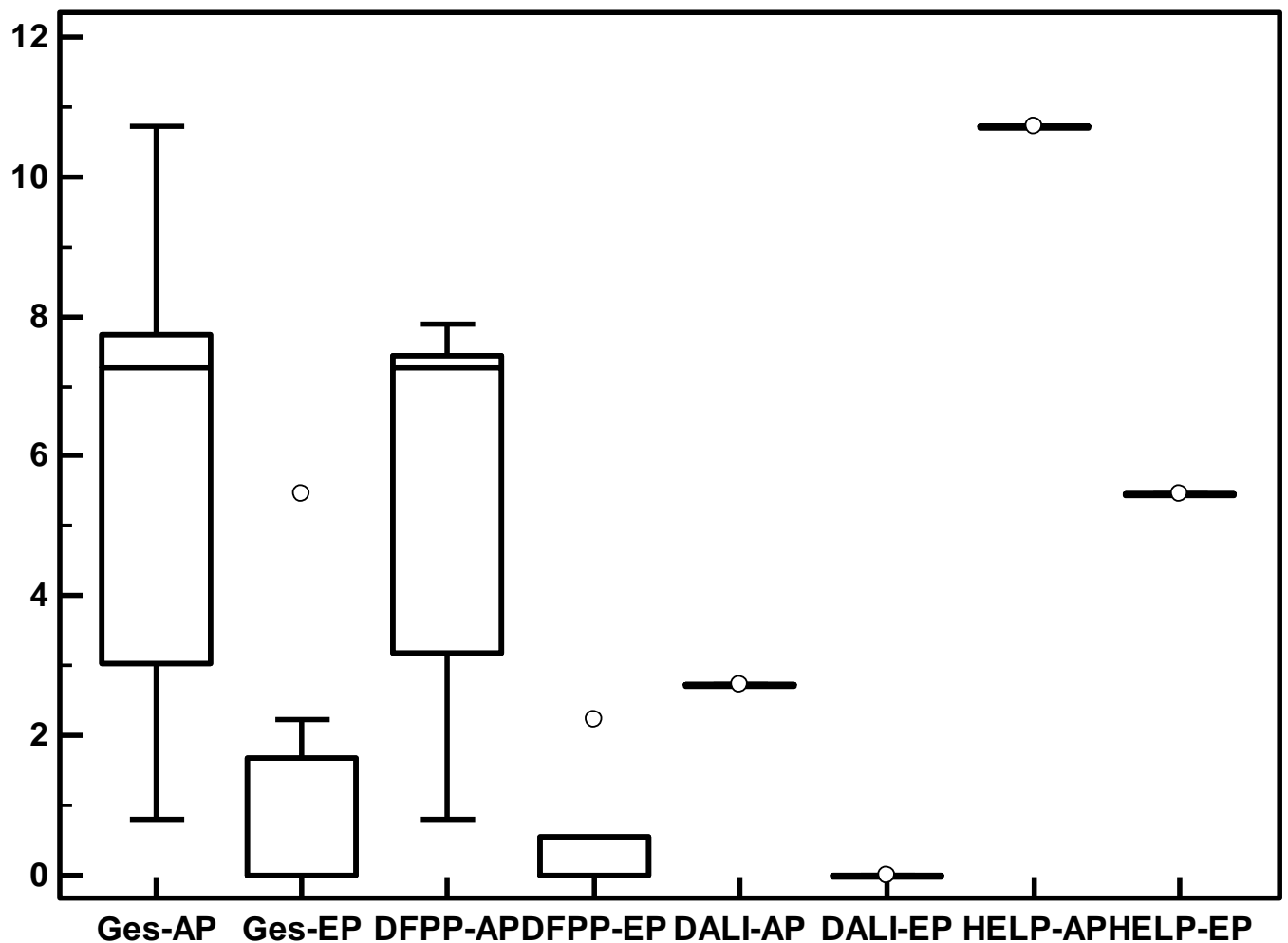

Abb. 3.8 Biomarker PAPP-A

Der Biomarker PAPP-A wird insgesamt um -88,68 $\pm 20,38 \%$ reduziert. Der Marker sinkt von 5,81 $\mu \mathrm{lU} / \mathrm{ml} \pm 3,43 \mu \mathrm{lU} / \mathrm{ml}$ auf $1,10 \mu \mathrm{lU} / \mathrm{ml} \pm 2,09 \mu \mathrm{lU} / \mathrm{ml}$.

Die Reduzierung ist mit einem $p$-Wert von 0,0020 statistisch signifikant.

Auch beim DFPP-Verfahren (von 5,45 $\mu \mathrm{lU} / \mathrm{ml} \pm 3,01 \mu \mathrm{lU} / \mathrm{ml}$ auf $0,45 \mu \mathrm{lU} / \mathrm{ml} \pm 1,00$ $\mu \mathrm{lU} / \mathrm{ml} ; \mathrm{p}=0,0146$ ) ist eine deutlich erniedrigte Konzentration, zum Teil unterhalb der Nachweisgrenze, von PAPP-A nachweisbar.

Es ist aber darauf hinzuweisen, dass diese Aussage auf Grund geringer Datenbasis nur bedingt zuverlässig getroffen werden kann, da der verwendete ELISA von der Firma nicht mehr geliefert wird und daher keine weiteren Messungen stattfinden können. Daher befinden sich in der H.E.L.P.- und in der DALI-Gruppe jeweils nur ein Messwert.

Aufgrund dieser geringen Datenlage wird auf einen statistischen Vergleich der drei Verfahren untereinander verzichtet. 
3.3.4 Biomarker für die Akute-Phase-Reaktion (hsCRP)

Tab. 3.13 Summenwerte der Biomarker für die Akute-Phase-Reaktion

\begin{tabular}{|l|c|c|c|c|c|}
\hline $\begin{array}{l}\text { Bio- } \\
\text { marker }\end{array}$ & Zeit & Gesamt & DFPP & DALI & H.E.L.P. \\
\hline $\begin{array}{l}\text { hsCRP } \\
\text { (ng/ml) }\end{array}$ & AP & $3,70 \pm 4,76$ & $6,06 \pm 6,11$ & $2,04 \pm 2,54$ & $1,41 \pm 0,88$ \\
\cline { 2 - 6 } & EP & $1,96 \pm 2,22$ & $3,01 \pm 2,55$ & $1,52 \pm 2,10$ & $0,65 \pm 0,33$ \\
\hline
\end{tabular}

Tab. 3.14 Differenzwerte der Biomarker für die Akute-Phase-Reaktion

\begin{tabular}{|l|c|c|c|c|c|}
\hline $\begin{array}{l}\text { Bio- } \\
\text { marker }\end{array}$ & Abw & Gesamt & DFPP & DALI & H.E.L.P. \\
\hline \multirow{2}{*}{ hsCRP } & abs. & $-1,74 \pm 2,75$ & $-3,05 \pm 3,71$ & $-0,52 \pm 0,46$ & $-0,76 \pm 0,65$ \\
\cline { 2 - 6 } & $\%$ & $-40,95 \pm 16,71$ & $-42,22 \pm 17,18$ & $-32,16 \pm 15,77$ & $-47,63 \pm 15,60$ \\
\hline
\end{tabular}

Tab. 3.15 Normalverteilung und $p$-Werte der Biomarker für die Akute-PhaseReaktion

\begin{tabular}{|l|c|c|c|c|}
\hline Marker & AP & EP & t-Test & WilcoxonTest \\
\hline hsCRP Kollektiv & n.v. & n.n.v. & $(p=0,0075)$ & $p<0,0001$ \\
\hline hsCRP DFPP & n.v. & n.v. & $p=0,0288$ & $p=0,002$ \\
\hline hsCRP DALI & n.v. & n.v. & $p=0,0395$ & $p=0,0312$ \\
\hline hsCRP H.E.L.P. & n.v. & n.v. & $p=0,0312$ & $p=0,0312$ \\
\hline
\end{tabular}




\section{Biomarker hsCRP}

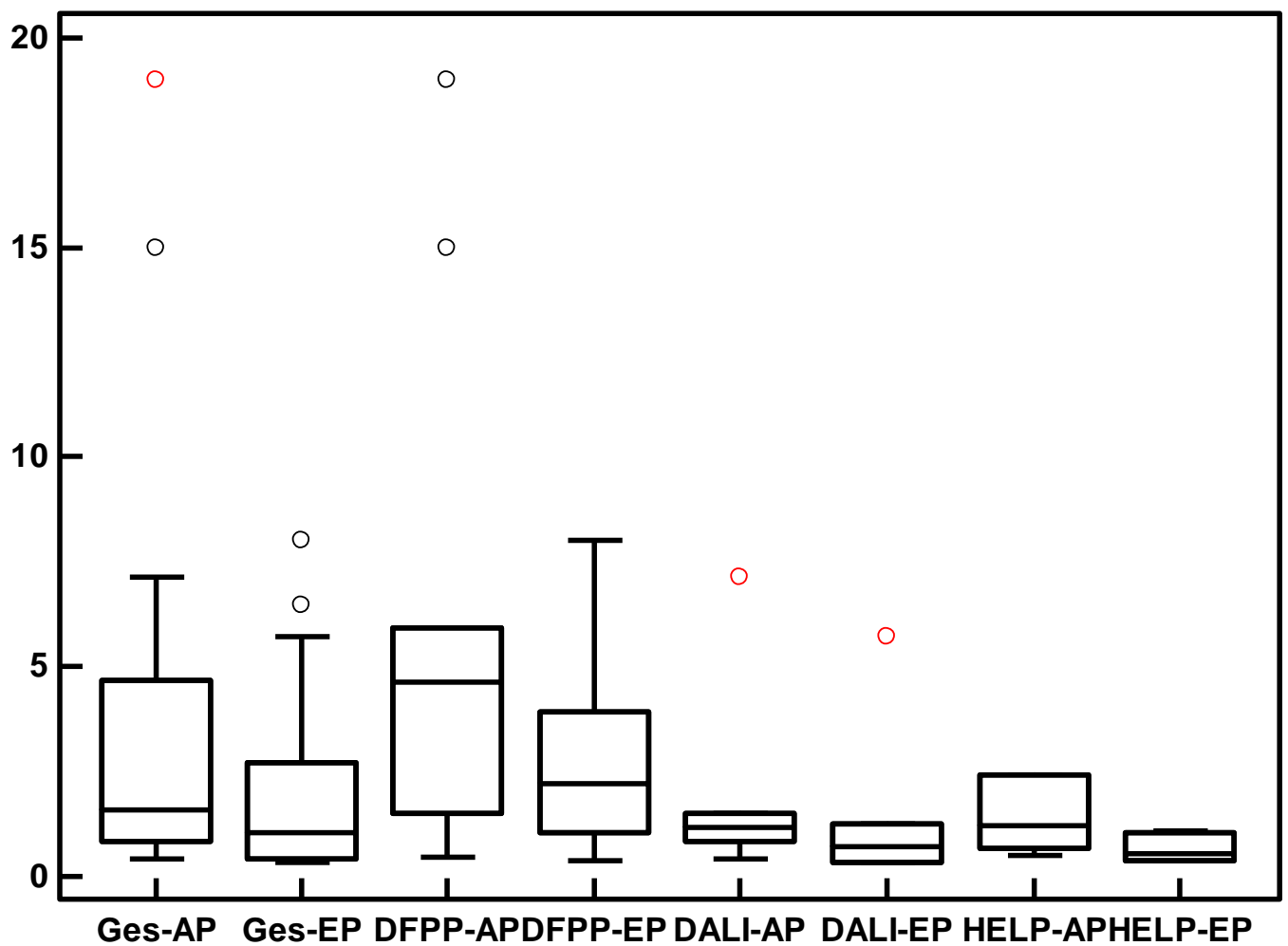

Abb. 3.9 Biomarker hsCRP

Im Vergleich der hsCRP-Konzentration zwischen den AP- und EP-Werten (von $3,70 \mathrm{ng} / \mathrm{ml} \pm 4,76 \mathrm{ng} / \mathrm{ml}$ auf $1,96 \mathrm{ng} / \mathrm{ml} \pm 2,22 \mathrm{ng} / \mathrm{ml}$ ) ist eine signifikante Abnahme von $-40,95 \pm 16,71 \%(p<0,0001)$ festzustellen. Dabei tritt die stärkste Reduzierung mit $-47,6 \pm 15,6 \%(p=0,0312)$ beim HELP-Verfahren (von $1,41 \mathrm{ng} / \mathrm{ml} \pm 0,88$ $\mathrm{ng} / \mathrm{ml}$ auf $0,65 \mathrm{ng} / \mathrm{ml} \pm 0,33 \mathrm{ng} / \mathrm{ml}$ ) auf. Es folgen DFPP (von 6,06 $\mathrm{ng} / \mathrm{ml} \pm 6,11$ $\mathrm{ng} / \mathrm{ml}$ auf $3,01 \mathrm{ng} / \mathrm{ml} \pm 2,55 \mathrm{ng} / \mathrm{ml})$ mit $-42,2 \pm 17,2 \%(\mathrm{p}=0,0288)$ und DALI (von $2,04 \mathrm{ng} / \mathrm{ml} \pm 2,54 \mathrm{ng} / \mathrm{ml}$ auf $1,52 \mathrm{ng} / \mathrm{ml} \pm 2,10 \mathrm{ng} / \mathrm{ml}) \mathrm{mit}-32,2 \pm 15,8 \%(p=$ 0,0395).

DFPP vs. DALI: $p=0,2123$

DFPP vs. HELP: $p=0,5152$

DALI vs. HELP: $p=0,0931$

Im Vergleich unterscheiden sich die drei Verfahren statistisch nicht voneinander. Somit ist keines der Verfahren überlegen. 
3.3.5 Biomarker für Myokardiale Dysfunktion (NT-proBNP, NTproANP)

Tab. 3.16 Summenwerte der Biomarker für Myokardiale Dysfunktion

\begin{tabular}{|l|c|c|c|c|c|}
\hline $\begin{array}{l}\text { Bio- } \\
\text { marker }\end{array}$ & Zeit & Gesamt & DFPP & DALI & H.E.L.P. \\
\hline $\begin{array}{l}\text { NT-pro } \\
\text { BNP } \\
(\mathbf{p g} / \mathbf{m l})\end{array}$ & AP & $525,3 \pm 1062,3$ & $527,29 \pm 764,5$ & $881,07 \pm 1832,1$ & $166,32 \pm 155,7$ \\
\cline { 2 - 6 } & EP & $495,8 \pm 975,7$ & $510,39 \pm 741,3$ & $801,07 \pm 1657,2$ & $166,10 \pm 141,6$ \\
\hline $\begin{array}{l}\text { NT-pro } \\
\text { ANP } \\
(\mathbf{n g} / \mathbf{m l})\end{array}$ & AP & $2516,1 \pm 1962,0$ & $3135,2 \pm 2695,8$ & $2343,00 \pm 788,5$ & $1657,2 \pm 880,9$ \\
\cline { 2 - 6 } & & $3520,7 \pm 2566,5$ & $4278,5 \pm 3534,4$ & $3455,5 \pm 755,9$ & $2322,8 \pm 1316,1$ \\
\hline
\end{tabular}

Tab. 3.17 Differenzwerte der Biomarker für Myokardiale Dysfunktion

\begin{tabular}{|l|c|c|c|c|c|}
\hline $\begin{array}{l}\text { Bio- } \\
\text { marker }\end{array}$ & Ab & Gesamt & DFPP & DALI & H.E.L.P. \\
\hline NT-pro & abs. & $-29,56 \pm 93,80$ & $-16,90 \pm 27,65$ & $-80,00 \pm 175,15$ & $-0,22 \pm 22,25$ \\
\cline { 2 - 6 } BNP & $\%$ & $3,22 \pm 15,87$ & $5,76 \pm 21,80$ & $-1,64 \pm 10,54$ & $3,87 \pm 7,04$ \\
\hline NT-pro & abs. & $-1004,6 \pm 896,5$ & $-1143,3 \pm 1070,8$ & $-1112,5 \pm 900,8$ & $-665, \pm 556,9$ \\
\cline { 2 - 6 } ANP & $\%$ & $-29,47 \pm 18,32$ & $-29,16 \pm 16,57$ & $-30,67 \pm 26,03$ & $-28,77 \pm 15,37$ \\
\hline
\end{tabular}


Tab. 3.18 Normalverteilung und p-Werte der Biomarker für Myokardiale Dysfunktion

\begin{tabular}{|l|c|c|c|c|}
\hline Marker & AP & EP & t-Test & WilcoxonTest \\
\hline NT-proBNP Kollektiv & n.n.v. & $n . n . v$. & $(p=0,1542)$ & $p=0,3382$ \\
\hline NT-proBNP DFPP & $n . v$. & $n . v$. & $p=0,0853$ & $p=0,3223$ \\
\hline NT-proBNP DALI & $n . v$. & $n . v$. & $p=0,3141$ & $p=0,4375$ \\
\hline NT-proBNP H.E.L.P. & $n . v$. & $n . v$. & $p=0,9819$ & $p=0,4375$ \\
\hline NT-proANP Kollektiv & n.v. & $n . v$. & $p<0,0001$ & $p=0,0001$ \\
\hline NT-proANP DFPP & n.v. & $n . v$. & $p=0,0082$ & $p=0,0020$ \\
\hline NT-proANP DALI & n.v. & $n . v$. & $p=0,0292$ & $p=0,0625$ \\
\hline NT-proANP H.E.L.P. & n.v. & $n . v$. & $p=0,0327$ & $p=0,0312$ \\
\hline
\end{tabular}

Biomarker NT-proBNP

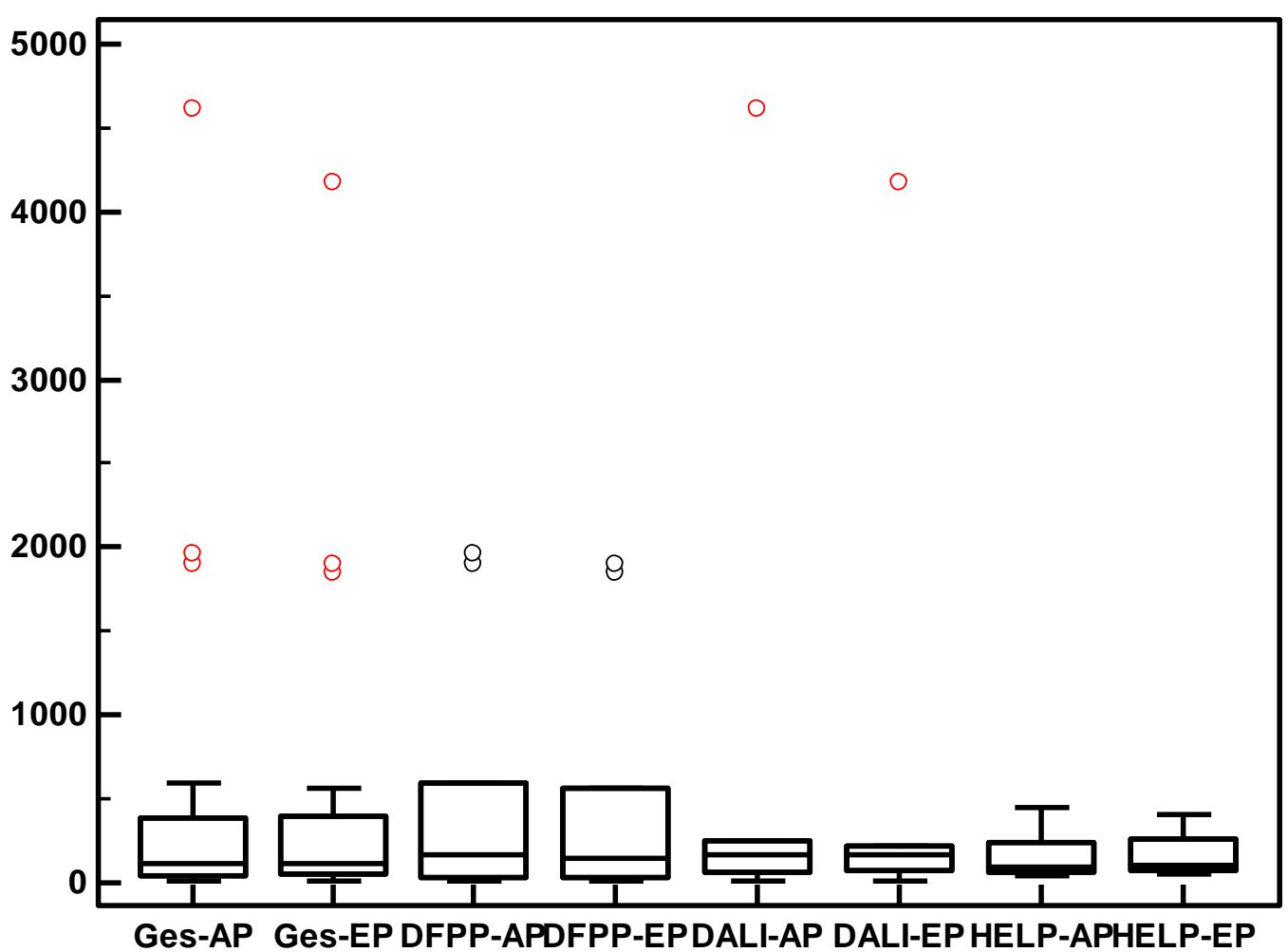

Abb. 3.10 Biomarker NT-proBNP

Die Analyse zeigt bezogen auf NT-proBNP kaum einen Effekt der LDLAphereseverfahren. Die Konzentration des Markers sinkt in allen drei Verfahren 
nur geringfügig ab. Der $p$-Wert ist mit 0,34 nicht signifikant.

\section{Biomarker NT-proANP}

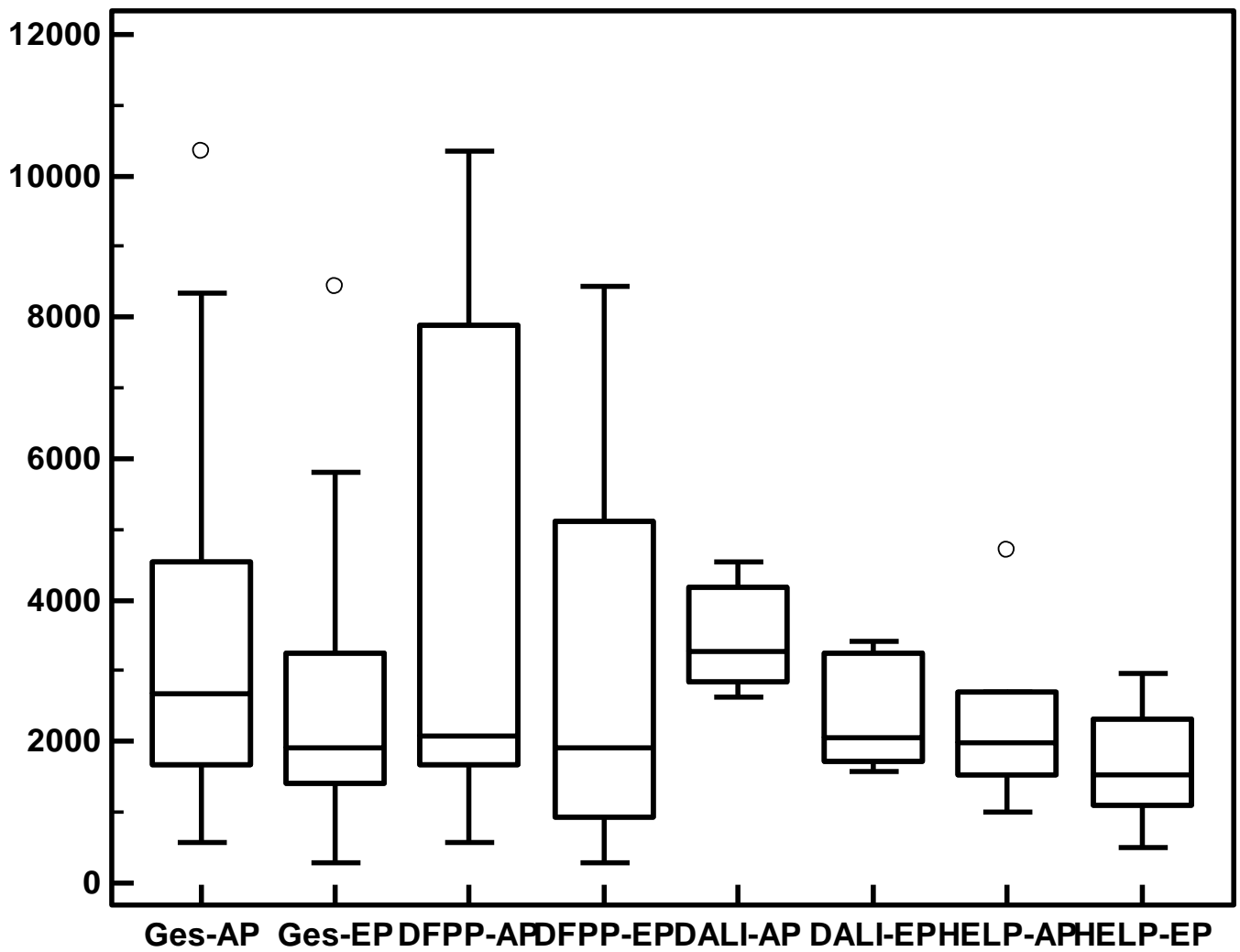

Abb. 3.11 Biomarker NT-proANP

Im Gegensatz zu NT-proBNP sind die Werte für NT-proANP deutlich reduziert (von $3520,68 \mathrm{ng} / \mathrm{ml} \pm 2566,49 \mathrm{ng} / \mathrm{ml}$ auf $2516,05 \mathrm{ng} / \mathrm{ml} \pm 1961,95 \mathrm{ng} / \mathrm{ml}$ ), wobei insgesamt eine signifikante Reduzierung um $-29,47 \pm 18,32 \%$ mit $p<0,0001$ festzustellen ist.

Die höchste Differenz wird mit dem DALI-Verfahren $(-30,67 \pm 26,03 \% ; p=$ $0,0292)$ erzielt. Aber auch die Verfahren DFPP $(-29,16 \pm 16,56 \% ; p=0,0082)$ und $\operatorname{HELP}(-28,77 \pm 15,37 \% ; p=0,0327)$ weisen ähnliche Werte auf.

DFPP vs. DALI: $p=0,5152$

DFPP vs. HELP: $p=0,9136$

DALI vs. HELP: $p=0,6310$

Es gibt statistisch gesehen kein signifikantes Überlegen eines der Verfahren, was die Reduktion des Markers NT-proANP angeht. 


\subsection{Patientenkollektive (Kontrollkollektive)}

Im Vergleich zu den LDL-Apheresepatienten erfolgt nun die Ergebnisdarstellung und Erläuterung für die Probanden aus den Kontrollkollektiven der Gruppen B und C. Bei diesen Patienten wird keine LDL-Apherese durchgeführt. Es werden die Ausgangs- und Endwerte der LDL-Apheresepatienten mit den Werten der Kontrollgruppen verglichen.

Die ausführlichen Tabellen mit den erhobenen Daten sind im Anhang dargestellt.

Ergänzend ist noch hinzuzufügen, dass bei den Patientenkollektiven nicht alle Werte erhoben werden, wie es bei den LDL-Apheresepatienten der Fall ist. Verglichen werden somit nur die Biomarker für Plaquedestabilisation (ADMA, MMP-9, sVCAM, PAPP-A) und hsCRP als akute Phase Marker.

Zum besseren Vergleich werden die Werte für diese Marker in den folgenden Tabellen dargestellt.

Tab. 3.19 Biomarkervergleich Gruppe A (LDL-Apheresepatienten)

\begin{tabular}{|c|c|c|c|c|c|}
\hline \multirow[t]{2}{*}{ Biomarker } & \multicolumn{2}{|r|}{ Gesamt } & \multicolumn{2}{|r|}{ DALI } & \multirow[t]{2}{*}{ H.E.L.P. } \\
\hline & & \multicolumn{3}{|c|}{ MW \pm STAW } & \\
\hline \multirow{2}{*}{$\begin{array}{l}\text { ADMA } \\
(\mu \mathrm{mol} / \mathrm{l})\end{array}$} & AP & $0,70 \pm 0,12$ & $0,67 \pm 0,09$ & $0,73 \pm 0,09$ & $0,72 \pm 0,18$ \\
\hline & EP & $0,21 \pm 0,12$ & $0,21 \pm 0,11$ & $0,08 \pm 0,00$ & $0,33 \pm 0,04$ \\
\hline \multirow{2}{*}{$\begin{array}{l}\text { MMP-9 } \\
\text { (ng/ml) }\end{array}$} & $\mathrm{AP}$ & $44,40 \pm 25,40$ & $46,47 \pm 28,80$ & $40,84 \pm 28,86$ & $44,53 \pm 18,95$ \\
\hline & EP & $52,72 \pm 76,16$ & $38,42 \pm 41,79$ & $51,22 \pm 64,20$ & $78,05 \pm 126,15$ \\
\hline \multirow{2}{*}{$\begin{array}{l}\text { sVCAM } \\
(\mathrm{ng} / \mathrm{ml})\end{array}$} & AP & $605,68 \pm 295,9$ & $684,40 \pm 373,61$ & $533,30 \pm 73,73$ & $546,84 \pm 296,82$ \\
\hline & EP & $161,17 \pm 66,65$ & $116,53 \pm 25,41$ & $182,41 \pm 81,50$ & $214,34 \pm 54,17$ \\
\hline \multirow{2}{*}{$\begin{array}{l}\text { PAPP-A } \\
(\mu \mathrm{lU} / \mathrm{ml})\end{array}$} & $\mathrm{AP}$ & $5,81 \pm 3,43$ & $5,45 \pm 3,01$ & $2,72 \pm 0,00$ & $10,73 \pm 0,00$ \\
\hline & EP & $1,10 \pm 2,09$ & $0,45 \pm 1,00$ & $0,00 \pm 0,00$ & $5,45 \pm 0,00$ \\
\hline \multirow{2}{*}{$\begin{array}{l}\text { hsCRP } \\
\text { (ng/ml) }\end{array}$} & $\mathrm{AP}$ & $3,70 \pm 4,76$ & $6,06 \pm 6,11$ & $2,04 \pm 2,54$ & $1,41 \pm 0,88$ \\
\hline & EP & $1,96 \pm 2,22$ & $3,01 \pm 2,55$ & $1,52 \pm 2,10$ & $0,65 \pm 0,33$ \\
\hline
\end{tabular}

(MW=Mittelwert, STAW=Standardabweichung) 
Tab. 3.20 Biomarkervergleich Gruppe B und C

\begin{tabular}{|l|c|c|}
\hline Biomarker & Gruppe B & Gruppe C \\
\hline & MW \pm STAW & MW \pm STAW \\
\hline ADMA $(\boldsymbol{\mu m o l} / \mathbf{l})$ & $0,67 \pm 0,10$ & $0,68 \pm 0,13$ \\
\hline MMP-9 $(\mathbf{n g} / \mathbf{m l})$ & $57,33 \pm 28,71$ & $150,26 \pm 169,89$ \\
\hline sVCAM $(\mathbf{n g} / \mathbf{m l})$ & $527,65 \pm 135,59$ & $627,02 \pm 186,81$ \\
\hline PAPP-A $(\boldsymbol{\mu l} \mathbf{l} / \mathbf{m l})$ & $0,22 \pm 0,26$ & $0,84 \pm 0,35$ \\
\hline hsCRP $(\mathbf{n g} / \mathbf{m l})$ & $1,75 \pm 2,24$ & $3,12 \pm 2,96$ \\
\hline
\end{tabular}

3.4.1 Biomarker ADMA im Vergleich

Tab. 3.21 Biomarker ADMA im Vergleich (MW und STAW)

\begin{tabular}{|l|c|c|c|c|}
\hline Biomarker & A - AP & A - EP & B & C \\
\hline $\begin{array}{l}\text { ADMA } \\
(\mu \mathrm{mol} / \mathrm{I})\end{array}$ & $0,70 \pm 0,12$ & $0,21 \pm 0,12$ & $0,67 \pm 0,10$ & $0,68 \pm 0,13$ \\
\hline
\end{tabular}




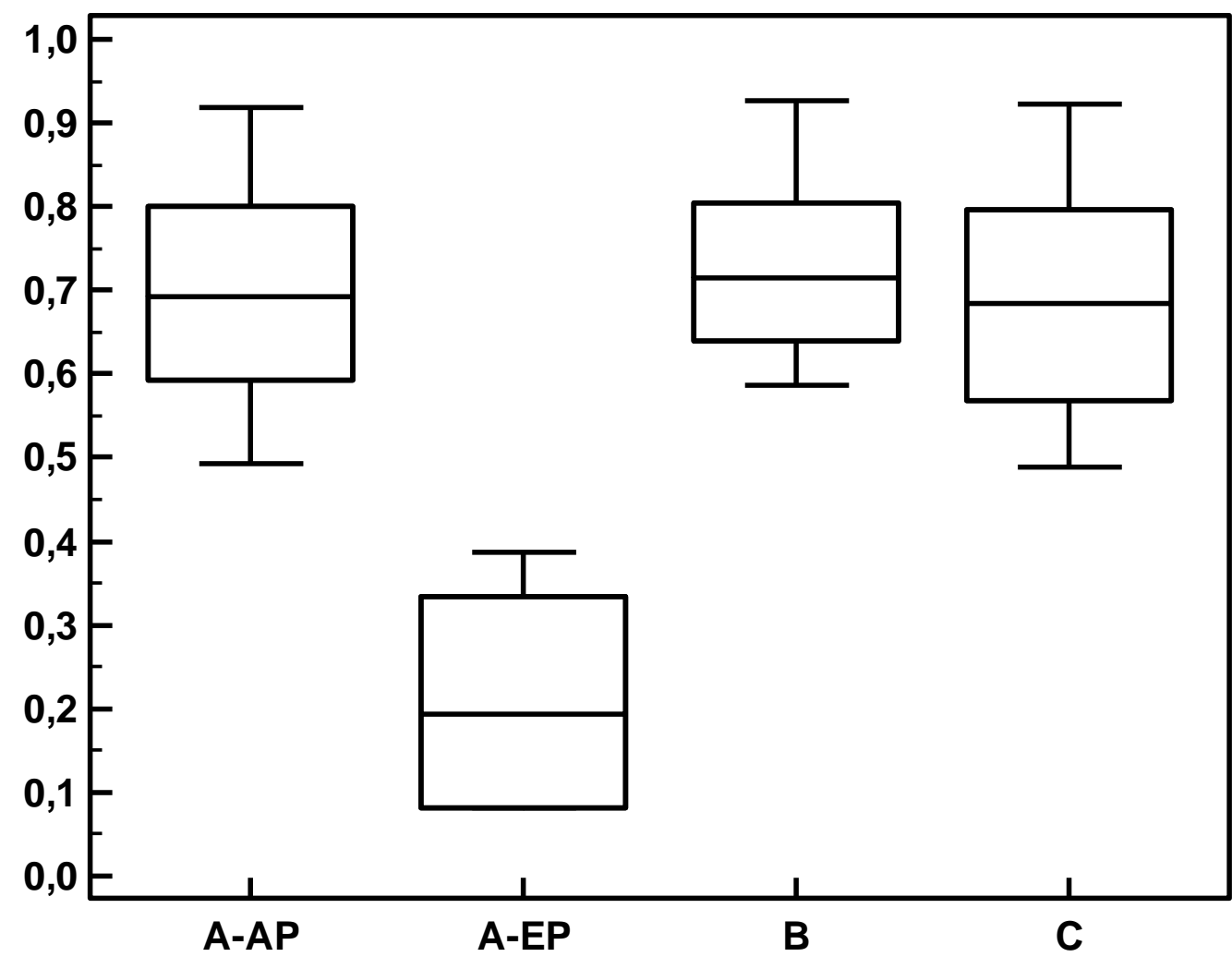

Abb. 3.12 Biomarker ADMA im Vergleich

(A-AP $=$ Gruppe A Anfangspunkt, A-EP = Gruppe A Endpunkt, B = Gruppe B, C = Gruppe C)

Bei dem Biomarker ADMA unterscheiden sich die Werte der Kontrollkollektive statistisch nicht signifikant von dem AP-Wert der LDL-Apheresepatienten. Deutlich niedriger zeigt sich wie schon oben erwähnt der ADMA Wert nach der Apherese, welcher im Vergleich zum AP in der Gruppe A statistisch signifikant abfällt $(p<$ 0,0001).

Vergleicht man nun A-EP mit der Gruppe B und C, so ist auch hier jeweils ein statistisch signifikanter Unterschied zu berechnen $(p<0,0001)$.

Die Gruppen B und C dagegen unterscheiden sich nicht signifikant voneinander $(p=0,1938)$. 


\subsubsection{Biomarker MMP-9 im Vergleich}

Tab. 3.22 Biomarker MMP-9 im Vergleich (MW und STAW)

\begin{tabular}{|l|c|c|c|c|}
\hline Biomarker & A - AP & A - EP & B & C \\
\hline $\begin{array}{l}\text { MMP-9 } \\
\text { (ng/ml) }\end{array}$ & $44,40 \pm 25,40$ & $52,72 \pm 76,16$ & $57,33 \pm 28,71$ & $150,26 \pm 169,89$ \\
\hline
\end{tabular}

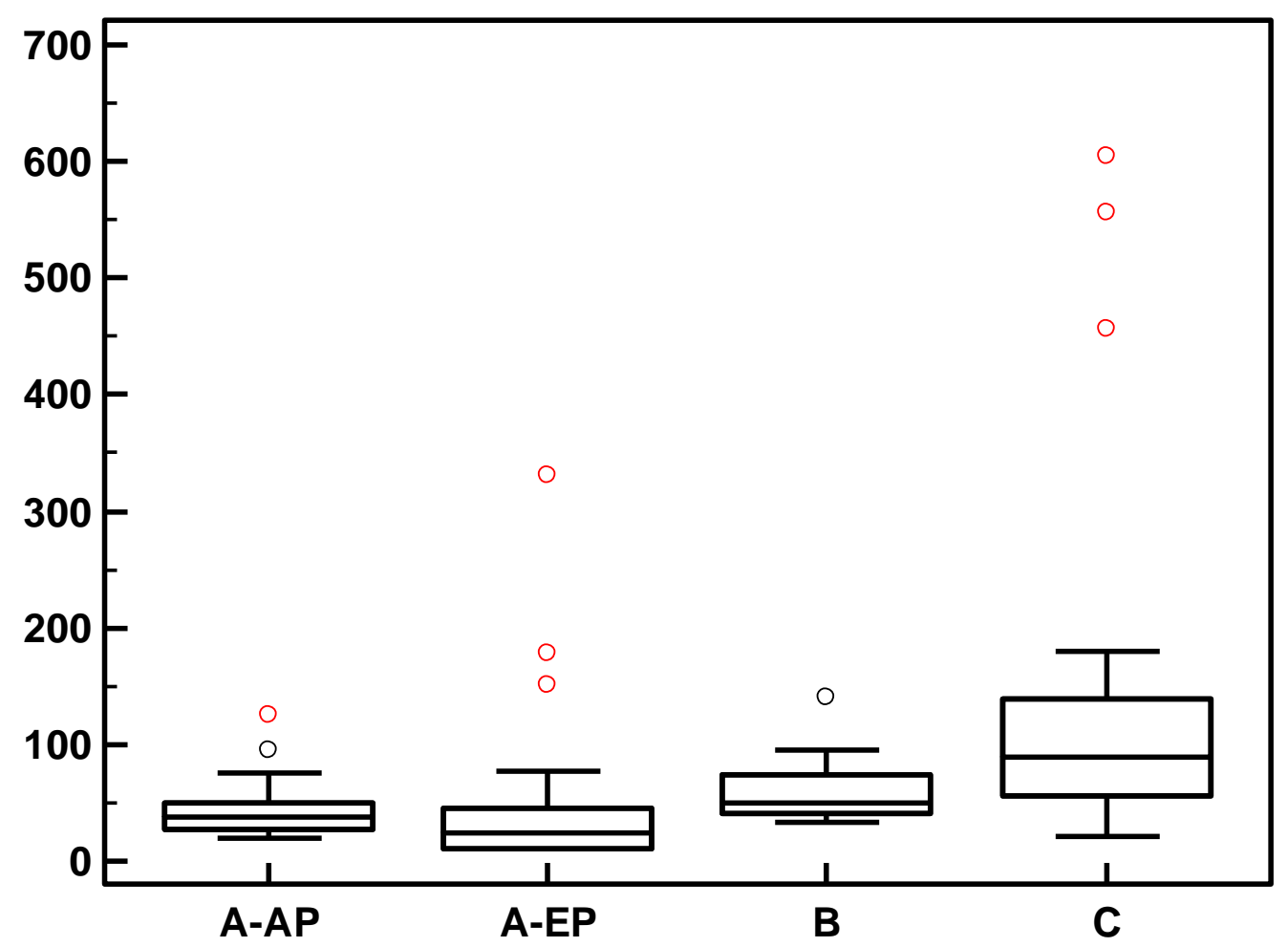

Abb. 3.13 Biomarker MMP-9 im Vergleich

Der Biomarker MMP-9 wird durch die LDL-Apherese nicht deutlich vermindert, sondern steigt je nach LDL-Aphereseart an. Auffällig im Vergleich mit den beiden Kontrollkollektiven ist jedoch, dass sich die Gruppe A und die Gruppe B deutlich von der Gruppe C unterscheiden. Die Gruppe C, welche dem kranken Kontrollkollektiv entspricht, hat deutlich höhere MMP-9 Werte als die anderen beiden Gruppen. Verglichen mit Gruppe A-AP und A-EP sind die Werte der Gruppe C statistisch signifikant erhöht $(p=0,0002)$. 
Auch die Gruppen B und C zeigen im Vergleich miteinander einen signifikanten Unterschied mit einem p-Wert von 0,0237.

\subsubsection{Biomarker sVCAM im Vergleich}

Tab. 3.23 Biomarker sVCAM im Vergleich (MW und STAW)

\begin{tabular}{|l|c|c|c|c|}
\hline Biomarker & A - AP & A - EP & B & C \\
\hline $\begin{array}{l}\text { sVCAM } \\
\text { (ng/ml) }\end{array}$ & $605,68 \pm 295,85$ & $161,17 \pm 66,65$ & $527,65135,59$ & $627,02186,81$ \\
\hline
\end{tabular}

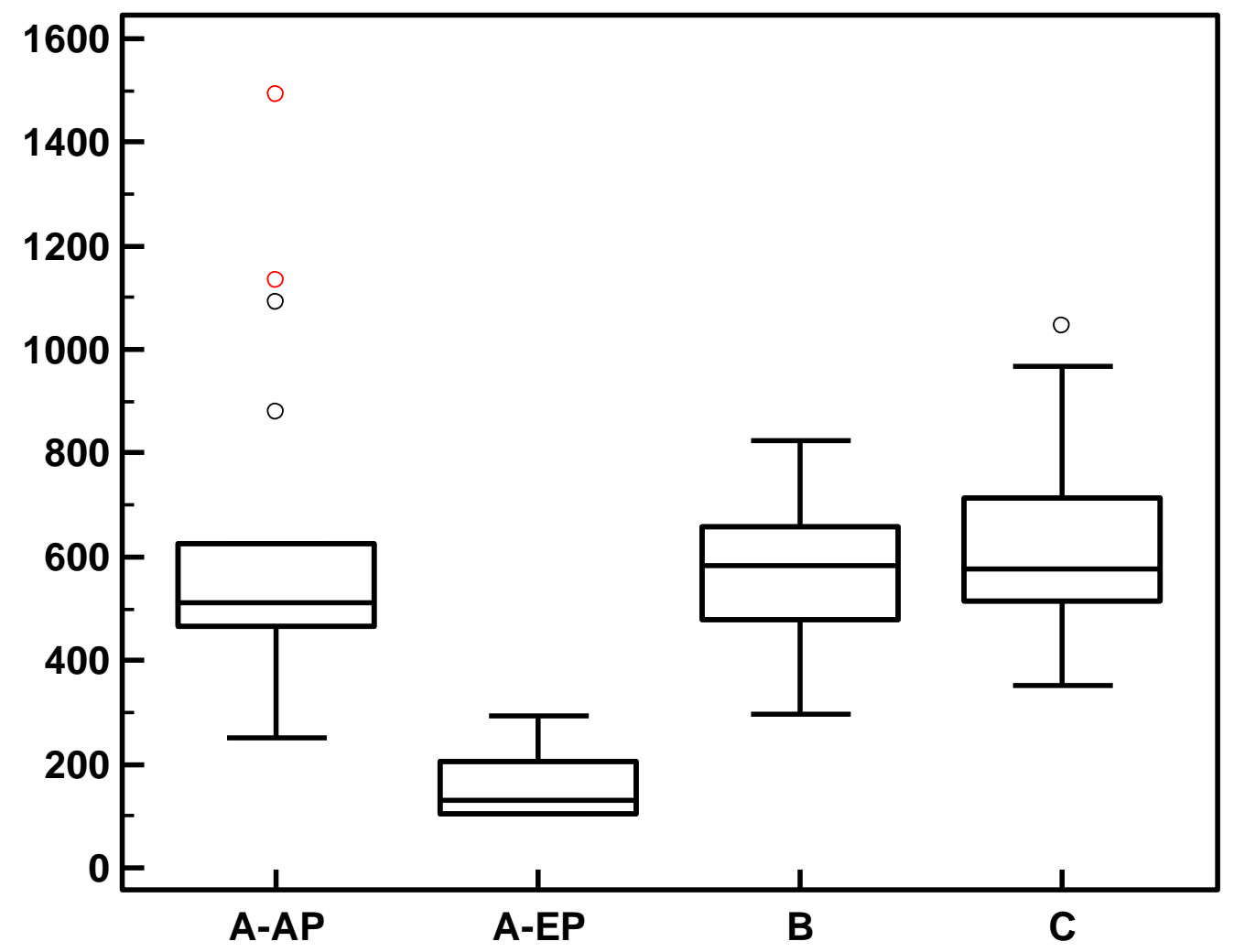

Abb. 3.14 Biomarker sVCAM im Vergleich

Alle drei Kollektive zeigen ähnlich hohe Werte für sVCAM, wobei jedoch das Kollektiv der Gruppe C die höchsten Werte aufzeigt, gefolgt vom Kollektiv der Gruppe A und dann der Gruppe B. Diese Unterschiede sind jedoch statistisch nicht signifikant. Die Gruppe A erfährt jedoch durch die LDL-Apherese eine 
deutliche Reduzierung der sVCAM Konzentration, wodurch sich die EP-Werte signifikant sowohl von den AP-Werten $(p<0,0001)$ als auch von den Werten der Gruppe B $(p<0,0001)$ und C $(p<0,0001)$ unterscheiden.

\subsubsection{Biomarker PAPP-A im Vergleich}

Tab. 3.24 Biomarker PAPP-A im Vergleich (MW und STAW)

\begin{tabular}{|l|c|c|c|c|}
\hline Biomarker & A - AP & A - EP & B & C \\
\hline $\begin{array}{l}\text { PAPP-A } \\
(\boldsymbol{\mu l} \mathbf{l} / \mathbf{m l})\end{array}$ & $5,81 \pm 3,43$ & $1,10 \pm 2,09$ & $0,22 \pm 0,26$ & $0,84 \pm 0,35$ \\
\hline
\end{tabular}

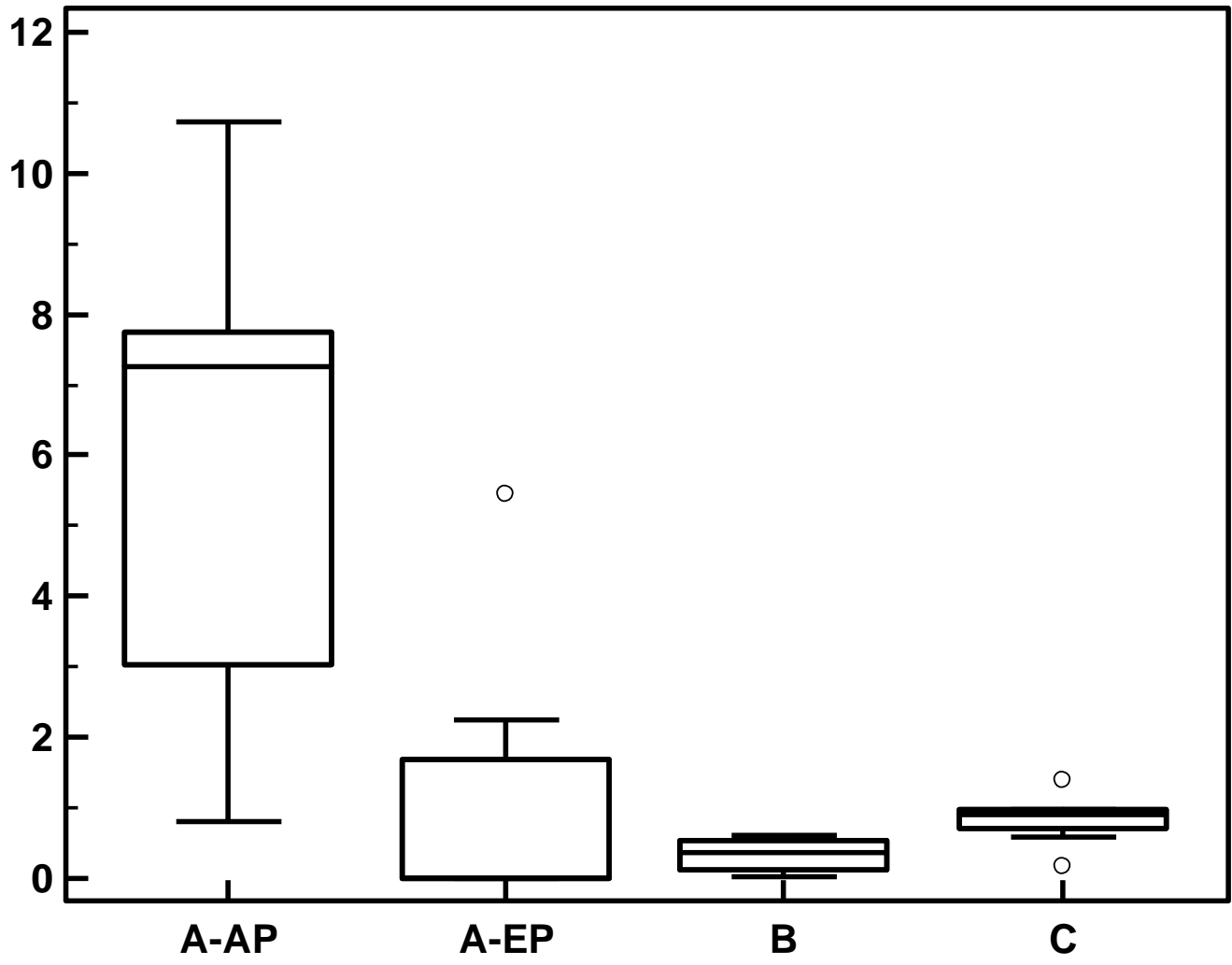

Abb. 3.15 Biomarker PAPP-A im Vergleich

Der Biomarker PAPP-A ist in der Gruppe A bereits vor der LDL-Apherese deutlich erhöht im Vergleich zu den Gruppen $B(p=0,0082)$ und $C(p=0,0109)$. Aber auch nach der LDL-Apherese erreicht die Gruppe A trotz signifikanter Reduzierung nicht 
die Werte der Gruppen B $(p=0,2458)$ und C $(p=0,1611)$, allerdings ist der Unterschied jetzt nicht mehr signifikant.

Das Kollektiv der Gruppe $C$ wiederum hat signifikant höhere Werte $(p=0,0415)$ als die Gruppe B, welche das gesunde Kontrollkollektiv darstellt.

\subsubsection{Biomarker hsCRP im Vergleich}

Tab. 3.25 Biomarker hsCRP im Vergleich (MW und STAW)

\begin{tabular}{|l|c|c|c|c|}
\hline Biomarker & A - AP & A - EP & B & C \\
\hline $\begin{array}{l}\text { hsCRP } \\
\text { (ng/ml) }\end{array}$ & $3,70 \pm 4,76$ & $1,96 \pm 2,22$ & $1,75 \pm 2,24$ & $3,12 \pm 2,96$ \\
\hline
\end{tabular}

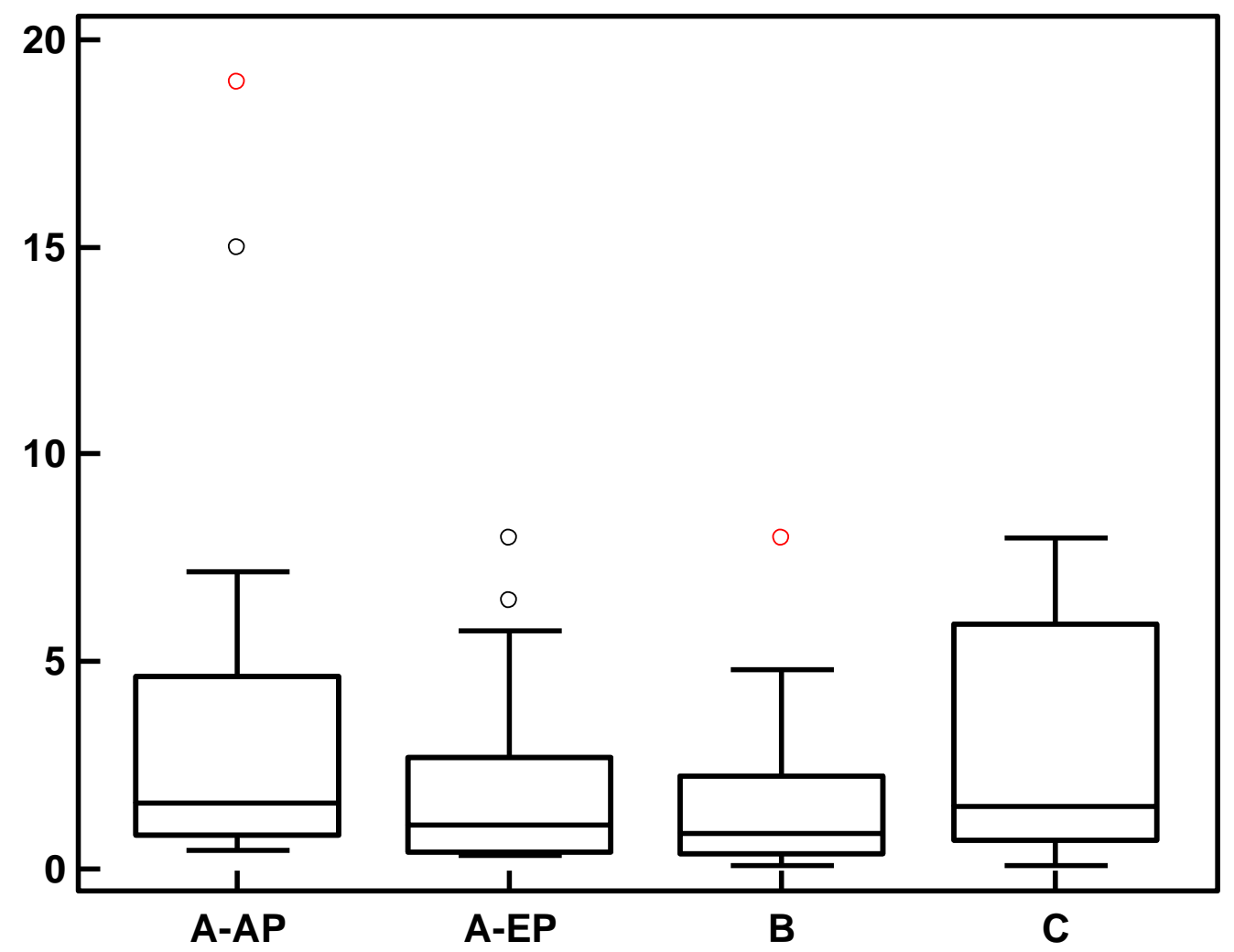

Abb. 3.16 Biomarker hsCRP im Vergleich 
Der Marker hsCRP fällt, wie zuvor erwähnt, nach der Apherese statistisch signifikant ab.

Die Werte der Gruppe A vor der LDL-Apherese gleichen den Werten der Gruppe C, wohingegen die Werte der Gruppe A sich nach der LDL-Apherese den Werten der Gruppe B nähern. Keiner dieser Werte unterscheidet sich jedoch statistisch signifikant. 


\section{DISKUSSION}

\subsection{Gesamtergebnis}

Die Reduzierung des LDL-Cholesterins und des Lp(a) ist der eigentliche und beobachtete Effekt der LDL-Apherese und wird allgemein als Ziel der Therapie gesehen.

Zunehmend ergeben sich jedoch Hinweise, dass es neben der LDL-Reduzierung noch weitere positive Effekte gibt.

In diesem Zusammenhang beschreiben Dihazi H et al. 2008 eine Verbesserung der Mikrozirkulation und eine Reduzierung der Entzündungsreaktion durch die Absenkung der Proteine mit rheologischen, adhäsiven und entzündlichen Eigenschaften während der LDL-Apherese (Dihazi $\mathrm{H}$ et al. 2008).

Von Rossenbach $\mathrm{J}$ et al. wird ebenfalls beschrieben, dass es durch die LDLApherese zu einer Verbesserung der Mikrozirkulation kommt, unabhängig vom LDL-Aphereseverfahren (Rossenbach J et al. 2011).

In 2009 und 2010 veröffentlichten Studien konnte durch Koziolek MJ et al. ein deutlicher Rückgang von kardiovaskulären Endpunkten durch die Reduzierung von LDL-Cholesterin und Lp(a) nachgewiesen werden (Koziolek MJ, Mueller GA 2009, Koziolek MJ et al 2010). Es konnte gezeigt werden, dass sich bei Patienten mit Hyperlipoproteinämie, welche sich regelmäßig einer LDL-Apheresebehandlung unterziehen, zwar weiterhin noch atherosklerotische Plaques entwickeln, diese jedoch stabiler sind und daher seltener rupturieren und somit auch seltener zu kardiovaskulären Ereignissen führen.

Die vorliegende Arbeit ist eine der ersten, um den Einfluss verschiedener LDLApherese-Verfahren auf die Konzentration ausgewählter Biomarker, die während verschiedener Phasen der Atherosklerose erhöht sind, systematisch zu untersuchen und zu vergleichen.

Zusammengefasst kann eine Reduzierung der Konzentration von Biomarkern festgestellt werden, vor allem in den Phasen der Inflammation, der Plaquedestabilisation, der akuten Phase Reaktion und der myokardialen Dysfunktion. Eingeschränkt, aufgrund geringer Fallzahl, ist auch eine Reduzierung 
in der Phase der Plaqueruptur zu verzeichnen. In der proinflammatorischen Phase dagegen ist ein positiver Effekt nicht nachzuweisen.

\subsection{Einschränkungen der Arbeit}

Diese Arbeit unterliegt einigen Einschränkungen:

Die Anzahl der ausgewählten Probanden ist mit 22 Apheresepatienten relativ gering. Dies trifft jedoch auch auf andere LDL-Apherese-Studien zu.

Eine zufällige Zuordnung von Patienten zu einer besonderen LDL-AphereseMethode ist nicht möglich, sondern wird aufgrund individueller Krankengeschichten der Patienten durch den behandelnden Arzt festgelegt.

Zudem wird der mögliche Zusammenhang zwischen den Änderungen der Konzentrationen dieser atherosklerotisch-relevanten Biomarker und der klinischen Entwicklung der Patienten hinsichtlich kardiovaskulärer Ereignisse in dieser Studie nicht untersucht, sondern von anderen Doktoranden bearbeitet.

\subsection{Ergebnisse in Bezug auf den Zeitpunkt der Atherosklerose}

\subsubsection{Proinflammation}

Die Biomarker IL-1ß, IL-6 sowie TNF- $\alpha$, die im Frühstadium der Atherosklerose, der sogenannten Proinflammation auftreten, werden in unserer Versuchsreihe durch keine der untersuchten Aphereseformen wesentlich beeinflusst. Dies steht auch in Übereinstimmung mit den Studien von Otto $C$ et al, in der ebenfalls keine Reduzierung von IL-6 während einer DALI-Apherese festgestellt wurde (Otto C et al. 2007).

Auch bei Utsumi $\mathrm{K}$ et al. konnte keine Reduktion von IL-1B, IL-6 oder TNF- $\alpha$ mittels DSA (Dextran-Sulfat-Cellulose-Adsorption, vergleichbar mit dem DALIVerfahren) nachgewiesen werden (Utsumi $\mathrm{K}$ et al. 2007).

In einer Untersuchung von Stefanutti $C$ et al. konnte mittels DSA nur eine geringe Reduktion der IL-6 Konzentration gemessen werden, welche statistisch nicht signifikant war. Jedoch beschreibt er in seiner Untersuchung einen deutlichen 
Rückgang von TNF- $\alpha$, der in dieser Versuchsreihe nicht festzustellen ist (Stefanutti C et al. 2011). Diese Reduzierung von TNF- $\alpha$ beschreibt auch Samtleben W et al. 1998 bei seinen Messungen während der H.E.L.P.-Apherese (Samtleben W et al. 1998). Diese Unterschiede können zum einen durch verschiedenen Patientenkollektiven und zum anderern durch voneinander abweichenden LDLAphereseverfahren zustande kommen.

Tab. 4.1 Vergleichbare Studien zu IL-1ß, IL-6, TNF- $\alpha$

\begin{tabular}{|c|c|c|}
\hline \multicolumn{3}{|c|}{ IL-1ß, IL-6, TNF- $\alpha$} \\
\hline Verfahren & Eigene Studie & $\begin{array}{c}\text { Studien mit vergleichbaren } \\
\text { Ergebnissen }\end{array}$ \\
\hline DFPP & nicht reduziert & keine vergleichbaren Studien \\
\hline DALI & nicht reduziert & $\begin{array}{l}\text { Utsumi K et al. } 2007 \text { (DSA) } \\
\rightarrow \text { alle nicht reduziert } \\
\text { Otto C et al. } 2007 \\
\rightarrow \text { IL-6 nicht reduziert } \\
\text { Stefanutti C et al. } 2011 \\
\rightarrow \text { IL-6 nicht signifikant reduziert } \\
\rightarrow \text { TNF- } \alpha \text { signifikant reduziert }\end{array}$ \\
\hline H.E.L.P. & nicht reduziert & $\begin{array}{l}\text { Samtleben W et al. } 1998 \\
\rightarrow \text { TNF- } \alpha \text { signifikant reduziert }\end{array}$ \\
\hline
\end{tabular}

Ein Fortschreiten der Erkrankung ergibt sich durch die Wechselwirkungen zwischen Makrophagen/Schaumzellen, Th1 und Th2, die einen chronisch entzündlichen Prozess, die Inflammation, mit nachfolgender Entwicklung einer fibrösen Plaque hervorrufen (Ross R 1999, Steinberg D et al. 1989, Paulsson G et al. 2000).

Diese Phase der Krankheitsentwicklung erfolgt unter dem Einfluss zellulärer und humoraler Wechselwirkungen (Glass CK, Witztum JL 2001, Blum A et al. 1995, Stemme S et al. 1991).

Die Ausbildung des Interleukin-2 Rezeptors (IL-2R) ist von zentraler Bedeutung für die autokrine Wachstumsstimulation nach der T-Zelle-Aktivierung in Atheromen 
(Blum A et al. 1995). Bei Patienten mit stabiler Angina pectoris werden erhöhte Konzentrationen seiner löslichen Form festgestellt (Simon AD et al. 2001). In dieser Arbeit kann eine bedeutende Abnahme von sIL-2R im Intervall von 16\% bis $33 \%$, abhängig vom jeweils eingesetzten LDL-Apherese-System, festgestellt werden. Besonders das H.E.L.P.-Verfahren ist bei diesem Marker den anderen beiden LDL-Apheresen signifikant überlegen. Es senkt den IL-2R um mehr als $33 \%$ im Vergleich zum Wert vor dem LDL-Apheresefilter zu Beginn der Behandlung.

Bislang gibt es keine weiteren publizierten Studien über den Einfluss der LDLApherese auf den sIL-2R-Level bei Patienten mit Hyperlipoproteinämie, so dass keine vergleichbaren Studien aufgeführt werden können.

\subsubsection{Plaque-Bildung/-Destabilisierung}

Ein weitere Marker, welcher der Übersicht halber in dieser Arbeit unter Plaquedestabilität aufgeführt und gemessen wird, ist das asymmetrische Dimethylarginin.

Durch die Inaktivierung von Stickstoffmonoxid bleibt die Relaxierung der glatten Gefäßmuskulatur aus. Die normalerweise eintretende Vasodilatation und somit Absenkung der Nachlast und des Blutdruckes fehlt.

Über die Senkung des Stickstoffmonoxid-Spiegels an den Endothelzellen der Gefäßwand begünstigt ADMA somit ebenfalls die Entstehung der Atherosklerose und damit auch das Eintreten von lebensgefährlichen Endorganschäden. Dies wurde unter anderem von Schnabel R et al. bereits 2005 veröffentlicht. $\mathrm{Er}$ bezeichnet in seiner Arbeit ADMA als einen der stärksten Risikofaktoren für das Auftreten von kardiovaskulären Ereignissen (Schnabel R et al. 2005).

In der vorliegenden Untersuchung konnte bei allen drei LDL-Aphereseverfahren, vor allem aber beim DALI-Verfahren, eine signifikante Reduzierung dieses Markers nachgewiesen werden. Die Werte vor der LDL-Apherese werden nach dem Filter zum Teil um mehr als $80 \%$ gesenkt.

Bislang gibt es nur eine weitere Studie über die Wirkung der LDL-Apherese auf den Biomarker ADMA von Rossenbach J et al., welche sich jedoch auf das gleiche Patientenkollektiv wie in dieser Arbeit bezieht und somit nicht als Vergleich herangezogen werden kann (Rossenbach J et al. 2011). 
Matrixmetalloproteinasen (MMPs) wie MMP-9 und MT1-MMP sind Marker für die Plaquedestabilisierung. Sie befinden sich in Makrophagen und sind in Bereichen von Plaquerupturen festzustellen. Es wird davon ausgegangen, dass sie die Plaquestabilität beeinflussen, indem sie die extrazellulären Matrixproteine abbauen (Glass CK, Witztum JL 2001). Erhöhte MMP-9-Konzentrationen sind mit zukünftigen kardiovaskulären Endpunkten verbunden (Blankenberg S et al. 2003 b).

Ähnlich zur Untersuchung von Utsumi K et al. wurden bei Nakamura et al. bei Patienten mit Typ 2-Diabetes und arteriosklerotischer Verschlusskrankheit während einer Behandlung mit DSA ebenfalls die Plasma Spiegel für MMP-9 gemessen. Diese wurden signifikant gesenkt (Utsumi K et al. 2007, Nakamura et al. 2003).

Dagegen tritt bei unseren Patienten lediglich eine Reduktion der MMP-9 Konzentration beim DFPP-Verfahren auf, während HELP und DALI keinen deutlichen Effekt aufweisen.

Diese Unterschiede können sowohl durch die Eigenschaften der untersuchten Probanden als auch durch die verwendeten LDL-Aphereseverfahren begründet sein.

Tab. 4.2 Vergleichbare Studien zu MMP-9

\begin{tabular}{|c|c|c|}
\hline \multicolumn{3}{|l|}{ MMP-9 } \\
\hline Verfahren & Eigene Studie & $\begin{array}{c}\text { Studien mit vergleichbaren } \\
\text { Ergebnissen }\end{array}$ \\
\hline DFPP & Nicht signifikant reduziert & Keine vergleichbaren Studien \\
\hline DALI & Nicht reduziert & $\begin{array}{l}\text { Utsumi K et al. } 2007 \text { (DSA) } \\
\rightarrow \text { signifikant reduziert } \\
\text { Nakamura et al. } 2003 \text { (DSA) } \\
\rightarrow \text { signifikant reduziert }\end{array}$ \\
\hline H.E.L.P. & Nicht reduziert & Keine vergleichbaren Studien \\
\hline
\end{tabular}

Wird eine endotheliale Modifizierung nicht früh genug erkannt und behandelt, kommt es zu einer bereits oben erwähnten chronischen Entzündung. 
Ein wichtiges Molekül in diesem Prozess ist VCAM-1 (Vascular cell adhesion molecule), welches durch pro-atherosklerotische Prozesse (O'Brien KD et al. 1993, Cybulsky MI, Gimbronejr MA 1991) induziert wird und somit ebenfalls zur Plaquedestabilisierung beiträgt.

Durch eine proteolytische Spaltung entsteht eine lösbare Form von VCAM-1, das sVCAM-1 (Leca G et al. 1995, Blankenberg S et al. 2003 a).

Diese scheint einen Hinweis für den Schweregrad der Atherosklerose darzustellen (Peter K et al. 1997, Blankenberg $S$ et al. 2001) und wird als ein starker unabhängiger Risikofaktor für zukünftige kardiovaskuläre Endpunkte, welche auch tödlich enden können, gesehen (Blankenberg S et al. 2003 b).

In den Untersuchungen zu dieser Arbeit finden wir eine statistisch signifikante Verminderung von sVCAM um bis $\mathrm{zu} 70 \%$ bei allen untersuchten Apheresesverfahren. Besonders deutlich ist die Reduktion unter der DFPPApherese (fast $80 \%$ ) zu erkennen.

Dies bestätigt auch die bereits erwähnte Studie von Utsumi K et al.. In dieser Studie unterziehen sich Dialyse-Patienten mit Diabetes mellitus Typ 2 und arteriosklerotischer Verschlusskrankheit einer DSA. Auch hier wurde eine relevante Reduzierung von sVCAM beschrieben (Utsumi K et al. 2007).

Vergleichbare Ergebnisse erzielten Horstkotte D und Mellwig KP für das DFPPVerfahren (Horstkotte D, Mellwig KP 2003).

Ein statistisch signifikantes Absenken des Biomarkers sVCAM mittels LDLApherese wird von verschiedenen Forschungsgruppen festgestellt. Vier von innen sind in der folgenden Tabelle mit aufgeführt. 
Tab. 4.3 Vergleichbare Studien zu sVCAM

\begin{tabular}{|c|c|c|}
\hline \multicolumn{3}{|l|}{ sVCAM } \\
\hline Verfahren & Eigene Studie & $\begin{array}{c}\text { Studien mit vergleichbaren } \\
\text { Ergebnissen }\end{array}$ \\
\hline DFPP & $\begin{array}{l}\text { Signifikant reduziert, } \\
\text { gegenüber dem H.E.L.P. } \\
\text { statistisch überlegen }\end{array}$ & $\begin{array}{l}\text { Horstkotte D, Mellwig KP } 2003 \\
\rightarrow \text { signifikant reduziert }\end{array}$ \\
\hline DALI & Signifikant reduziert & $\begin{array}{l}\text { Utsumi K et al. } 2007 \text { (DSA) } \\
\rightarrow \text { signifikant reduziert }\end{array}$ \\
\hline H.E.L.P. & Signifikant reduziert & $\begin{array}{l}\text { Wang Y et al. } 2004 \\
\rightarrow \text { signifikant reduziert } \\
\text { Pulawski E et al. } 2002 \\
\rightarrow \text { signifikant reduziert }\end{array}$ \\
\hline
\end{tabular}

\subsubsection{Plaqueruptur}

Als Marker für die Plaqueruptur wurde der Biomarker PAPP-A als Repräsentant gewählt. Dieser Marker ist mitverantwortlich für die Zerstörung der stabilisierenden Plaqueoberfläche und führt somit zur Plaqueruptur (Apple FS et al. 2005).

Bereits in anderen Studien wurde eine erhöhte Konzentration dieses Biomarkers bei Patienten mit instabilen Plaques und plötzlichem Herztod gefunden (BayesGenis A et al. 2001). Vor allem bei einer instabilen Angina pectoris scheint PAPPA ein wegweisender Marker zu sein.

Aufgrund niedriger Versuchszahlen in Bezug auf diesen Marker sind die Ergebnisse dieser Arbeit nur eingeschränkt zu bewerten. Es zeigt sich in allen drei Verfahren eine deutliche Reduzierung um im Mittel fast $90 \%$.

Bislang gibt es nur wenige veröffentlichte Studien über die Auswirkung der LDLApherese auf diesen Biomarker, so dass wir aktuell unsere Ergebnisse nicht durch andere Studien untermauern können.

Die Daten werden jedoch durch weitere klinische Untersuchungen bekräftigt, bei denen, wie bereits erwähnt, zwar keine Effekte der LDL-Apherese auf die denovo- Plaquebildung im Rahmen der endothelialen Phase gesehen werden, dafür 
aber auf die allgemeine Plaquestabilität, welche zu weniger kardiovaskulären Endpunkten führt (Koziolek MJ et al. 2010).

\subsubsection{Akute-Phase-Reaktion}

Bei der Entwicklung der Atherosklerose treten eine Reihe zellulärer und molekularer Ereignisse auf, die als entzündlicher Prozess bezeichnet werden können. Innerhalb der verschiedenen Phasen sind charakteristische Biomarker erhöht.

Die Biomarker der Proinflammation (IL-1ß, IL-6 und TNF- $\alpha$ ) fördern die Synthese von mehreren Akute-Phase-Proteinen in der Leber, wie C-reaktives Protein (CRP), Serum Amyloid A und Fibrinogen. In einer Studie von Dihazi H et al. von 2008 wurden diese Proteine durch verschiedenen LDL-Apherese-Methoden reduziert (Dihazi $\mathrm{H}$ et al. 2008). Auch Wang $\mathrm{Y}$ et al. konnte eine Reduktion des hsCRP sowie des sVCAM während der H.E.L.P.-Apherese nachweisen (Wang $Y$ et al. 2004).

Vor allem dem CRP wird hier eine bedeutende Rolle als proatherogener Marker zugeteilt, welcher mit zukünftigen kardiovaskulären Ereignissen in Verbindung gebracht werden kann (Khuseyinova N, Koenig W 2006).

In dieser Arbeit wird eine bedeutende Abnahme von hsCRP in allen drei Aphereseverfahren zwischen $32 \%$ bis $47 \%$ beobachtet. Dabei ist keines der LDLAphereseverfahren dabei statistisch signifikant überlegen.

Obwohl es bislang nur wenige Daten über den Einfluss der LDL-Apherese auf hsCRP gibt, liegen erste Erkenntnisse über ein Absenken durch das HELPVerfahren vor (Moriarty PM et al. 2001). Dies bestätigte Otto $C$ et al. ebenfalls für das DALI-Verfahren. Hier wurden sowohl das CRP als auch weitere Entzündungsparameter wie das Fibrinogen während der LDL-Apherese gesenkt (Otto C et al. 2007). Auch Kobayashi S et al. kam 2006 zu vergleichbaren Ergenissen in Bezug auf hsCRP und Fibrinogen (Kobayashi S et al. 2006).

Hershcovici $T$ et al. erzielte vergleichbare Messungen während des DALIVerfahrens. Auch hier kam es während der Behandlung zu einer statistisch signifikanten Reduktion des hsCRP und des Fibrinogens (Hershcovici $\mathrm{T}$ et al. 2004). 
Für die DFPP-Behandlung liegt aktuell noch keine entsprechende Veröffentlichung vor.

Tab. 4.4 Vergleichbare Studien zu hsCRP

\begin{tabular}{|c|c|c|}
\hline \multicolumn{3}{|l|}{ hsCRP } \\
\hline Verfahren & Eigene Studie & $\begin{array}{c}\text { Studien mit vergleichbaren } \\
\text { Ergebnissen }\end{array}$ \\
\hline DFPP & Signifikant reduziert & Keine vergleichbaren Studien \\
\hline DALI & Signifikant reduziert & $\begin{array}{l}\text { Otto C et al. } 2007 \\
\rightarrow \text { signifikant reduziert } \\
\text { Hershcovici T et al. } 2004 \\
\rightarrow \text { signifikant reduziert }\end{array}$ \\
\hline H.E.L.P. & Signifikant reduziert & $\begin{array}{l}\text { Moriarty PM et al. } 2001 \\
\rightarrow \text { signifikant reduziert }\end{array}$ \\
\hline
\end{tabular}

\subsubsection{Myokardiale Dysfunktion}

Natriuretische Peptide werden als Marker für die frühe Diagnose und für die Prognose einer linken ventrikulären Funktionsstörung (LVD) beschrieben (Mair W et al. 1999). Die meisten vergleichbaren Studien zeigen, dass NT-probrain natriuretic peptide (NT-proBNP) und NT-proatrial natriuretic peptide (NT-proANP) besser als andere natriuretische Peptide geeignet sind um asymptomatische und symptomatische LVD zu diagnostizieren (Yamamoto K et al. 1996, Friedl W et al. 1996, Cowie MR et al. 1997, McDonagh TA et al. 1998).

Bei der Analyse zu dieser Arbeit wurden eine signifikante Reduzierung von NTproANP, aber nicht von NT-proBNP festgestellt. Jedoch kommt es bei allen Verfahren bis auf das H.E.L.P.-Verfahren zu einer leichten Absenkung der NTproBNP Konzentration. Diese ist zwar nicht statistisch signifikant, jedoch erkennbar. An dieser Stelle kann man nur Spekulationen abgeben, was die Biomarker für die myokardiale Dysfunktion angeht. Für eindeutige Erkenntnisse sind weitere Messreihen an größeren Patientenkollektiven ratsam. 
Bislang gibt es allerdings noch keine weiteren Studien, die sich mit vergleichbaren Messungen beschäftigen, so dass bei diesen Markern erneut keine Vergleiche angeführt werden können.

\subsubsection{Vergleich der drei Gruppen (A,B, und C)}

Nimmt man nun die beiden Kontrollgruppen dazu und vergleicht die Messdaten miteinander, ergeben sich für die jeweiligen Marker unterschiedliche Aussagen. Verglichen werden hierzu als Marker der Plaquedestabilisation ADMA, MMP-9 und sVCAM, als Marker für die Plaqueruptur PAPP-A und als Akute-Phase-Marker hsCRP.

Bei dem Biomarker ADMA unterscheiden sich die Ausgangswerte der drei Kollektive kaum voneinander. Nur in Bezug auf den Messwert nach dem Filter scheinen die Apheresepatienten eine deutliche Reduktion des Markers zu erfahren.

Ein ähnliches Bild zeigt sich bei sVCAM. Auch hier fällt der Wert nach der LDLApherese deutlich unter die Ausgangswerte der drei Kollektive.

Diese beiden Werte werden somit bei dem Hauptkollektiv im Vergleich zu den beiden Kontrollkollektiven deutlich abgesenkt.

Hieraus kann gegebenenfalls ein positiver Effekt gegen das Fortschreiten der Atherosklerose abgeleitet werden.

Zudem kann spekuliert werden, dass diese beiden Marker (ADMA und sVCAM), welche durch die LDL-Apherese gesenkt werden, nach der Behandlung wieder ansteigen und somit ohne LDL-Apherese noch höher wären. Man kann allerdings auch annehmen, dass der Anstieg nach der Behandlung als Reaktion auf die Therapie zurück zu führen ist. Dies wäre somit ein negativer Effekt, den die LDLApherese auf die Konzentration dieser beiden Marker hätte. Eine endgültige Aussage kann zum jetzigen Zeitpunkt nicht getroffen werden.

Bei den MMP-9 Werten weist vor allem das kranke Kontrollkollektiv deutlich erhöhten Werten im Vergleich zu der gesunden Kontrollgruppe auf, aber auch im Vergleich zu dem Hauptkollektiv sowohl vor als auch nach der Apherese. 
Aufgrund dieser Daten kann vermutet werden, dass die regelmäßige LDLApherese einen anhaltend senkenden Effekt auf MMP-9 hat. Die Werte des Hauptkollektives nähern sich den Werte der gesunden Gruppe an, wohingegen die Gruppe ohne LDL-Apherese, aber mit Hyperlipoproteinämie deutlich höhere Werte aufweist.

Hiervon unterscheidet sich der Marker PAPP-A deutlich. Auch dieser Marker wird durch die LDL-Apherese signifikant reduziert. Auffällig ist jedoch der Wert vor dem Filter, welcher im Vergleich zu den beiden Kontrollkollektiven deutlich erhöht ist. Erst nach der LDL-Apherese nähert sich der PAPP-A Wert der LDLApheresepatienten an die beiden anderen Gruppen an.

Bei dem Akute-Phase-Marker hsCRP wird deutlich, dass es sich bei der Atherosklerose um einen Entzündungsprozess handelt, welcher vor allem bei prädisponierten Personen stattfindet. Dies spiegelt sich auch in den Messdaten zu diesem Marker wider. Vor allem die beiden kranken Kollektive (Hauptkollektiv und krankes Kontrollkollektiv) haben primär im Vergleich zum gesunden Kontrollkollektiv deutlich erhöhte Werte. Erst nach der LDL-Apherese nähert sich das Hauptkollektiv den Werten des gesunden Kollektives an.

Insgesamt sind dies aber nur erste Hinweise, welche in weiterführenden Studien noch bestätigt werden müssten. In der Literatur sind hierzu bislang noch keine vergleichbaren Aussagen getroffen worden.

\subsubsection{Schlussfolgerung und Ausblicke}

Es gibt bereits einige klinische Studien, welche sich mit den Langzeitergebnissen der LDL-Apherese beschäftigen und diese Studie untermauern. Koziolek MJ et al. hat 2010 eine Langzeitstudie über ein LDL-Apherese-Kollektiv veröffentlicht. Hier zeigte sich, dass die LDL-Apherese keinen deutlichen Einfluss auf die Plaqueentstehung, wohl aber auf die Plaquestabilität besitzt. Dies bedeutet, dass die Patienten weiterhin Plaques vor allem im Bereich der Koronararterien entwickeln, diese durch die LDL-Apheresebehandlung jedoch deutlich stabiler sind und es zu weniger Plaquerupturen und damit zu weniger kardiovaskulären 
Endpunkten kommt (Koziolek M et al. 2010). Durch die Behandlung konnte in dieser Langzeitstudie eine Reduzierung der Morbidität und Mortalität nachgewiesen werden. Diese Langzeitergebnisse stimmen mit unserer Versuchsreihe überein. Auch bei unseren Messungen konnte besonders im Bereich der Plaquestabilität ein positives Ergebniss durch die LDL-Apherese nachgewisen werden. Zum Zeitpunkt der Proinflammation ist jedoch kaum eine Reduktion der entsprechenden Biomarker zu verzeichnen.

Diese Ergebnisse bestätigt ebenfalls eine über sechs Jahre verlaufende Studie von Mabuchi $\mathrm{H}$ et al. Auch hier konnte eine deutliche Reduzierung der LDLCholesterinwerte und daraus resultierend eine Verringerung kardiovaskulärer Endpunkt um mehr als 70\% im Vergleich zu medikamenös therapierten Patienten mit familiärer Hyperlipoproteinämie gezeigt werden (Mabuchi $\mathrm{H}$ et al. 1998).

Aus den von uns in vitro gemessenen Ergebnissen kann man letztendlich noch keine definitive Schlussfolgerung über die Auswirkung der LDL-Apherese in vivo treffen. Es kann jedoch die Vermutung aufgestellt werden, dass durch die Reduzierung eines bestimmten Biomarkers die LDL-Aphereseerfahren einen hemmenden Einfluss auf besondere Phasen der Atherosklerose in vivo besitzen. Hierzu sind weitere in vivo-Versuche, bzw. Versuche im Bereich der Atheroskleroseentstehung, wie zum Beispiel der Koronararterien, erforderlich.

Obwohl die gemessenen und ermittelten Daten Unterschiede in der Reduzierung bestimmter Biomarker in Abhängigkeit vom angewandten Aphereseverfahren zeigen, können sie nicht als Beweis über die Überlegenheit einer besonderer LDLApherese-Methode zur Reduzierung kardiovaskulärer Gefahren herangezogen werden.

Für die Zukunft wäre es denkbar aufgrund der vielen kleinen LDLApheresekollektive eine bundesweite Datenbank zu erstellen, um verlässliche und aussagekräftige Messergebnisse erzielen zu können. Hierzu erfolgen bereits erste Langzeitstudien über die Patientenkollektive und deren Endpunkte. Diese Daten könnten mit Hilfe einer bundesweiten Datenbank verglichen und ein Nutzen der LDL-Apherese hervorgehoben werden. Anhand dieser Ergebnisse könnte es ggf. zu einer erneuten Anpassung der Indikationsstellung kommen. Auch Schettler $V$ et al. empfehlen bereits 2009 ein deutsches LDL-Apherese Register. Dies würde Langzeitergebnisse bekräftigen und den nachgewiesenen Nutzen bestätigen, so 
dass eventuell weitere Patientenkollektive von einer LDL-Apheresebehandlung profitieren könnten (Schettler V et al. 2009).

Aufbauend auf dieser Arbeit sind weitere Messungen an größeren Patientenkollektiven sinnvoll. Es sollten ebenfalls weitere in vivo-Versuche mit herangezogen werden um die in vitro-Messungen zu untermauern.

In der Zukunft könnten dann vielleicht Methoden gefunden werden um einzelne Biomarker, welche vorrangig an der Entstehung bzw. dem Fortschreiten der Atherosklerose maßgeblich beteiligt sind, selektiv zu senken.

Auch könnte man Biomarker, welche nicht mit Hilfe der LDL-Apherese zu senken sind, aber die Atherosklerose nachweisbar vorantreiben versuchen durch andere Mittel, wie z.B. neue Medikamente, zu senken.

Abschließend ist $z u$ sagen, dass es in diesem Bereich noch viel Forschungspotenzial gibt, dessen Ergebnisse den betroffenen Patienten zugutekommen könnte. 


\section{Zusammenfassung}

Die LDL-Apherese dient primär der Reduktion von LDL-Cholesterin und Lp(a) im Blut von Patienten mit genetisch bedingter Hyperlipoproteinämie.

In unsere Studie werden 22 Patienten eingeschlossen, welche sich einer wöchentlichen bis zweiwöchentlichen LDL-Apheresebehandlung unterziehen.

Zum Einsatz kommen hierbei als Vollblutverfahren die DALI-Apherese (Direkte Adsorption von Lipoproteinen; $n=6$ ) und als selektive Plasmaverfahren das H.E.L.P.Verfahren (Heparininduzierte LDL-Präzipitation; $n=6$ ) und die DFPP (Thermofiltration; $n=10)$.

Untersucht wurden Biomarker der endothelialen Entzündungsreaktion (IL-1ß, IL-6, TNF- $\alpha$, hs CRP) und in diesem Zusammenhang der Zellaktivierung (sIL-2R) sowie der Plaquedestabilisation (ADMA, MMP-9, sVCAM), der Plaqueruptur (PAPP-A) und der myokardialen Funktion (NT-proANP, NT-proBNP). Die Messungen erfolgen jeweils vor dem Filter (AP) und nach dem Filter (EP) des jeweiligen LDLAphereseverfahrens kurz nach Beginn der LDL-Apheresebehandlung.

Darüber hinaus wurden für die Marker hsCRP, ADMA, MMP-9, sVCAM und PAPP-A noch Kontrollkollektive rekrutiert. Hierbei handelt es sich zum einen um ein gesundes Kontrollkollektiv ohne medikamentöse Therapie und ohne Endorganschäden $(n=15)$ und zum anderen um ein bereits an Endorganschäden erkranktes Kontrollkollektiv, welches eine vergleichbare medikamentöse Therapie erhält wie das Hauptkollektiv und ebenfalls Endorganschäden hat, nicht aber die Indikationen für eine LDLApheresebehandlung erfüllt $(n=20)$.

In der Messreihe der LDL-Apheresepatienten zeigt sich, dass die LDL-Apherese keinen Einfluss auf die proinflammatorischen Zytokine IL-1ß, IL-6 und TNF- $\alpha$ hat.

sIL-2R wird dagegen in allen drei LDL-Aphereseverfahren reduziert, im Mittel um $21,4 \pm 13,1 \%$ mit einem $p-W e r t$ von $<0,0001$.

Die Biomarker, welche im Zusammenhang mit den progressiven Erkrankungsphasen (Plaquedestabilisation, Plaqueruptur, akute Phase-Reaktion) auftreten, werden dagegen nachweisbar beeinflusst und größtenteils reduziert. 
Vor allem bei dem Biomarker sVCAM konnte eine signifikante Absenkung der Konzentration bei allen drei LDL-Aphereseverfahren gemessen werden (im Mittel $69,62 \pm 14 \%)$.

Dies trifft auch auf den Marker ADMA zu, welcher ebenfalls in allen drei Verfahren signifikant, bis maximal $88,60 \pm 1,60 \%$ im DALI Verfahren, vermindert wird.

Dagegen wird eine signifikante Absenkung des Markers MMP-9 lediglich mit dem DFPP-Verfahren erzielt.

Der Biomarker PAPP-A, welcher mit der Plaqueruptur in Verbindung gebracht wird, fällt ebenfalls signifikant ab. Dies ist aber aufgrund der geringen Messwerte nicht als statistisch signifikant zu werten und kann nur als ein Trend beschrieben werden. NT-proANP, nicht aber NT-proBNP, wird signifikant um 29,47 $\pm 18,32 \%$ reduziert.

Auch im Vergleich mit den beiden Kontrollkollektiven kann ein positiver Nutzen der LDL-Apherese nachgewiesen werden. Die Marker ADMA und SVCAM werden durch die LDL-Apherese deutlich gesenkt, so dass sie nach dem Filter niedriger sind als die Messwerte der Kontrollkollektive.

MMP-9 ist bei den LDL-Apheresepatienten vergleichbar mit dem gesunden Kontrollkollektiv, aber deutlich niedriger als bei den an Endorganen erkrankten Patienten des zweiten Kontrollkollektivs, so dass ein nachhaltiger positiver Effekt der LDL-Apherese auf diesen Marker anzunehmen ist.

Der Biomarker PAPP-A dagegen ist vor dem Filter deutlich erhöht, wird erst durch die LDL-Apherese gesenkt und ist dann vergleichbar mit den Werten der Kontrollkollektive. Aufgrund der geringen Datenmenge können auf Basis dieser Ergebnisse nur Vermutungen angestellt werden. Um diese zu untermauern, müssten weitere Studien folgen.

Zusammengefasst ist eine Reduzierung der Plasmakonzentration für Marker der Plaquedestabilisierung, der Zellaktivierung und der myokardialen Funktion durch die LDL-Apherese mit quantitativen und qualitativen Unterschieden in den drei untersuchten LDL-Aphereseverfahren zu beobachten.

Die Daten zeigen somit im Bereich der untersuchten Surrogatoparameter einen möglichen pleiotropen Effekt der LDL-Apherese und geben Hinweise für weitere Untersuchungen in diesem Bereich. 


\section{Literaturverzeichnis}

Apple FS, Wu AH, Mair J, Ravkilde J, Panteghini M, Tate J, Pagani F, Christenson $\mathrm{RH}$, Mockel M, Danne O, Jaffe AS; Committee on Standardization of Markers of Cardiac Damage of the IFCC (2005): Future biomarkers for detection of ischemia and risk stratification in acute coronary syndrome. Clin Chem 51(5), 810-24

Armstrong VW, Schuff-Werner P, Eisenhauer T, Helmhold M, Stix M, Seidel D (1994): Heparin extracorporeal LDL precipitation (HELP): an effective apheresis procedure for lowering Lp(a) levels. Chem Phys Lipids $\underline{67-68}, 315-21$

Bayes-Genis A, Conover CA, Overgaard MT, Bailey KR, Christiansen M, Holmes DR, Virmani R, Oxvig C, Schwartz RS (2001): Pregnancy-associated plasma protein A as a marker of acute coronary syndromes N Engl J Med $\underline{345}, 1022-9$

Blankenberg S, Rupprecht HJ, Bickel C, Peetz D, Hafner G, Tiret L, Meyer J. (2001): Circulating cell adhesion molecules and death in patients with coronary artery disease. Circulation $\underline{104}(12), 1336-42$

Blankenberg S, Barbaux S, Tiret L (2003 a): Adhesion molecules and atherosclerosis. Atherosclerosis 170, 191-203

Blankenberg S, Rupprecht HJ, Poirier O, Bickel C, Smieja M, Hafner G, Meyer J, Cambien F, Tiret L; AtheroGene Investigators (2003 b): Plasma concentrations and genetic variation of matrix metalloproteinase 9 and prognosis of patients with cardiovascular disease. Circulation 107(12), 1579-85

Blum A, Sclarovsky S, Shohat B (1995): T lymphocyte activation in stable angina pectoris and after percutaneous transluminal coronary angioplasty. Circulation $\underline{91}$, 20-22

Bosch T, Keller C (2003): Clinical effects of direct adsorption of lipoprotein apheresis: beyond cholesterol reduction. Ther Apher Dial $\underline{7}(3), 341-4$

Brown DL, Hibbs MS, Kearney M, Loushin C, Isner JM (1995): Identification of 92$\mathrm{kD}$ gelatinase in human coronary atherosclerotic lesions. Association of active enzyme synthesis with unstable angina. Circulation 91(8), 2125-31

Busse R, Fleming I (1995): Regulation and functional consequences of endothelial nitric oxide formation. Ann Med 27(3), 331-40 
Cosin-Sales J, Christiansen M, Kaminski P, Oxvig C, Overgaard MT, Cole D, Holt DW, Kaski JC (2004): Pregnancy-associated plasma protein A and its endogenous inhibitor, the proform of eosinophil major basic protein (proMBP), are related to complex stenosis morphology in patients with stable angina pectoris. Circulation $\underline{109}(14), 1724-8$

Cowie MR, Struthers AD, Wood DA, Coats AJ, Thompson SG, Poole-Wilson PA, Sutton GC (1997): Value of natriuretic peptides in assessment of patients with possible new heart failure in primary care. Lancet $\underline{350}$ (9088), 1349-53

Creemers EE, Cleutjens JP, Smits JF, Daemen MJ (2001): Matrix metalloproteinase inhibition after myocardial infarction: a new approach to prevent heart failure? Circ Res $\underline{89}(3), 201-10$

Cullen B, Silcock D, Brown LJ, Gosiewska A, Geesin JC (1997): The differential regulation and secretion of proteinases from fetal and neonatal fibroblasts by growth factors. Int J Biochem Cell Biol 29(1), 241-50

Cybulsky MI, Gimbronejr MA (1991): Endothelial expression of a mononuclear leukocyte adhesion molecule during atherogenesis. Science 251, 788-791

Danne O, Möckel M, Lueders C, Mügge C, Zschunke GA, Lufft H, Müller C, Frei U (2003): Prognostic implications of elevated whole blood choline levels in acute coronary syndromes. Am J Cardiol 91(9), 1060-7

De Caterina R, Basta G, Lazzerini G, Dell'Omo G, Petrucci R, Morale M, Carmassi F, Pedrinelli R. (1997): Soluble vascular cell adhesion molecule-1 as a biohumoral correlate of atherosclerosis. Arterioscler Thromb Vasc Biol 17(11), 2646-54

De Ferranti SD, Rifai N. (2007): C-reactive protein: a nontraditional serum marker of cardiovascular risk. Cardiovasc Pathol 16(1), 14-21

Dihazi H, Koziolek MJ, Söllner T, Kahler E, Neuhoff R, Klingel R, Strutz F, Mueller GA (2008): Protein adsorption during LDL-apheresis: Proteomic Analysis. Nephrol Dial Transplant 23(9), 2925-35

Folts JD, Stamler J, Loscalzo J. (1991): Intravenous nitroglycerin infusion inhibits cyclic blood flow responses caused by periodic platelet thrombus formation in stenosed canine coronary arteries. Circulation $\underline{83}(6), 2122-7$

Friedl W, Mair J, Thomas S, Pichler M, Puschendorf B (1996): Natriuretic peptides and cyclic guanosine $3^{\prime}, 5^{\prime}-$-monophosphate in asymptomatic and symptomatic left ventricular dysfunction. Heart $\underline{76}(2), 129-36$ 
Galis ZS, Khatri JJ (2002): Matrix metalloproteinases in vascular remodeling and atherogenesis: the good, the bad, and the ugly. Circ Res $\underline{90}(3), 251-62$

Galis ZS, Sukhova GK, Lark MW, Libby P (1994): Increased expression of matrix metalloproteinases and matrix degrading activity in vulnerable regions of human atherosclerotic plaques. J Clin Invest $\underline{94(6), 2493-50}$

Glass CK, Witztum JL (2001): Atherosclerosis: The Road Ahead. Cell 104, 503516

Grützmacher P, Landgraf H, Esser R, Okon J, Vlachojannis J, Ehrly AM, Schoeppe W. (1990): In vivo rheologic effects of lipid apheresis techniques: comparison of dextran sulfate LDL adsorption and heparin induced LDL precipitation. ASAIO Trans $\underline{36}(3)$, M327-30

Güray U, Erbay AR, Güray Y, Yilmaz MB, Boyaci AA, Sasmaz H, Korkmaz S, Kütük $E$ (2004): Levels of soluble adhesion molecules in various clinical presentations of coronary atherosclerosis. Int J Cardiol 96(2), 235-40

Hanemaaijer R, Koolwijk P, le Clercq L, de Vree WJ, van Hinsbergh VW (1993): Regulation of matrix metalloproteinase expression in human vein and microvascular endothelial cells. Effects of tumour necrosis factor alpha, interleukin 1 and phorbol ester. Biochem J 296 ( Pt 3), 803-9

Hershcovici T, Schechner V, Orlin J, Harell D, Beigel Y (2004): Effect of different LDL-apheresis methods on parameters involved in atherosclerosis. J Clin Apher $\underline{19}(2), 90-7$

Horstkotte D, Mellwig KP (2003): Heparin-induced extracorporeal LDL precipitation (H.E.L.P.). Z Kardiol 92(Suppl 3), III1-5

Ignarro LJ. (1990): Biosynthesis and metabolism of endothelium-derived nitric oxide. Annu Rev Pharmacol Toxicol $\underline{30}$, 535-60

Ikata J, Wakatsuki T, Oishi Y, Oki T, Ito S (2000): Leukocyte counts and concentrations of soluble adhesion molecules as predictors of coronary atherosclerosis. Coron Artery Dis 11(6), 445-9

Jefferson BK, Topol EJ (2005): Molecular mechanisms of myocardial infarction. Curr Probl Cardiol 30(7), 333-74 
Karatzis EN (2005): The role of inflammatory agents in endothelial function and their contribution to atherosclerosis. Hellenic J Cardiol 466(3), 232-9

Kassenärztliche Bundesvereinigung (2003): Mitteilungen: Zum Beschluss des Bundesausschusses der Ärzte und Krankenkassen vom 24. 3. 2003 zu den therapeutischen Apheresen. Dtsch Ärztebl 30, 2035-2036

Katsuda S, Kaji T (2003): Atherosclerosis and extracellular matrix. J Atheroscler Thromb 10 $(5), 267-74$

Khuseyinova N, Koenig W (2006): Biomarkers of outcome from cardiovascular disease. Curr Opin Crit Care 12(5), 412-9

Kobayashi S, Oka M, Moriya H, Maesato K, Okamoto K, Ohtake T (2006): LDLapheresis reduces P-Selectin, CRP and fibrinogen -- possible important implications for improving atherosclerosis. Ther Apher Dial 10(3), 219-23

Koziolek MJ (2005): LDL-Apherese. Symposium Moderne Diagnostik und Therapie der Hyperlipoproteinämie. Zitiert nach Inhaltsangaben des Vortrags (gehalten am 18.10.2005) in Göttingen

Koziolek MJ, Mueller GA (2009): Impact of LDL-Apheresis on inflammation and microcirculation. Atheroscler Suppl 10 (5), 56-8

Koziolek MJ, Hennig U, Zapf A, Bramlage C, Grupp C, Armstrong VW, Strutz F, Müller GA (2010): Retrospective analysis of long-term lipid apheresis at a single center. Ther Apher Dial 14(2), 143-52

Krempl TK, Maas R, Sydow K, Meinertz T, Böger RH, Kähler J (2005): Elevation of asymmetric dimethylarginine in patients with unstable angina and recurrent cardiovascular events. Eur Heart J $\underline{26}(18), 1846-51$

Krishnaswamy G, Kelley J, Yerra L, Smith JK, Chi DS (1999): Human endothelium as a source of multifunctional cytokines: molecular regulation and possible role in human disease. J Interferon Cytokine Res 19(2), 91-104

Kushner I (1993): Regulation of the acute phase response by cytokines. Perspect Biol Med $\underline{36}(4), 611-22$

Laffón A, González-Amaro R (1995): Cell adhesion molecules: an overview. Br J Rheumatol 34(12), 1101-2 
Leca G, Mansur SE, Bensussan A (1995): Expression of VCAM-1 (CD106) by a subset of TCR gamma delta-bearing lymphocyte clones. Involvement of a metalloprotase in the specific hydrolytic release of the soluble isoform. $\mathrm{J}$ Immunol $\underline{154}, 1069-1077$

Lescuyer P, Allard L, Hochstrasser DF, Sanchez JC (2005): Heart-fatty acidbinding protein as a marker for early detection of acute myocardial infarction and stroke. Mol Diagn $\underline{9}(1), 1-7$

Libby P, Theroux P (2005): Pathophysiology of coronary artery disease.

Circulation 111(25), 3481-8

Lyons JG, Birkedal-Hansen B, Pierson MC, Whitelock JM, Birkedal-Hansen H (1993): Interleukin-1 beta and transforming growth factor-alpha/epidermal growth factor induce expression of M(r) 95,000 type IV collagenase/gelatinase and interstitial fibroblast-type collagenase by rat mucosal keratinocytes. J Biol Chem $\underline{268}(25), 19143-51$

Mabuchi H, Koizumi J, Shimizu M, Kajinami K, Miyamoto S, Ueda K, Takegoshi T. (1998): Long-term efficacy of low-density lipoprotein apheresis on coronary heart disease in familial hypercholesterolemia. Hokuriku-FH-LDL-Apheresis Study Group. Am J Cardiol 15;82(12), 1489-95

Mair W, Friedl S, Puschendorf TB (1999): Natriuretic peptides in assessment of left-ventricular dysfunction. Scand J Clin Lab Invest. Suppl 230, 132-142

McDonagh TA, Robb SD, Murdoch DR, Morton JJ, Ford I, Morrison CE, TunstallPedoe H, McMurray JJ, Dargie HJ (1998): Biochemical detection of left-ventricular systolic dysfunction. Lancet 351(9095), 9-13

Mellwig KP (2003): Heparin-induced extracorporeal low-density lipoprotein precipitation. Ther Apher Dial $\underline{7}(3), 365-9$

Mitra AK, Dhume AS, Agrawal DK (2004): "Vulnerable Plaques"-ticking of the time bomb. Can J Physiol Pharmacol 82(10), 860-71

Moriarty PM, Gibson CA, Shih J, Matias MS (2001): C-reactive protein and other markers of inflammation among patients undergoing HELP LDL apheresis.

Atherosclerosis 158(2), 495-8 
Nakamura T, Matsuda T, Suzuki Y, Ueda Y, Koide H (2003): Effects of low-density lipoprotein apheresis on plasma matrix metalloproteinase- 9 and serum tissue inhibitor of metalloproteinase-1 levels in diabetic hemodialysis patients with arteriosclerosis obliterans. ASAIO J $\underline{49}(4)$, 430-4

O'Brien KD, Allen MD, McDonald TO, Chait A, Harlan JM, Fishbein D et al. (1993): Vascular cell adhesion molecule-1 is expressed in human coronary atherosclerotic plaques. Implications for the mode of progression of advanced coronary atherosclerosis. J. Clin. Invest 92, 945-951

Ogiwara F, Takahashi M, Ikeda U (2004): Inflammatory markers and cytokines in cardiovascular disease. Rinsho Byori 52(8), 686-92

Otto C, Berster J, Otto B, Parhofer KG. (2007): Effects of two whole blood systems (DALI and Liposorber D) for LDL apheresis on lipids and cardiovascular risk markers in severe hypercholesterolemia. J Clin Apher 22, 301-305

Parhofer KG, Geiss HC, Schwandt P (2000): Efficacy of different low-density lipoprotein apheresis methods. Ther Apher $\underline{4}(5), 382-5$

Paulsson G, Zhou X, Torrielli M, Hansson GK (2000): Oligoclonal T cell expansion in atheroslcerotic lesions of apoliprotein E- deficient mice. Aterioscler Thromb Vasc Biol 20, 10-17

Peter K, Nawroth P, Conradt C, Nordt T, Weiss T, Boehme M, Wunsch A, Allenberg J, Kübler W, Bode C. (1997): Circulating vascular cell adhesion molecule-1 correlates with the extent of human atherosclerosis in contrast to circulating intercellular adhesion molecule-1, E-selectin, P-selectin, and thrombomodulin. Arterioscler Thromb Vasc Biol 17(3), 505-12

Pulawski E, Mellwig KP, Brinkmann T, Kleesiek K, Horstkotte D (2002): Influence of single low-density lipoprotein apheresis on the adhesion molecules soluble vascular cellular adhesion molecule-1, soluble intercellular adhesion molecule-1, and P-selectin. Ther Apher $\underline{6}(3), 229-33$

Renz-Polster H, Krautzig S, Braun J: Fettstoffwechselstörungen, in: Basislehrbuch Innere Medizin, Elsevier GmbH, München 2004, 849-860

Ridker PM (2001): High-sensitivity C-reactive protein: potential adjunct for global risk assessment in the primary prevention of cardiovascular disease. Circulation $\underline{103}(13), 1813-8$ 
Ross R (1999): Atherosclerosis-an inflammatory disease. N Eng J Med $\underline{340}, 115-$ 126

Rossenbach J, Mueller GA, Lange K, Armstrong VW, Schmitto JD, Hintze E, Helfmann J, Konstantinides S, Koziolek MJ (2011): Lipid-apheresis improves microcirculation of the upper limbs. J Clin Apher 26 (4), 167-73

Roy D, Quiles J, Aldama G, Sinha M, Avanzas P, Arroyo-Espliguero R, Gaze D, Collinson P, Carlos Kaski J (2004): Ischemia Modified Albumin for the assessment of patients presenting to the emergency department with acute chest pain but normal or non-diagnostic 12-lead electrocardiograms and negative cardiac troponin T. Int J Cardiol 97(2), 297-301

Rubanyi GM (1993): The role of endothelium in cardiovascular homeostasis and diseases. J Cardiovasc Pharmacol 22 Suppl 4, S1-14

Samtleben W, Bengsch S, Boos KS, Seidel D (1998): HELP apheresis in the treatment of sepsis. Artif Organs 22(1), 43-6

Schettler V, Jaeger BR, Klingel R; German apheresis working group (2009): The German Lipid Apheresis Registry - remaining to be established. Atheroscler Suppl $\underline{10}(5), 59-61$

Schettler V, Wieland E, Armstrong VW, Kleinoeder T, Grunewald W, Müller GA, and the Participants of the Göttingen Consensus Conferences (2002): First Steps toward the establishment of a German low-density lipoprotein-apheresis registry: recommendations for the indication and for the quality management. Ther Apher 6, 381-383

Schnabel R, Blankenberg S, Lubos E, Lackner KJ, Rupprecht HJ, Espinola Klein C, Jachmann N, Post F, Peetz D, Bickel C, Cambien F, Tiret L, Münzel T (2005): Asymmetric dimethylarginine and the risk of cardiovascular events and death in patients with coronary artery disease: results from the AtheroGene Study. Circ Res $\underline{97}(5)$, e53-9

Schulze F, Wesemann R, Schwedhelm E, Sydow K, Albsmeier J, Cooke JP, Böger RH. (2004): Determination of asymmetric dimethylarginine (ADMA) using a novel ELISA assay. Clin Chem Lab Med 42(12), 1377-83

Simon AD, Yazdani S, Wang W, Schwartz A, Rabbani LE (2001): Elevated plasma levels of interleukin-2 and soluble IL-2 receptor in ischemic heart disease. Clin Cardiol 24(3), 253-6 
Stefanutti C, Vivenzio A, Di Giacomo S, Mazzarella B, Ferraro PM, Abbolito S. (2010): Treatment of symptomatic hyperLp(a)lipidemia with LDL-apheresis vs. usual care. Transfus Apher Sci 42(1), 21-6

Stefanutti C, Vivenzio A, Di Giacomo S, Ferraro PM. (2011): Cytokines profile in serum of homozygous familial hypercholesterolemia is changed by LDL-apheresis. Cytokine 55(2), 245-50

Steinberg D, Parthasarathy S, Carew TE, Khoo JC, Witztum JL (1989): Beyond cholesterol. Modifications of low-density lipoprotein that increase its atherogenicity. N Engl J Med $\underline{320}$, 915-924

Stemme S, Rymo L, Hansson GK. (1991): Polyclonal origin of T-lymphocytes in human atherosclerotic plaques. Lab Invest $\underline{65}, 654-660$

Stoneman VE, Bennett MR (2004): Role of apoptosis in atherosclerosis and its therapeutic implications. Clin Sci (Lond) 107(4), 343-54

Sundström J, Evans JC, Benjamin EJ, Levy D, Larson MG, Sawyer DB, Siwik DA, Colucci WS, Sutherland P, Wilson PW, Vasan RS (2004): Relations of plasma matrix metalloproteinase- 9 to clinical cardiovascular risk factors and echocardiographic left ventricular measures: the Framingham Heart Study. Circulation $\underline{109}(23)$, 2850-6

Tesfamariam B (1994): Free radicals in diabetic endothelial cell dysfunction. Free Radic Biol Med 16(3), 383-91

Trion A, van der Laarse A (2004): Vascular smooth muscle cells and calcification in atherosclerosis. Am Heart $\mathrm{J} \underline{147(5), 808-14}$

Utsumi K, Kawabe M, Hirama A, Ueda K, Kamada Y, Arii K, Komaba Y, Katsura K, lino Y, Katayama Y (2007): Effects of selective LDL apheresis on plasma concentrations of ICAM-1, VCAM-1 and P-selectin in diabetic patients with arteriosclerosis obliterans and receiving maintenance hemodialysis. Clin Chim Acta $\underline{377}, 198-200$

Wang Y, Blessing F, Walli AK, Uberfuhr P, Fraunberger P, Seidel D (2004): Effects of heparin-mediated extracorporeal low-density lipoprotein precipitation beyond lowering proatherogenic lipoproteins--reduction of circulating proinflammatory and procoagulatory markers. Atherosclerosis $\underline{175}(1), 145-50$ 
Wendler T, Schilling R, Lennertz A, Sodemann K, Kleophas W, Messner H, Riechers G, Wagner J, Keller C, Bosch T (2003): Efficacy and safety of DALI LDLapheresis at high blood flow rates: a prospective multicenter study. J Clin Apher 18(4), 157-66

Yamamoto K, Burnett JC Jr, Jougasaki M, Nishimura RA, Bailey KR, Saito Y, Nakao K, Redfield MM (1996): Superiority of brain natriuretic peptide as a hormonal marker of ventricular systolic and diastolic dysfunction and ventricular hypertrophy. Hypertension $\underline{28}(6), 988-94$ 


\section{Danksagung}

Ich danke Herrn Prof. Dr. G. Müller und meinem Doktorvater Herrn PD. Dr. M. Koziolek für die freundliche Überlassung des Themas der Dissertation.

Besonders bedanken möchte ich mich bei PD. Dr. M. Koziolek für die Betreuung meiner Arbeit und die vielen wichtigen Anregungen.

Des Weiteren möchte ich der Abteilung Kardiologie, insbesonderem Herrn Prof. Dr. S. Konstantinidis und Frau Dr. M. Puls für die interdisziplinäre Zusammenarbeit danken.

Ebenso bedanke ich mich bei Frau Dr. M. Lankeit für die Hilfe und Unterstützung vor allem im experimentellen Teil und Frau Zapf sowie Herrn Helms für die Hilfe bei statistischen Fragen.

Zuletzt bedanke ich mich besonders bei den drei hilfsbereiten Krankenschwestern der LDL-Apheresestation der UMG Kerstin, Ilka und Andrea für ihre Unterstützung während der gesamten Zeit. 


\section{Lebenslauf}

Am 27. September 1981 wurde ich, Julia Strauchmann, als zweites Kind von Dieter und Annemarie Strauchmann, geb. Weber, in Unna geboren.

Im Sommer 1988 wurde ich in die Grundschule in Unna-Hemmerde eingeschult. Ab dem Sommer 1992 besuchte ich das Ursulinengymnasium Werl.

Nach meinem Abitur im Sommer 2001 begann ich mit dem Medizinstudium im Wintersemester 2001/02 an der Georg-August-Universität Göttingen. Im März 2003 absolvierte ich das Physikum.

Das praktische Jahr begann ich im Winter 2006. Die ersten beiden Tertiale absolvierte ich am Klinikum Göttingen im Zentrum Anaesthesiologie, Rettungsund Intensivmedizin und im Zentrum Innere Medizin in der Abteilung Nephrologie. Das Chirurgie-Tertial verbrachte ich im Uni-Spital Zürich in der Schweiz. Im Dezember 2007 absolvierte ich das Staatsexamen in Göttingen.

Seit dem 01.02.2008 arbeite ich als Assistenzärztin im Zentrum Anaesthesiologie, Rettungs- und Intensivmedizin der Universität Göttingen. 